\author{
UNIVERSIDADE DE SÃO PAULO \\ PROGRAMA DE PÓS-GRADUAÇÃO EM ENERGIA \\ (EP/FEA/IEE/IF)
}

MANOEL LÉLIO MARTINS DE CARVALHO JUNIOR

RESFRIAMENTO DE AR DE ENTRADA EM TURBINAS A GÁS

NO PARQUE GERADOR ELÉTRICO BRASILEIRO

São Paulo

2012 
MANOEL LÉLIO MARTINS DE CARVALHO JUNIOR

\title{
RESFRIAMENTO DE AR DE ENTRADA EM TURBINAS A GÁS NO PARQUE GERADOR ELÉTRICO BRASILEIRO
}

Tese apresentada ao Programa de Pós-Graduação em Energia da Universidade de São Paulo (Escola Politécnica/ Faculdade de Economia e Administração/ Instituto de Eletrotécnica e Energia/ Instituto de Física) para obtenção de grau de Doutor em Ciências

Orientador: Prof. Dr. Geraldo Francisco Burani

\section{Versão Corrigida}

(versão original disponível na Biblioteca da Unidade que aloja o Programa e na Biblioteca Digital de Teses e Dissertações da USP)

\author{
SÃO PAULO
}




\begin{abstract}
AUTORIzo A REPRODUÇÃo E DIVULGaÇÃo TOTAL OU PARCIAL DESTE TRABALHO, POR QUALQUER MEIO CONVENCIONAL OU ELETRÔNICO, PARA FINS DE ESTUDO E PESQUISA, DESDE QUE CITADA A FONTE.
\end{abstract}

FICHA CATALOGRÁFICA

Carvalho Junior, Manoel Lélio Martins de

Resfriamento de ar de entrada em turbinas a gás no parque gerador de eletricidade brasileiro. / Manoel Lélio Martins de Carvalho Junior; orientador Geraldo Francisco Burani - São Paulo, 2012.

120 f. : il.; $30 \mathrm{~cm}$.

Tese (Doutorado - Programa de Pós-Graduação em Energia) - 
UNIVERSIDADE DE SÃO PAULO

PROGRAMA DE PÓS-GRADUAÇÃo EM ENERGIA

(EP/FEA/IEE/IF)

\section{MANOEL LÉLIO MARTINS DE CARVALHO JUNIOR}

"Resfriamento de ar de entrada em turbinas a gás no parque gerador elétrico brasileiro"

Tese defendida e aprovada em pela Comissão Julgadora:

Prof. Dr. Geraldo Francisco Burani - PPGE/USP

Orientador e Presidente da Comissão Julgadora

Prof. Dr. Murilo Tadeu Werneck Fagá - PPGE/USP

Prof. Dr. José Roberto Simões Moreira - PPGE/USP

Dr. Carlos Cezar da Silva - IFSMG

Prof. Dr. Edson Gomes - EP/USP 
Dedico este trabalho à minha família: aos que estão aqui e aos que já se foram. 


\section{AGRADECIMENTOS}

Agradeço ao meu orientador Professor Francisco Burani pela paciência e apoio.

Agradeço também aos amigos da USP e da Petrobras que sempre me apoiaram e encorajaram. 


\section{RESUMO}

Carvalho Junior, Manoel Lélio Martins de. Resfriamento de ar de entrada em turbinas a gás no parque gerador de eletricidade brasileiro, 2012. $120 \mathrm{f}$. Tese (Doutorado em Ciências). Programa de Pós-Graduação em Energia da Universidade de São Paulo, 2012.

Nos últimos 15 anos houve um grande aumento na presença de turbinas a gás no parque gerador de eletricidade brasileiro. O Brasil tem predominantemente climas tropicais e subtropicais com temperaturas oscilando entre 20 e $35^{\circ} \mathrm{C}$ na maior parte do ano. A máxima potência que pode ser gerada por uma turbina a gás aumenta com a redução da temperatura do ar de entrada na turbina. Decorre daí o interesse na aplicação de sistemas de resfriamento do ar de entrada de turbinas. Dentre os sistemas de resfriamento, os de aplicação mais simples são o de resfriamento por meio evaporativo rígido e o de resfriamento por ciclo de compressão com acionamento elétrico. Não há na literatura um estudo sistemático da aplicação de sistemas de resfriamento de ar de entrada de turbinas a gás para operação no Brasil.

Este trabalho estuda a aplicação dos dois tipos mais simples de sistemas de resfriamento de ar de entrada em turbinas operando ou a serem instaladas no território brasileiro. Um modelo para simulação da resposta de turbinas a gás às variações nas condições climáticas do ar de entrada (temperatura, umidade e pressão atmosférica) é desenvolvido. O modelo necessita como parâmetros somente de dados publicados em catálogo pelo fabricante da turbina. A simulação é feita para 27 localidades brasileiras comparando a operação de um mesmo tipo de turbina sem resfriamento e com os dois tipos de resfriamento. O dados climáticos usados são dos tipos anos metereológicos típicos e anos teste de referência.

O modelo de turbina desenvolvido simula de maneira satisfatória as curvas de uma turbina comercial do tipo heavy duty. Um aumento de energia anual gerada de até $4,2 \%$ foi observado para o sistema de resfriamento por meio evaporativo rígido. O aumento de energia no resfriamento evaporativo depende da depressão de bulbo úmido média do local de instalação da turbina. Para o resfriamento por ciclo de compressão com acionamento elétrico o aumento observado foi de até $11,2 \%$. O aumento de energia para este tipo de sistema depende da temperatura de bulbo seco média do local.

Palavras chaves: 1 Geração de energia 2 Turbinas a gás 3 Gás natural 


\section{ABSTRACT}

Carvalho Junior, Manoel Lélio Martins de. Gas turbine inlet air cooling in Brazilian power plants, 2012. 120 f. Doctor's Thesis. Graduate Program on Energy at the Universidade de São Paulo, 2012.

In the last 15 years an ever increasing presence of gas turbines was felt in electrical power generation in Brazil. Tropical and subtropical climates dominate most of the country, with temperatures ranging from 20 to $35^{\circ} \mathrm{C}$ during most of the year. The maximum power that can be generated by a gas turbine increases at lower inlet air temperatures. Consequently, there is great interest in applying inlet air cooling systems in gas turbines. Among the inlet air cooling systems, the evaporative cooling by rigid wet media and the compression thermal cycle with electrical power chiller systems are the ones with most straightforward implementation. There is no systematic study of the application of gas turbine inlet air cooling systems for turbines operating in Brazil.

This thesis studies the application of the two methods of gas turbine inlet air cooling mentioned above in turbines operating or to be installed in Brazil. A model to simulate the response of gas turbines to changes in the inlet air (temperature, humidity and pressure) is developed. The model uses turbine catalogue data as parameters. The simulation is performed for 27 Brazilian locations, comparing the operation of a model of turbine operating with and without cooling systems, for both types of cooling systems. Typical meteorological year and test reference year data are used in the study.

The turbine model developed reproduces the turbines data curves with satisfactory accuracy. An annual increase in energy generation of up to 4,2\% was observed for evaporative cooling. The energy gain for evaporative cooling depends on the annual mean wet bulb depression of the local. The compression thermal cycle increases the annual energy generation by up to $11,2 \%$. The energy increase in this type of system depends on the mean dry bulb temperature of the local.

Keywords: Power generation, Gas turbines, Natural Gas 


\section{SUMÁRIO}

Lista de Ilustrações

Lista de Tabelas

Lista de Abreviaturas e Siglas

Lista de Símbolos

1 Introdução $\quad 21$

1.1 Apresentação . . . . . . . . . . . . . . . . . . . 21

1.2 Métodos de resfriamento de ar de entrada de turbinas . . . . . . . 22

1.2.1 Resfriamento evaporativo por meio rígido . . . . . . . 23

1.2.2 Resfriamento evaporativo por névoa $(\mathrm{EVN}) \quad \ldots . . . .27$

1.2.3 Resfriamento por ciclo termodinâmico por compressão (CTC) 29

1.2.4 Resfriamento por combinação de armazenamento térmico com ciclo térmico por compressão (ATC) . . . . . . . . 33

1.2.5 Resfriamento por ciclo térmico de absorção . . . . . . . . 36

1.3 Objetivos ............................. 41

1.4 Metodologia ...................... 41

2 Revisão Bibliográfica 43

2.1 Resfriamento do ar de entrada de turbinas a gás . . . . . . . . 43 
2.2 Modelos de turbinas a gás . . . . . . . . . . . . . . . . 49

$\begin{array}{lll}3 & \text { Estudo do sistema evaporativo } & 52\end{array}$

3.1 Modelo da turbina a gás . . . . . . . . . . . . . 52

3.2 Modelo do sistema de resfriamento evaporativo . . . . . . . . . 71

3.3 Dados Climáticos . . . . . . . . . . . . . 76

3.4 Simulação dos Modelos com Dados Climáticos . . . . . . . . . 82

3.5 Análise Econômica do Resfriamento Evaporativo . . . . . . . . 88

4 Estudo do resfriamento por ciclo térmico 93

4.1 Modelo do resfriamento por ciclo termodinâmico por compressão

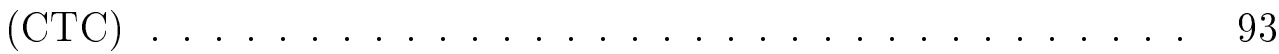

4.2 Simulação do resfriamento por do ciclo de compressão . . . . . . 102

4.3 Análise Econômica do Resfriamento CTC . . . . . . . . . . . 110

5 Conclusões 112

5.1 Trabalhos futuros . . . . . . . . . . . . . . . 113

Referências 


\section{LISTA DE ILUSTRAÇÕES}

1 Diagrama do sistema de resfriamento de ar de entrada da turbina por meio evaporativo rígido. . . . . . . . . . . . . . . 24

2 Ilustração do resfriamento EMR e seus componentes principais (adaptada da referência (Munters, 2012)) . . . . . . . . 25

3 Resfriamento por EMR de uma temperatura de $30^{\circ} \mathrm{C}$ e umidade relativa $40 \%$ até uma condição próxima à de bulbo úmido representada no diagrama psicrométrico. . . . . . . . . 25

$4 \quad$ Foto de montagem do EMR.(Fonte (Donaldson Europe, 2011)) . . 26

5 Diagrama do sistema de resfriamento de ar de entrada da turbina por fogging. ....................... 27

6 Chuveiro de EVN instalado na entrada da turbina e detalhe do bocal de aspersão.(Fonte (Mee Industries, 2008)) . . . . . . . . . 28

7 Diagrama do sistema de resfriamento de ar de entrada da turbina

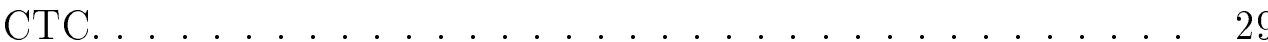

8 Resfriamento do ar a $30^{\circ} \mathrm{C}$ e $\phi 40 \%$ até a temperatura de $8^{\circ} \mathrm{C}$ representada no diagrama psicrométrico. . . . . . . . . . 30

9 Detalhes da serpentina e eliminador de gotas usados na implementação do CTC (adptado de (GE Energy, 2008b)). . . . . . . . . . 31

10 Instalação da serpentina na casa de filtros da turbina. (Fonte (GE

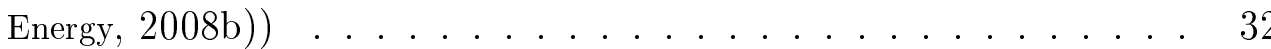


11 Diagrama do sistema de resfriamento de ar de entrada da turbina por chiller com armazenamento de água ou gelo. . . . . . . . . . 34

12 Diagrama do sistema ATC com gelo da Mueller "Ice Harvester"(adaptado de (Paul Mueller Company, 2000)) . . . . . . . . . 35

13 Foto do reservatório de gelo da Muller para o "Ice Harvester" com capacidade de armazenar $11.356 \mathrm{~m}^{3}$ de gelo.(Fonte (Paul Mueller

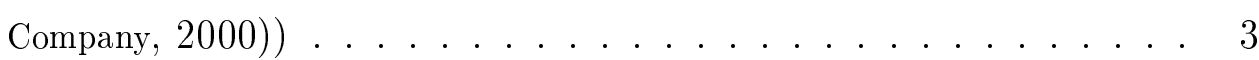

14 Diagrama do sistema de resfriamento de ar de entrada da turbina por ciclo de absorção . . . . . . . . . . . . . . . 38

15 Diagrama simplificado do ciclo do chiller de absorção. . . . . . . . 39

16 Foto de 5 chillers de absorção de capacidade 5,8 MW de refrigeração cada usados no resfriamento de ar de entrada de turbinas. (Fonte (PUNWANI et al., 5-8 Novembro 2001)) . . . . . . . . . 40

17 Quantidade de turbinas por modelo nas termelétricas brasileiras com potência maior que $50 \mathrm{MW} . \ldots \ldots \ldots . \ldots . \ldots 54$

18 Potência instalada por modelo de turbina nas termelétricas brasileiras com potência maior que 50 MW. . . . . . . . . 55

19 Fator de correção de potência para a temperatura do ar de entrada da turbina , $f_{W T}$, para os modelos de turbinas com maior participação nas termelétricas brasileiras. (Adaptado de (BROOKS, 2000; SIEMENS, 2008; BADEER, 2000).) _.......... 57 
20 Diagrama de turbina a gás. Componentes: C - compressor; CC câmara de combustão; E - expansor. Pontos de processo: 1 - entrada da turbina (compressor); 2 - descarga do compressor (entrada da câmara de combustão; 3 - entrada do expansor (descarga da câmara de combustão); 4 - descarga do expansor (descarga da turbina); 5 - entrada de gás natural na câmara de combustão. . 58

21 Diagrama do Ciclo Brayton percorrido pelo ar na turbina modelada. 58

22 Combinação das curvas características do compressor e expansor de uma turbina a gás (CSANADY, 1964). . . . . . . . . 62

23 Curvas de controle de uma turbina a gás. (ROWEN, 1983; ROWEN,

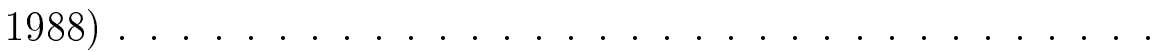

24 Resposta da turbina a temperatura de bulbo seco do ar de entrada $T_{1}\left({ }^{\circ} \mathrm{C}\right): f_{W T}$ fator de potência; $f_{H R T}$ fator e heat rate; $f_{m e T}$ fator de vazão de exaustão da turbina(linhas contínuas representam dados do fabricante; linhas pontilhadas indicam resultados do modelo). .

25 Resposta da turbina a umidade absoluta do ar de entrada $\omega_{1}(\mathrm{~kg} / \mathrm{kg}): f_{W \omega}$ fator de potência; $f_{H R \omega}$ fator e heat rate (linhas contínuas representam dado dos fabricantes; linhas pontilhadas indicam resultados do modelo). . . . . . . . . . . . 68

26 Resposta da turbina a altitude de operação $Z(\mathrm{~m}): f_{W Z}$ fator de potência (linha contínua representa dados dos fabricantes; linha pontilhada indica resultado do modelo). . . . . . . . . . .

27 Resposta da turbina a perda de carga na entrada $\Delta p(\mathrm{kPa}): f_{W \Delta p}$ fator de potência; $f_{H R \Delta p}$ fator e heat rate (linhas contínuas representam dado dos fabricantes; linhas pontilhadas indicam resultados do modelo). . . . . . . . . . . . . . . . . . 
28 Diagrama do sistema de resfriamento com meio evaporativo rígido

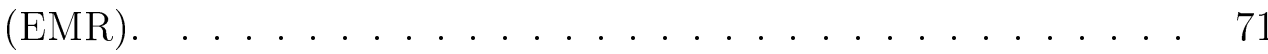

29 Diagrama psicrométrico do resfriamento no EMR. . . . . . . . 73

30 Gráfico dos dados de um mês do arquivo TMY de Belo Horizonte apresentando $p_{a t}$, ur e $T_{b s} \ldots \ldots \ldots \ldots \ldots 78$

31 Potência gerada em Vitória (MW) por uma turbina GE 7FA com resfriamento EMR (linha contínua) e sem resfriamento (linha tracejada) de ar de entrada num período de 2 dias (48 horas). . . . .

32 Ganho de potência ( $W G$ em MW) de uma turbina GE 7FA com o uso de EMR (linha contínua) e depressão de bulbo úmido ( $D B U$ em $\left.{ }^{\circ} \mathrm{C}\right)$ (linha tracejada) em Vitória no mesmo período mostrado na figura 31.

33 Ganho de energia anual $\left(E G_{a n}\right)$ ordenada por depressão de bulbo úmido média anual $\left(D B U_{m}\right)$ e faixa de altitude $(F A)$ para locali-

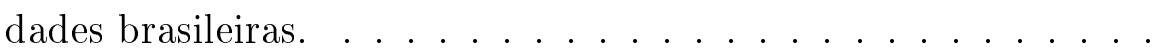

34 Ganho de energia anual relativo de uma turbina GE 7FA $\left(E G_{a n r}\right)$ e depressão de bulbo úmido anual média $\left(D B U_{m}\right)$ para localidades brasileiras. . . . . . . . . . . . . . . . . .

35 Ganho de energia anual relativo de uma turbina GE 7FA (EG $\left.G_{a n r}\right)$ versus depressão de bulbo úmido anual média $\left(D B U_{m}\right)$ para diferentes faixas de altitude $(F A) \ldots \ldots \ldots$. . . . . . 86

36 Volume de água consumido em um ano $\left(V A C_{a n}\right)$ pelo resfriamento evaporativo EMR pela turbina GE 7FA em locais brasileiros, indicando também o diferencial de umidade absoluta médio $\left(D U A_{m}\right)$ e faixa de altitude $(F A) . \ldots \ldots \ldots$ 
37 Volume de água consumido em um ano $\left(V A C_{a n}\right)$ pelo resfriamento evaporativo EMR pela turbina GE 7FA em função do diferencial de umidade absoluta médio $\left(D U A_{m}\right)$ para diferentes faixas de altitude $(F A) \ldots \ldots \ldots \ldots \ldots \ldots \ldots$

38 Ganho de energia anual relativo, $E G_{a n r}$, ordenado pela classificação climática de Köppen-Geiger e faixa de altitude, FA. . . . . . 88

39 Ganho de energia, REG, custo do aumento do consumo de gás, $C G N$, custo do aumento de consumo de água, $C A G$,receita anual líquida, $R L$ em função da depressão de bulbo úmido, $D B U_{m}$. . . . 92

40 Payback, PB, em função. . . . . . . . . . . . . . . . . . . . 92

41 Diagrama do sistema de resfriamento de ar de entrada da turbina

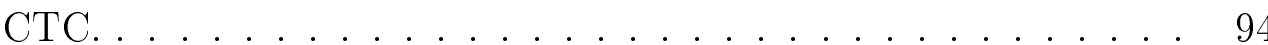

42 Efeito do resfriamento por ciclo térmico, CTC, do ar de entrada de turbina a gás quando o resfriamento tem capacidade suficiente para regular a temperatura do ar. ............. 95

43 Efeito do resfriamento por ciclo térmico, CTC, do ar de entrada de turbina a gás quando o resfriamento não tem capacidade suficiente para regular a temperatura do ar. . . . . . . . . . . 96

44 Resfriamento do ar a $30^{\circ} \mathrm{C}$ e $\phi 40 \%$ até a temperatura de $8^{\circ} \mathrm{C}$ representada no diagrama psicrometrico: A - condição ambiente; O - ponto de orvalho; C - condição desejada. . . . . . . . . . 98

45 Ganho anual de energia em GWh, $E G_{a n}$, para uma turbina GE 7FA em função da temperatura de bulbo seco média anual, $T_{b s m}$, e da faixa de altitute, $F A$, para 27 locais no Brasil. . . . . . . . 104 
46 Ganho anual de energia , $E G_{a n r}$, em função de $T_{b s m}$ para diferentes valores de $T_{C} \ldots \ldots \ldots \ldots \ldots \ldots \ldots$

47 Fração de ganho de energia, $F E G$, em função da capacidade de resfriamento de projeto, $\dot{Q}_{\text {resfp }}$, em quatro locais diferentes do Brasil.106

48 Ganho anual de energia, $E G_{a n}$, em função da capacidade de resfriamento de projeto, $\dot{Q}_{\text {resfp }}$, em três locais diferentes do Brasil com $T_{\text {bum }}$ indicado. . . . . . . . . . . . . . 107

49 Fração de ganho de energia, $F E G$, em função da temperatura de bulbo úmido média, $T_{\text {bum }}$, para diferentes capacidades de resfriamento, $\dot{Q}_{\text {resfp }}$, e diferentes faixas de altitude, $F A$. . . . . . . 109

50 Redução de temperatura do ar em função da capacidade de resfriamento $\dot{Q}_{\text {resfp }}$ a partir de temperatura de bulbo seco $30^{\circ} \mathrm{C}$ e temperaturas de bulbo úmido $23,8^{\circ} \mathrm{C}$ e $27,08^{\circ} \mathrm{C}$ a $101,3 \mathrm{kPa}$. . . . 109

$51 R L, C C H, C A G, R E G$ e $C G N$ em função de $T_{b s m} \ldots \ldots 111$ 


\section{LISTA DE TABELAS}

1 Relação de dados das turbinas instaladas nas termelétricas brasileiras de potência total maior que 50MW (Agência Nacional de Energia Elétrica, 2008; Turbine Inlet Cooling Association (TICA), 2012). . . . 53

2 Condições de operação conforme $($ ISO, 1997) . . . . . . . . . 55

3 Fatores de correção para a condição de operação da turbina usados neste trabalho. ................... 56

4 Parâmetros de operação da turbina GE 7FA na condição ISO (BRO-

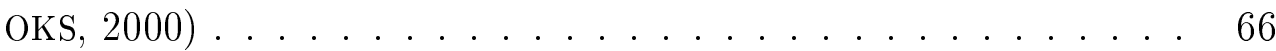

5 Parâmetros complementares da turbina MS0017FA e propriedades do ar e vapor ...................... 70

6 Dados metereológicos dos locais brasileiros estudados e resultados principais das simulações do sistema de resfriamento EMR . . . . 77

$7 \quad$ Resultados de simulação para resfriamento CTC para $T_{C} 10^{\circ} \mathrm{C}$. . 103

8 Fração de ganho de energia $F E G$ em função da capacidade de resfriamento $Q_{\text {resfp }}$ para $T_{C}=10^{\circ} \mathrm{C} \ldots \ldots \ldots 108$ 


\section{LISTA DE ABREVIATURAS E SIGLAS}

EMR Sistema de resfriamento por meio evaporativo rígido

CTC Sistema de resfriamento por ciclo térmico de compressão 


\section{LISTA DE SÍMBOLOS}

$C A G$ custo anual da água usada no resfriamento (U\$/ano)

CCH custo do resfriamento CTC (U\$)

CECHcusto específico do resfriamento CTC (U\$/MW)

CEAG custo específico da água usada no resfriamento $\left(\mathrm{U} \$ / \mathrm{m}^{3}\right)$

$c_{d}$ dureza da água em termos de concentração de $\mathrm{CaCO}_{3}$

CEGN custo específico do gás natural (U\$/MWh)

CGN custo anual do gás natural (U\$/ano)

CEIEMR custo específico do resfriamento EMR (U\$/MW)

CIEMR custo total do resfriamento EMR $(\mathrm{U} \$)$

$c_{p} \quad$ calor específico a pressão constante $\left(\mathrm{kJ} / \mathrm{kg} .{ }^{\circ} \mathrm{C}\right)$

$c_{v} \quad$ calor específico a volume constante $\left(\mathrm{kJ} / \mathrm{kg} .{ }^{\circ} \mathrm{C}\right)$

CVU custo variável unitário $(\mathrm{U} \$ / \mathrm{MWh})$

$D B U$ depressão de bulbo úmido $\left({ }^{\circ} \mathrm{C}\right)$

DUA diferença de umidade absoluta para saturação ( $\mathrm{kg}$ de vapor $/ \mathrm{kg}$ de ar seco)

e energia politrópica $(\mathrm{kJ} / \mathrm{kg})$

EG aumento de energia gerada (GWh)

$E G_{g n}$ aumento do consumo de energia de gás natural (GWh)

$f \quad$ fator de correção para a condição de operação da turbina

$F A$ faixa de altitude (m) 
$h \quad$ entalpia $(\mathrm{kJ} / \mathrm{kg})$

$h_{g n} \quad$ poder calorífico inferior do gás natural $(\mathrm{kJ} / \mathrm{kg})$

$h_{l s} \quad$ entalpia de evaporação da água $(\mathrm{kJ} / \mathrm{kg})$

$H G R E_{a n}$ horas graus anuais de resfriamento evaporativo $\left(\mathrm{h} .{ }^{\circ} \mathrm{C}\right)$

$H R$ heat rate $(\mathrm{kJ} / \mathrm{kWh})$

$H R R$ ganho relativo de heat rate (\%)

$k \quad$ razão de calores específicos

$\dot{m} \quad$ vazão em massa $(\mathrm{kg} / \mathrm{s})$

$n \quad$ expoente politrópico

$p \quad$ pressão absoluta $(\mathrm{kPa})$

$\dot{Q} \quad$ fluxo de calor $(\mathrm{kJ})$

$R_{a} \quad$ constante do ar $\left(\mathrm{kPa} . \mathrm{m}^{3} / \mathrm{kg} . \mathrm{K}\right)$

$R E G$ receita da venda de energia (U\$/ano)

$R L \quad$ receita líquida $(\mathrm{U} \$ / \mathrm{ano})$

$t \quad$ tempo (h)

$T$ temperatura $\left(\mathrm{K} \mathrm{ou}{ }^{\circ} \mathrm{C}\right)$

$T M Y$ ano metereológico típico (tipical metereological year)

$T R Y$ ano de referência típico (tipical reference year)

$\dot{V} \quad$ vazão em volume $\left(\mathrm{m}^{3} / \mathrm{s}\right)$

$V A C$ volume de água consumido anualmente $\left(\mathrm{m}^{3}\right)$

$\dot{W G}$ ganho de potência gerada (MW)

Z altitude (m) 
$\alpha \quad$ coeficiente politrópico

$\beta \quad$ coeficiente de performance do resfriamento

$\Delta p \quad$ perda de carga na entrada da turbina $(\mathrm{kPa})$

$\gamma \quad$ peso específico $\left(\mathrm{N} / \mathrm{m}^{3}\right)$

$\eta \quad$ eficiência

$\eta_{p} \quad$ eficiência politrópica

$\rho \quad$ densidade $\left(\mathrm{kg} / \mathrm{m}^{3}\right)$

$\tau \quad$ período de tempo (h)

$\phi \quad$ umidade relativa do ar (\%)

$\omega \quad$ umidade absoluta do ar ( $\mathrm{kg}$ de vapor $/ \mathrm{kg}$ de ar seco)

Subscritos

0 condição atmosférica

1 condição de entrada do compressor ou saída do resfriador

2 condição de saída do compressor

3 condição de entrada do expansor

4 condição de saída do expansor ou turbina

ag água

alim alimentação

an anual

as ar seco 


$$
\begin{array}{ll}
\text { at } & \text { atmosférico } \\
\text { au } & \text { ar úmido } \\
a v & \text { água evaporada } \\
b & \text { bombeamento } \\
b s & \text { bulbo seco } \\
b s m & \text { bulbo seco médio } \\
b u & \text { bulbo úmido } \\
b u m & \text { bulbo úmido médo } \\
c & \text { compressor } \\
c c & \text { câmara de combustão }
\end{array}
$$

CTC resfriamento por ciclo térmico de compressão

dreno

e expansor

$E M R$ resfriamento evaporativo por meio rígido

ev condição de saída do resfriador evaporativo

evap evaporada

gn gás natural (combustível)

$H R$ heat rate

ISO condição de operação conforme ISO (ISO, 1997)

$l \quad$ líquido

$m \quad$ média anual

me vazão em massa de gases de exaustão da turbina 


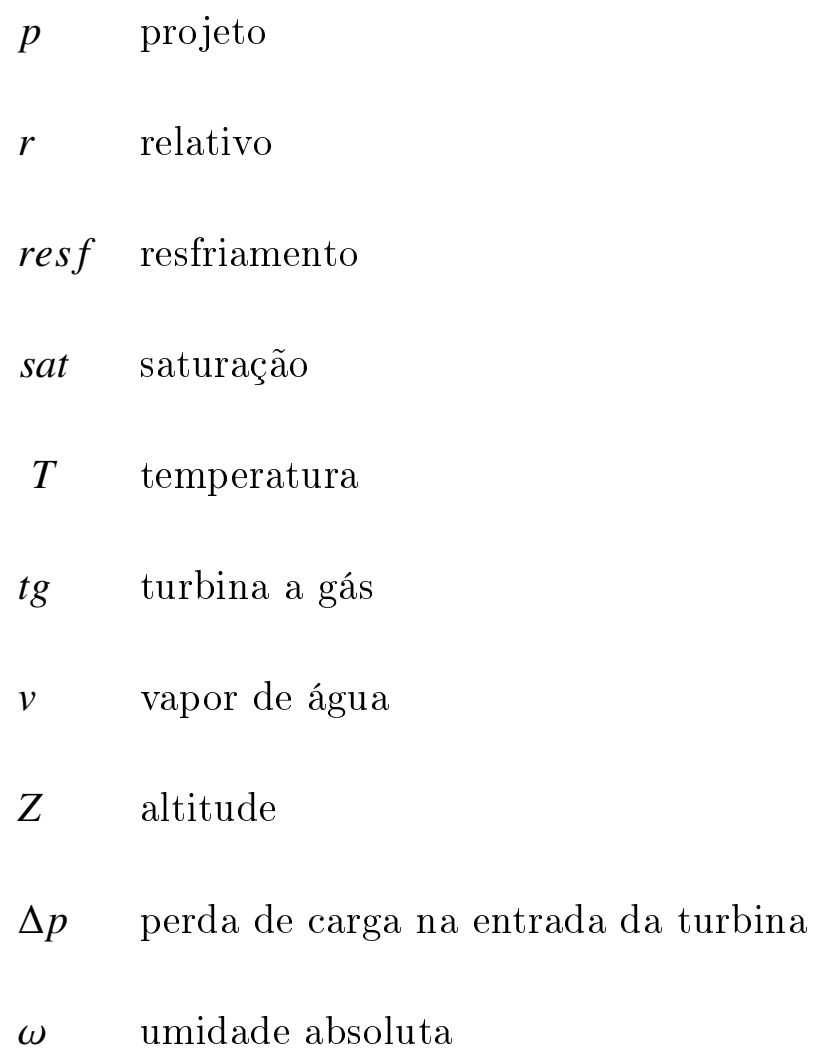




\section{INTRODUÇÃO}

\subsection{Apresentação}

A geração de energia no sistema elétrico brasileiro é predominantemente hidrelétrica. Hidrelétricas representam em torno de $85 \%$ da capacidade de geração instalada. A energia termelétrica tem papel complementar no parque gerador brasileiro. Num sistema com predomínio hidrelétrico a incerteza de afluência nos rios onde estão instaladas as barragens precisa ter seus efeitos minimizados. Termelétricas, por não dependerem de condições climáticas, têm o papel de aumentar a confiabilidade do sistema elétrico. Termelétricas com turbinas têm alta eficiência, podem ser usadas em co-geração, fornecendo vapor para plantas industriais, e podem partir em curto espaço de tempo, atendendo cargas de pico. Estas características e a expansão da rede de gasodutos brasileira fizeram das termelétricas com turbinas a gás opção para a complementação da geração de energia elétrica no Brasil (OLIVEIRA; MARRECO, 2006).

A energia gerada e a eficiência de uma turbina a gás são influenciadas pela temperatura, pressão e umidade de entrada do ar na turbina. A temperatura tem maior impacto na energia e eficiência da turbina. Quanto maior a temperatura, menor a energia gerada pela turbina . O balanço termodinâmico entre a energia consumida pelo resfriamento do ar da turbina e o ganho pela redução da temperatura do ar de entrada resulta num ganho líquido da energia gerada e da eficiência da turbina. O clima no Brasil é caracterizado por altas temperaturas 
na maior parte do ano. A aplicação do resfriamento do ar de entrada nas turbinas a gás instaladas no Brasil tem grande potencial em aumentar a capacidade e a eficiência do parque gerador brasileiro.

\subsection{Métodos de resfriamento de ar de entrada de turbinas}

Cinco métodos de resfriamento de ar de entrada de turbinas a gás são normalmente empregados:

- Evaporativo por meio rígido (EMR);

- Evaporativo por névoa, chamado comumente de "fogging" (EVN);

- Ciclo termodinâmico por compressão, usando chiller com motor elétrico, turbina ou motor de combustão (CTC);

- Combinação de armazenamento térmico com ciclo térmico por compressão (ATC);

- Ciclo termodinâmico por absorção, usando chiller de absorção (CTA).

Do ponto de vista térmico, este trabalho divide este métodos de resfriamento em dois tipos principais:

- Os métodos evaporativos que aproveitam a evaporação da água no ar para abaixar a temperatura do mesmo, que inclui o EMR eo EN;

- Os métodos por ciclo termodinâmico, onde um ciclo termodinâmico é usado para reduzir a temperatura do ar, que inclui o CTC, o CTA e o ATC.

Em seguida descrevemos detalhadamente cada um dos tipos de sistema de resfriamento. 


\subsubsection{Resfriamento evaporativo por meio rígido}

No resfriamento evaporativo por meio rígido, que abreviamos por EMR, o ar de entrada da turbina passa através de um meio rígido mantido úmido. Ao passar pelo meio úmido o ar faz evaporar água e é resfriado num processo de saturação adiabática.

A figura 1 mostra um diagrama do sistema de resfriamento EMR. Água de alimentação é fornecida a um reservatório sob o meio rígido úmido. Esta água é bombeada pela bomba de recirculação até o topo do meio úmido. A água flui por gravidade no meio úmido que se constitui de um material fibroso corrugado, cuja finalidade é aumentar a superfície de contato entre a água e o ar que entra na turbina. O meio úmido fica localizado na casa de filtros após os filtros de ar. O ar ao passar pelo meio úmido evapora parte da água, sendo resfriado. O excesso de água flui para o reservatório, onde parte é drenada para manter a concentração de materiais dissolvidos dentro de limites que minimizem a sua deposição sobre o meio úmido. As gotículas de água que o ar tende a transportar na saída do meio úmido são retiradas em um eliminador de gotículas colocado após o meio úmido. A água do eliminador de gotículas também é coletada no reservatório. A figura 2 mostra uma ilustração do resfriamento EMR e seus componentes principais.

A figura 3 mostra o processo de resfriamento do ar no diagrama psicrométrico que ocorre no EMR. No processo de saturação adiabática a temperatura mínima que pode ser obtida é a temperatura de bulbo úmido do ar ambiente. O processo EMR resfria o ar até uma temperatura próxima à temperatura de bulbo úmido (JOHNSON, 1989).

A instalação do EMR demanda alteração da casa de filtros da turbina, devido à necessidade de reduzir a velocidade do ar que passa no meio úmido em relação à velocidade do ar nos filtros. A figura 4 mostra a instalação de um EMR. 
A água usada no EMR pode ter qualidade similar à água usada normalmente em torres de resfriamento. Conforme mencionado, o resfriamento está limitado à temperatura de bulbo úmido ambiente. Devido ao meio úmido rígido e ao eliminador de gotículas, o EMR acrescenta uma perda de carga permanente de $0,15 \mathrm{kPa}$ ao ar de entrada da turbina (GE Energy, 2008a). O custo do EMR varia de $\mathrm{U} \$ 34$ a $81 / \mathrm{kW}$ de potência adicionada à turbina pelo sistema. O consumo de energia elétrica pelo EMR varia de 0,3 a $0,5 \%$ da potência adiconada à turbina (CHACARTEGUI et al., 2008). Estes dois últimos parâmetros serão discutidos mais adiante neste trabalho.

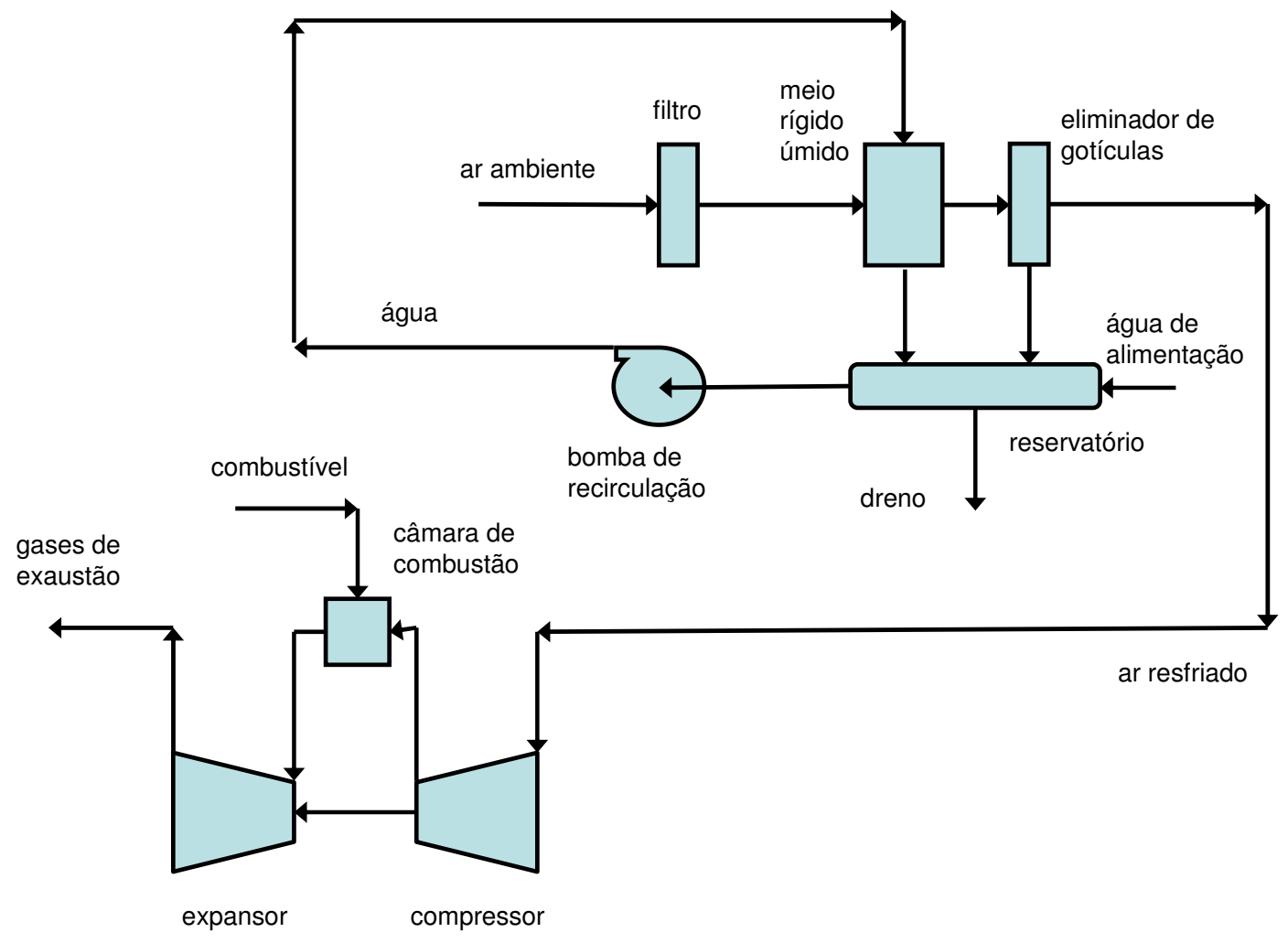

Figura 1: Diagrama do sistema de resfriamento de ar de entrada da turbina por meio evaporativo rígido. 


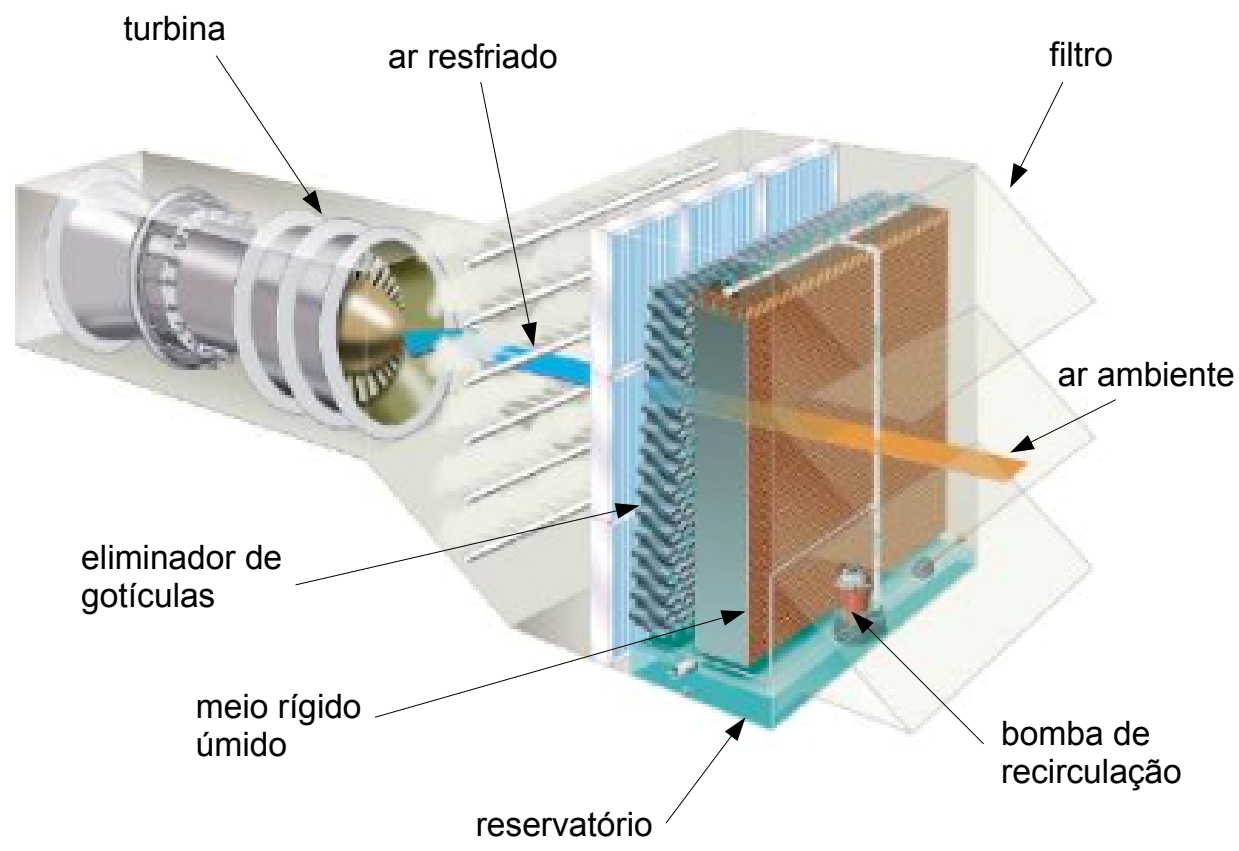

Figura 2: Ilustração do resfriamento EMR e seus componentes principais (adaptada da referência (Munters, 2012)) .

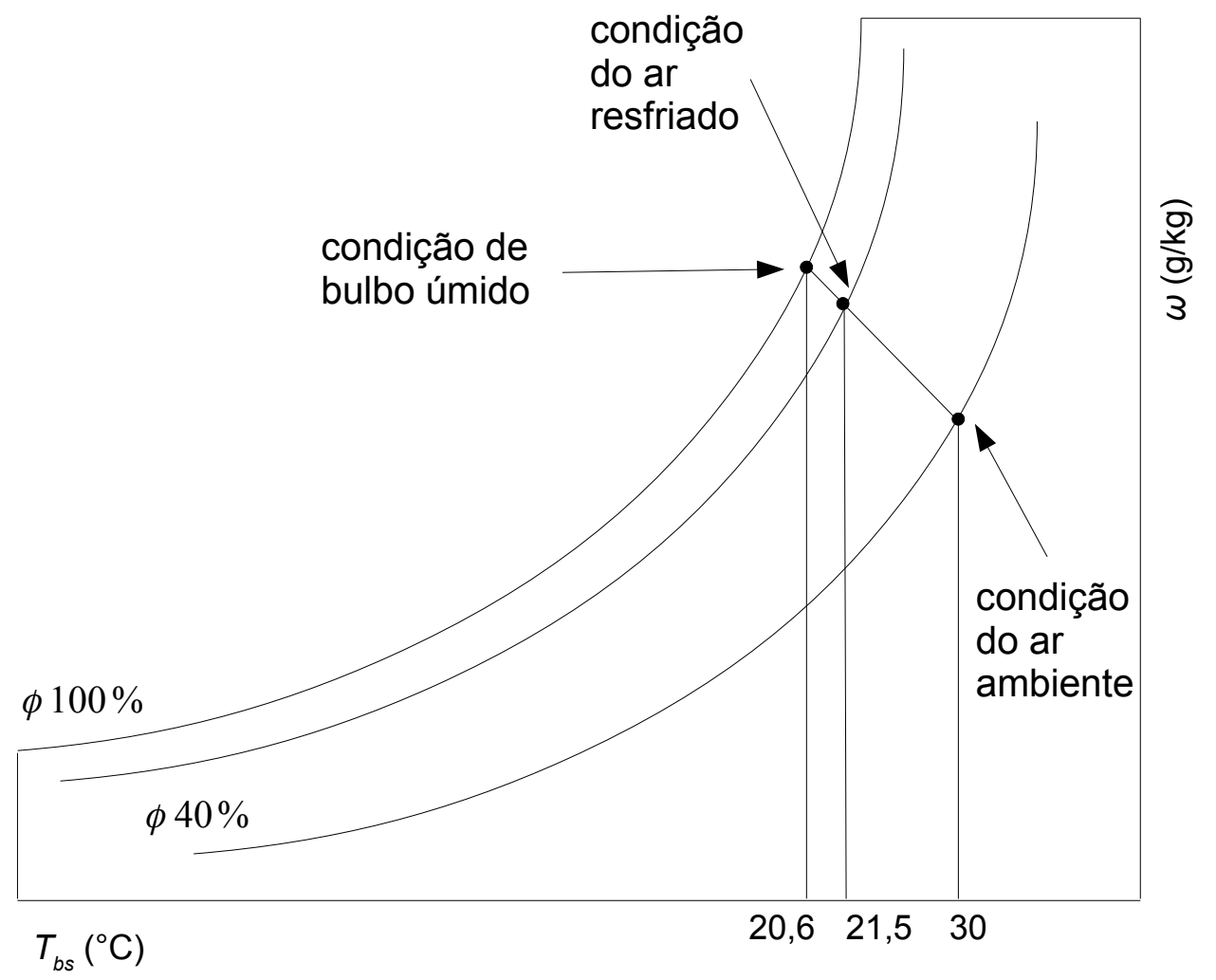

Figura 3: Resfriamento por EMR de uma temperatura de $30^{\circ} \mathrm{C}$ e umidade relativa $40 \%$ até uma condição próxima à de bulbo úmido representada no diagrama psicrométrico. 


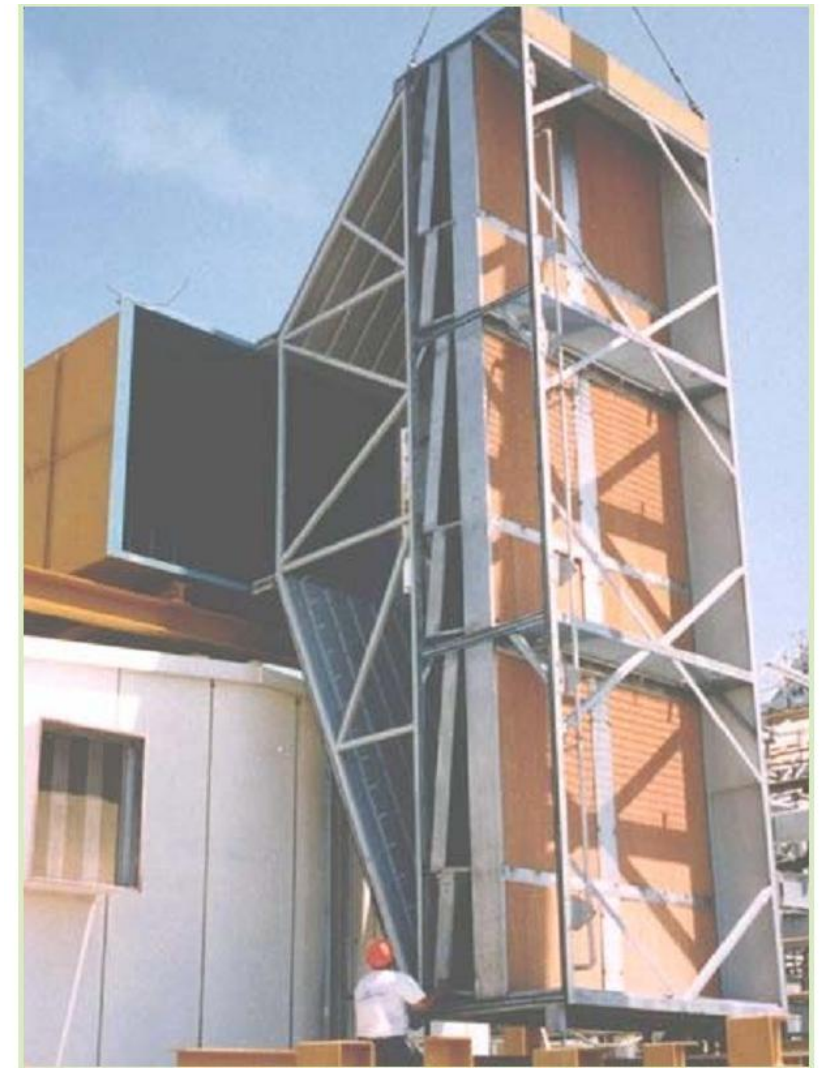

Figura 4: Foto de montagem do EMR.(Fonte (Donaldson Europe, 2011)) 


\subsubsection{Resfriamento evaporativo por névoa $(\mathrm{EVN})$}

No resfriamento evaporativo por névoa, que abreviamos por EVN, água desmineralizada é injetada na forma de gotículas no ar de entrada da turbina. Estas gotículas evaporam-se no ar ao longo do trajeto da casa de filtros até a entrada do compressor saturando o ar e reduzindo sua temperatura até a temperatura de bulbo úmido. A figura 5 mostra um diagrama do sistema de resfriamento EVN. Este sistema é conhecido na literatura industrial por "fogging".

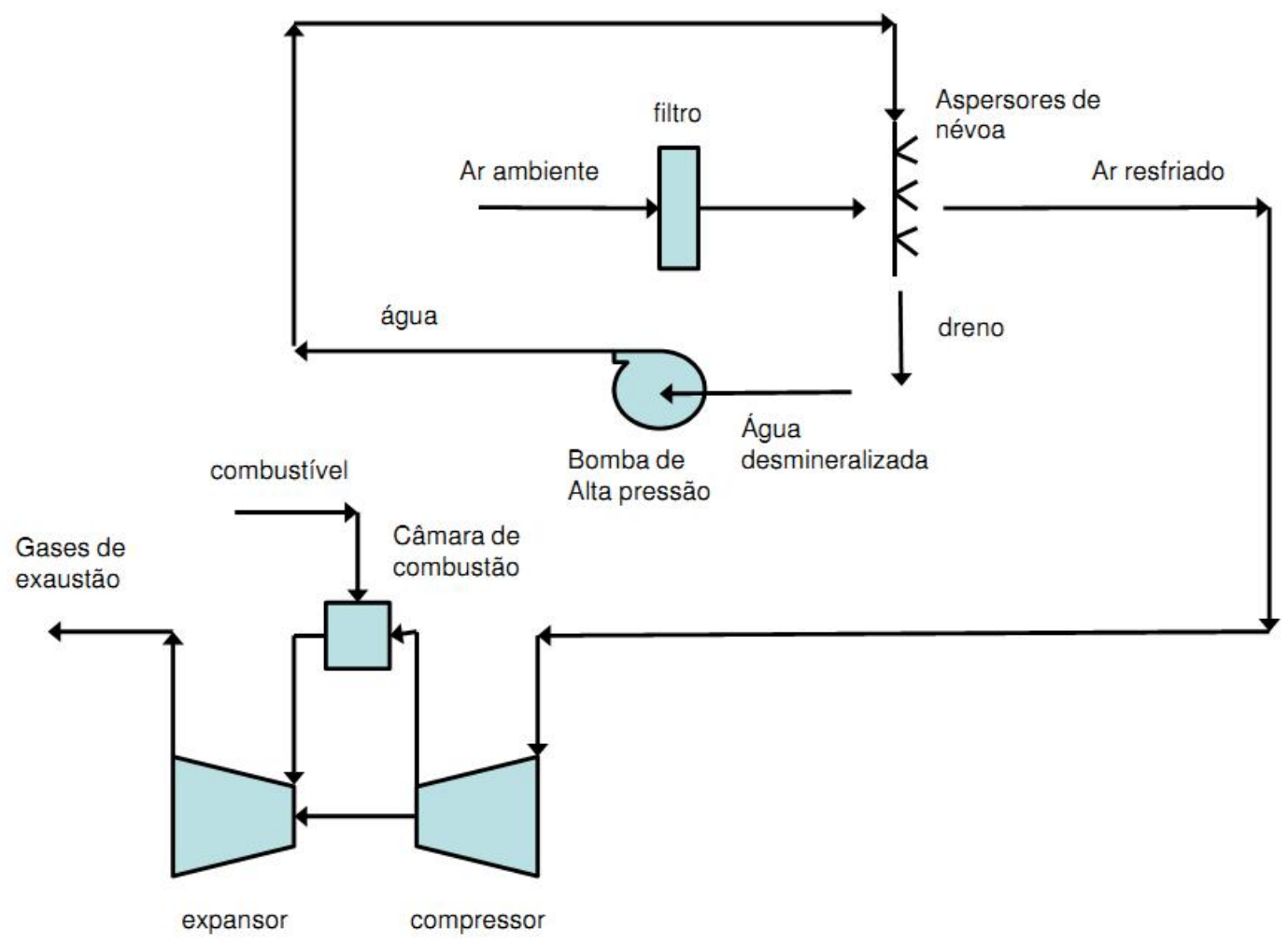

Figura 5: Diagrama do sistema de resfriamento de ar de entrada da turbina por fogging.

O sistema é instalado após os filtros de ar na forma de um chuveiro com bocais capazes de aspergir gotículas com dimensão da ordem de mícrons (figura 6). O chuveiro é alimentado por bombas de alta pressão, da ordem de 140 bar. Este sistema permite reduzir a temperatura do ar até um valor mais próximo da de bulbo úmido que o EMR. O consumo de água é controlado na quantidade de 
água evaporada, não há recirculação ou drenagem contínua. É possível injetar água em excesso para que esta evapore nos estágios intermediários do compressor, potencializando o resfriamento do ar. A instalação do chuveiro requer menor modificação da turbina que a instalação do meio úmido do EMR. O sistema não acrescenta perda de carga no ar de entrada da turbina. No entanto é necessário usar água desmineralizada para evitar deposição e bloqueio das passagens micrométricas dos bocais de aspersão (MEHER-HOMJI; MEE III, 8-11 Maio 2000). O custo de implementação do EVN varia de $\mathrm{U} \$ 40$ a $95 / \mathrm{kW}$ adicionado à potência da turbina pelo sistema. Consumo adicional de energia pelo EVN é da ordem de 0,5 a 0,7\% da potência adicionada à turbina (CHACARTEGUI et al., 2008).
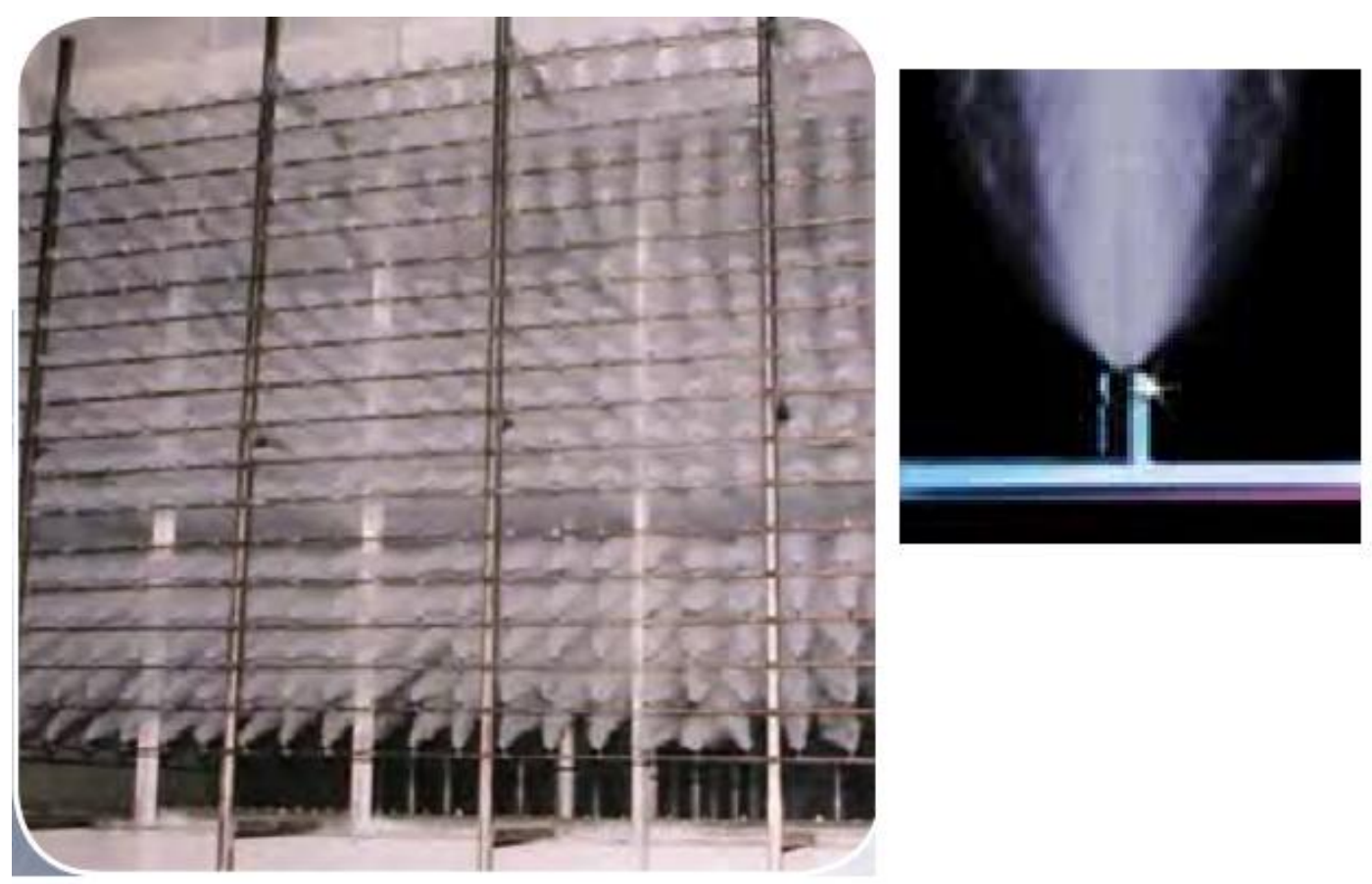

Figura 6: Chuveiro de EVN instalado na entrada da turbina e detalhe do bocal de aspersão.(Fonte (Mee Industries, 2008)) 


\subsubsection{Resfriamento por ciclo termodinâmico por compressão (CTC)}

No resfriamento por ciclo termodinâmico por compressão, que neste trabalho abreviamos por CTC,um ciclo de refrigeração implementado por um chiller, resfria uma solução de água e etileno glicol, que é feita circular em uma serpentina colocada na sucção da turbina após os filtros. O ar de entrada da turbina passa através da serpentina, que se constitui de uma série de tubos aletados por placas, sendo resfriado. O calor retirado do ar mais o que é produzido no chiller, é normalmente dissipado em uma torre de resfriamento. Em lugares onde a água é escassa pode-se usar trocadores do tipo radiador (torre seca). A figura 7 mostra o esquema do CTC.

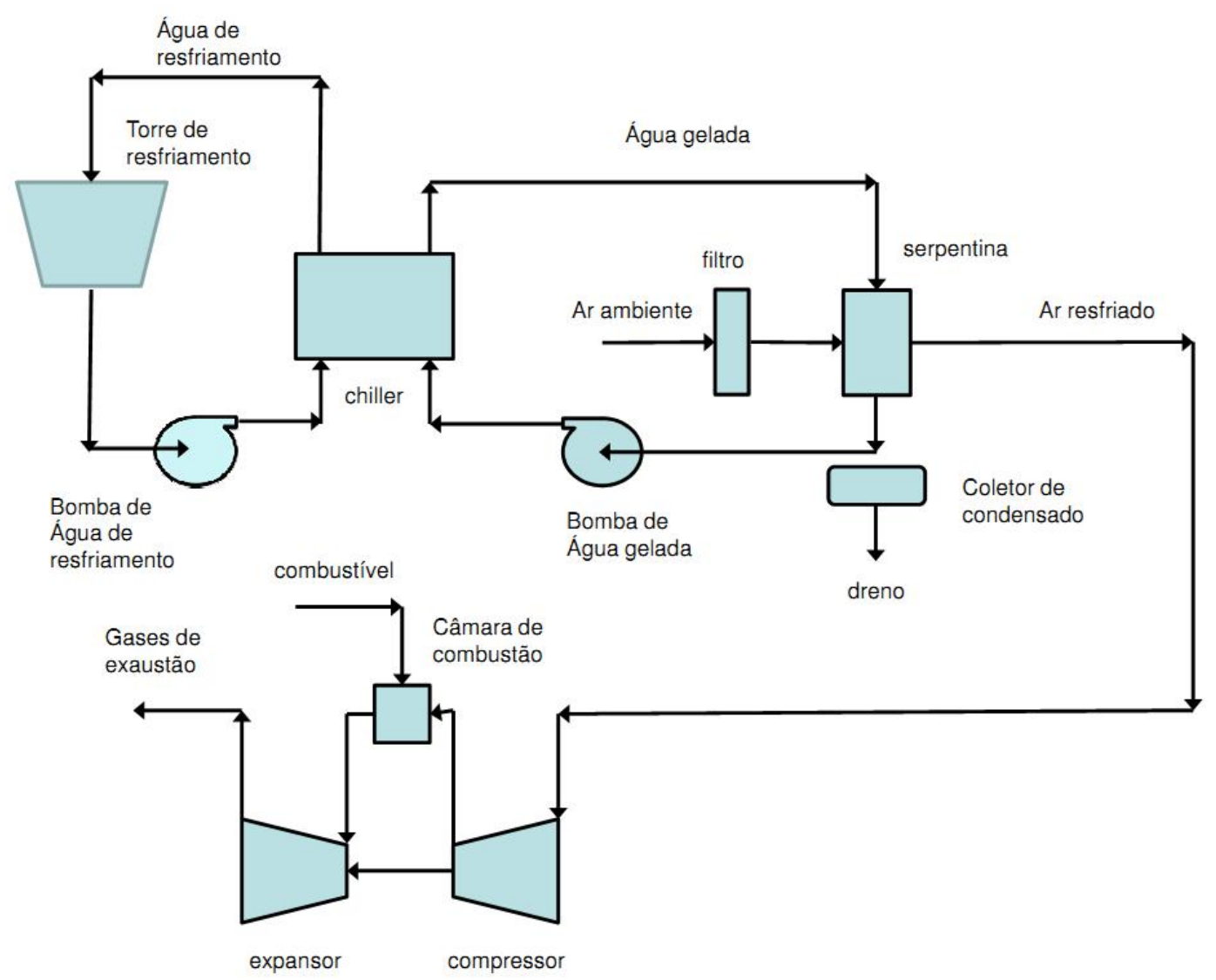

Figura 7: Diagrama do sistema de resfriamento de ar de entrada da turbina CTC.

A redução de temperatura do ar de entrada das turbinas só é limitada pela capacidade de projeto do CTC. O ar pode ter a sua temperatura reduzida abaixo 
da temperatura de bulbo úmido ambiente. Desta forma, a capacidade e aumento da potência da turbina pelo resfriamento CTC é maior que pelo resfriamento evaporativo EMR ou EN. Na prática a temperatura do ar é limitada a $7^{\circ} \mathrm{C}$ para que não haja formação de gelo na entrada do compressor da turbina. A figura 8 mostra o processo ideal de resfriamento do ar no diagrama psicrométrico. $\mathrm{O}$ ar é resfriado com concentração de vapor constante (umidade absoluta constante) até o ponto de orvalho. Esta parte do processo é chamada de retirada de calor sensível do ar. Para temperaturas inferiores ao ponto de orvalho, o processo segue condensando o vapor de água do ar, que durante o processo fica na condição de saturado (umidade relativa 100\%). Esta parte do processo é chamada de retirada de calor latente. A retirada de calor latente implica na condensação de parte do vapor d'água contido no ar e portanto num grande aumento da carga de refrigeração em relação à retirada de calor sensível.

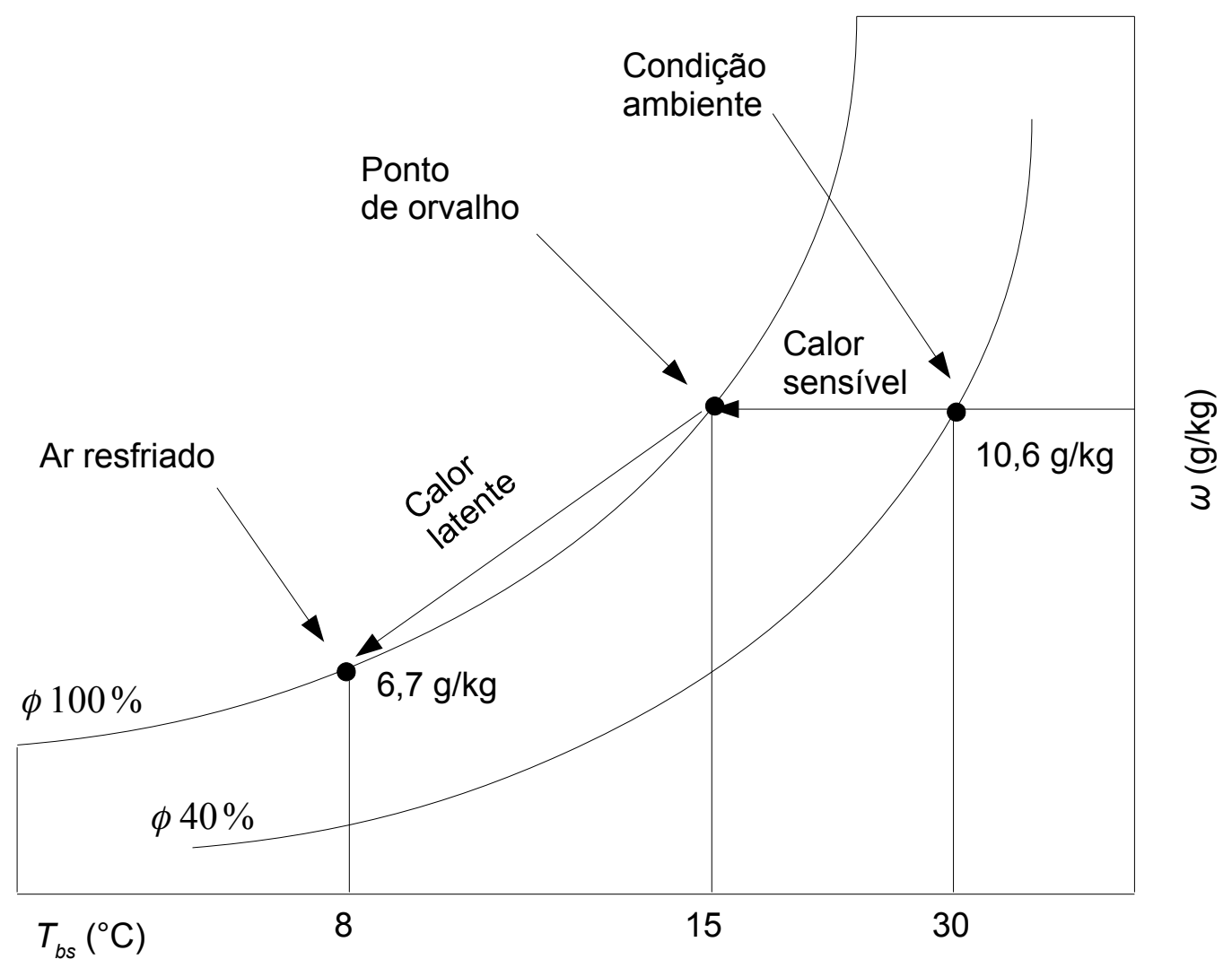

Figura 8: Resfriamento do ar a $30^{\circ} \mathrm{C}$ e $\phi 40 \%$ até a temperatura de $8^{\circ} \mathrm{C}$ representada no diagrama psicrométrico. 
O condensado resulta em gotículas na corrente e ar que são retiradas pelo eliminador de gotículas para evitar danos ao compressor da turbina. A figura 9 mostra os detalhes da serpentina e eliminador de gotas usados no CTC. A figura 10 mostra a fotografia de uma instalação de serpentina na casa de filtros de uma turbina. A serpentina e o eliminador de gotículas acrescentam uma perda de carga permanente de até $0,25 \mathrm{kPa}$ no ar de entrada da turbina.

O consumo de energia do CTC com chiller de acionamento elétrico é em torno de $0,25 \mathrm{~kW}$ de eletricidade para cada kW de carga de resfriamento do ar de entrada (CHACARTEGUI et al., 2008). O custo do CTC é indicado como sendo U\$336/kW de carga de resfriamento do ar de entrada da turbina em (CHACARTEGUI et al., 2008).

\section{Componentes principais do resfriamento CTC}

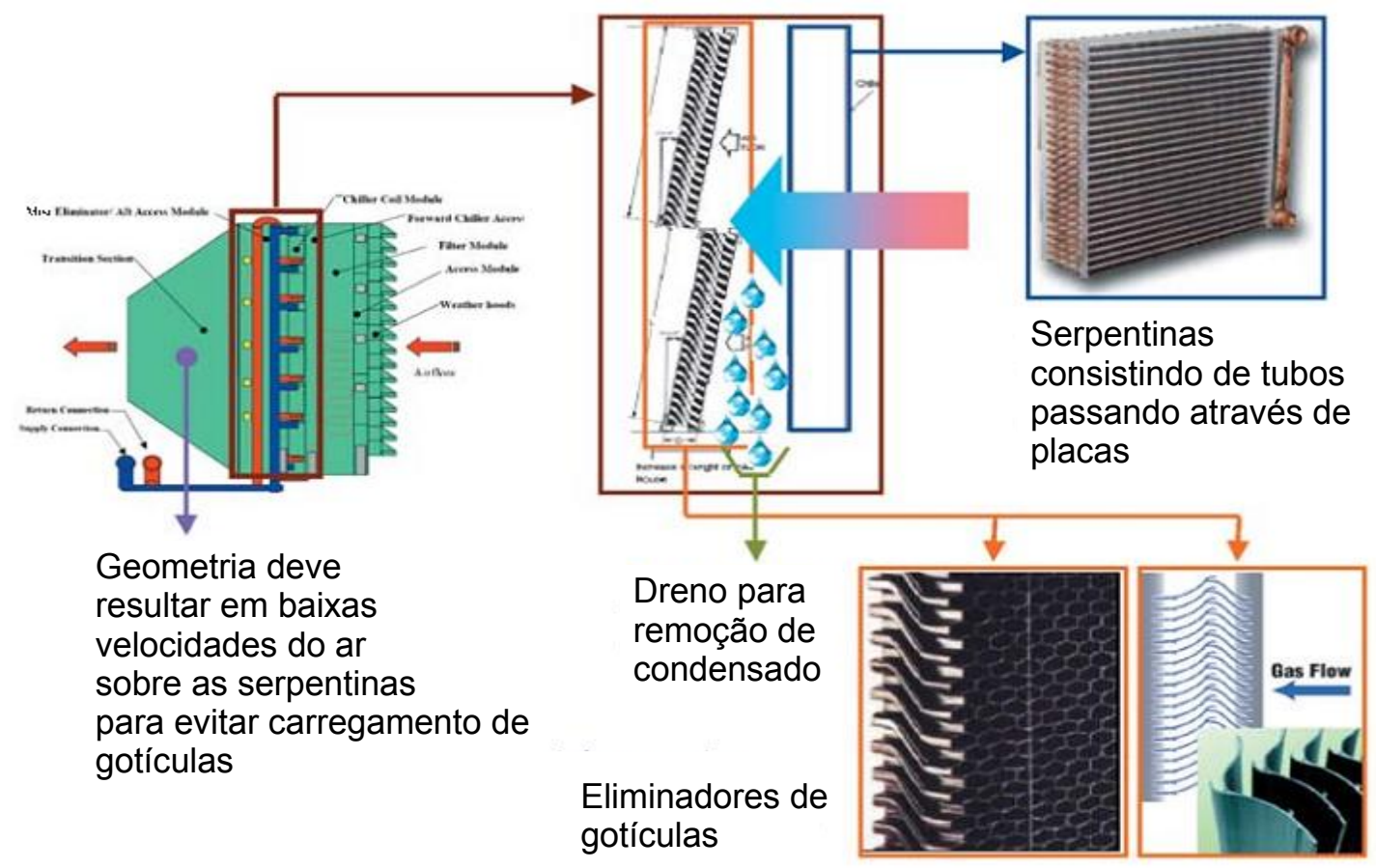

Figura 9: Detalhes da serpentina e eliminador de gotas usados na implementação do CTC (adptado de (GE Energy, 2008b)). 


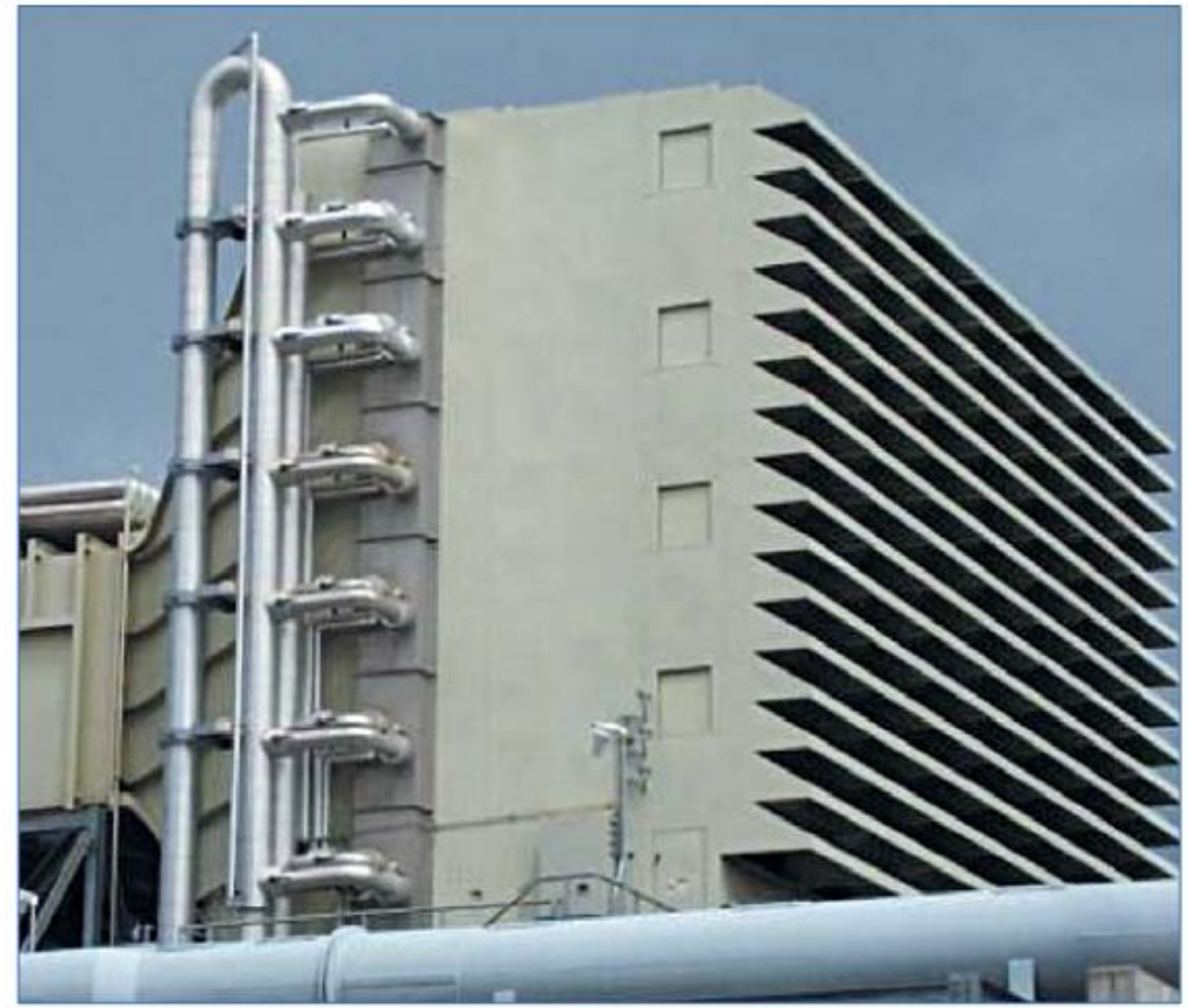

Figura 10: Instalação da serpentina na casa de filtros da turbina. (Fonte (GE Energy, 2008b)) 


\subsubsection{Resfriamento por combinação de armazenamento térmico com ciclo térmico por compressão (ATC)}

No resfriamento por combinação de armazenamento térmico com ciclo térmico por compressão, que abreviamos por ATC, um chiller elétrico resfria água em um reservatório. A água gelada ou gelo formado é usado para resfriar o ar de entrada da turbina. A figura 11 mostra o diagrama do sistema ATC. Este sistema tem duas vantagens potenciais:

- O chiller pode ser desligado nos períodos de pico, reduzindo o consumo de eletricidade, e aumentando a potência gerada na planta.

- Um chiller de menor capacidade pode ser usado para atender períodos de pico de demanda de refrigeração. A diferença entre a demanda e a capacidade do chiller é coberta pela água gelada ou gelo armazenados.

O uso do ATC é economicamente justificavel quando, usando este sistema, for possível operar o chiller por menos de 6 horas diárias (CHACARTEGUI et al., 2008). O ATC com água gelada é mais simples de instalar e responde mais rapidamente aos picos de demanda de refrigeração. Os sistemas com gelo são 6 vezes menores que os de água gelada, porque a sua capacidade de refrigeração é armazenada na forma de calor latente, porém necessitam de chillers que produzam temperaturas mais baixas, o que reduz o coeficiente de performance do sistema de resfriamento (CHACARTEGUI et al., 2008).

A figura 12 mostra o diagrama do sistema ATC da Mueller chamado de "Ice Harvester". Neste sistema o evaporador do chiller é montado sobre o reservatório de gelo. A água do reservatório é bombeada para o evaporador, que funcina como uma máquina de gelo. O gelo formado cai para o reservatório. Quando o sistema resfria o ar, a água gelada em contato com o gelo é circulada na serpentina na entrada da turbina. A figura 13 mostra o reservatório com o evaporador no topo 


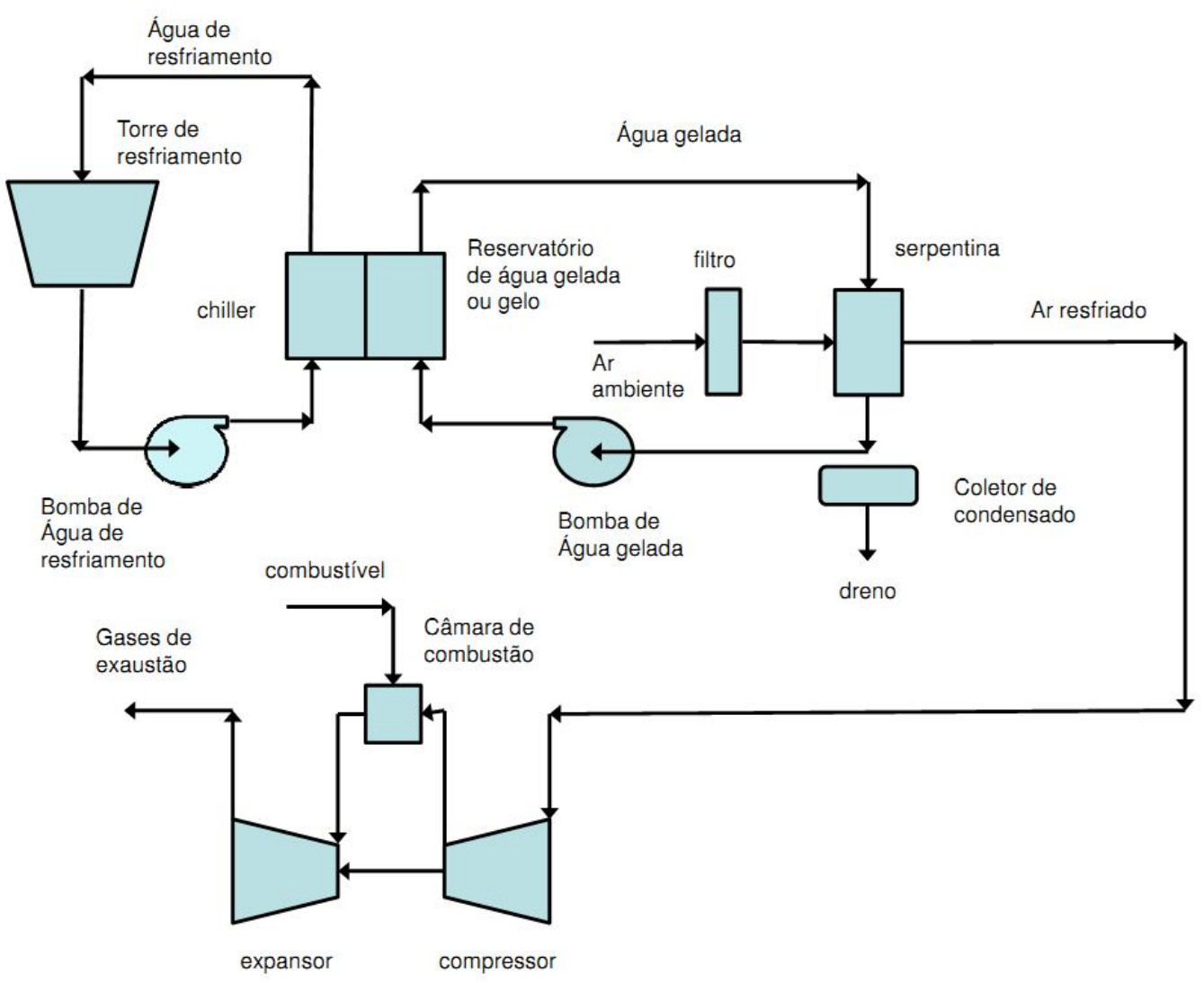

Figura 11: Diagrama do sistema de resfriamento de ar de entrada da turbina por chiller com armazenamento de água ou gelo.

para $11.356 \mathrm{~m}^{3}$ de gelo e água. A capacidade de armazenamento térmico é de 2.120 GJ e o sistema pode atender uma carga de resfriamento do ar de entrada da turbina de 35.700 MW (Paul Mueller Company, 2000). O custo de um sistema ATC é de U\$ 15/MJ de capacidade de armazenamento de gelo (CHACARTEGUI et al., 2008). 


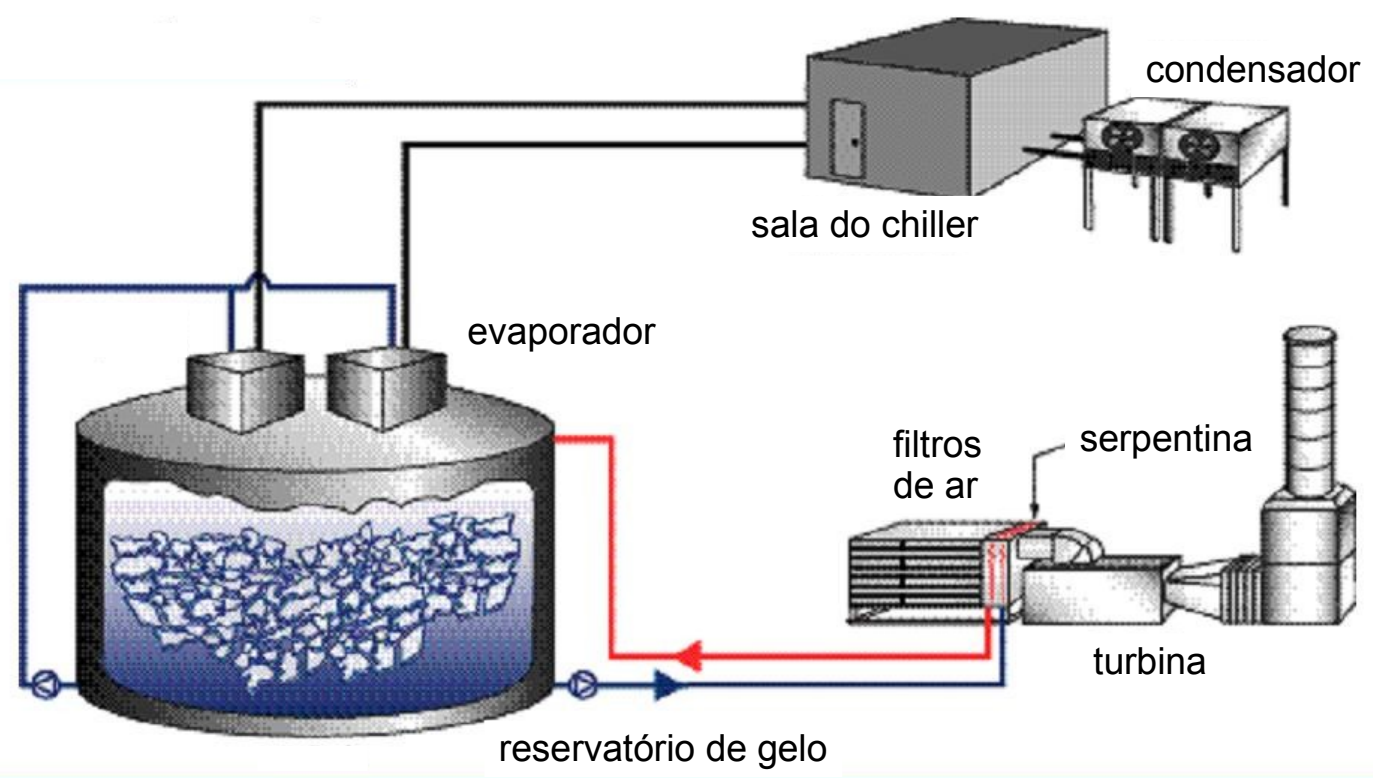

Figura 12: Diagrama do sistema ATC com gelo da Mueller "Ice Harvester"(adaptado de (Paul Mueller Company, 2000)).

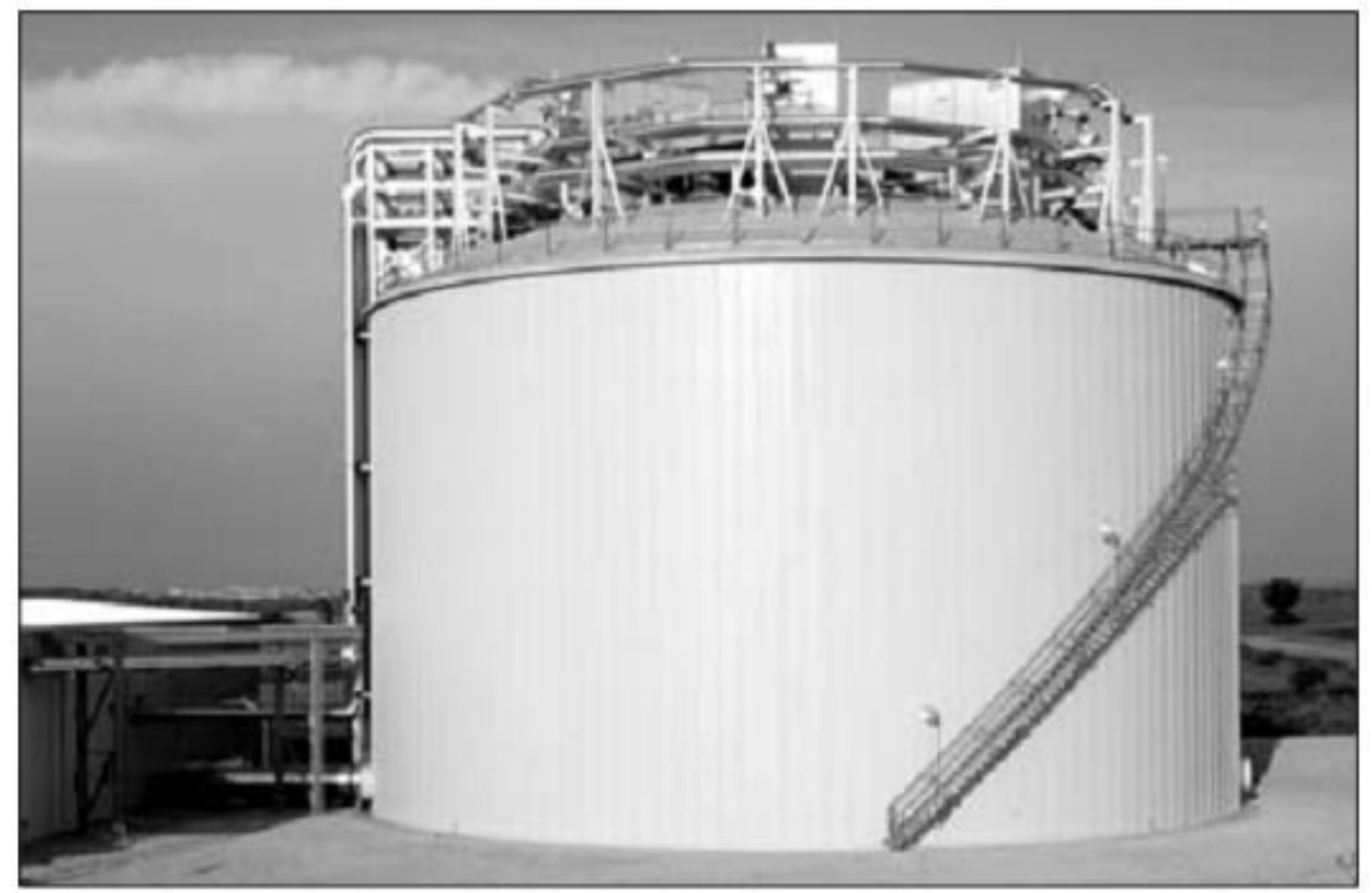

Figura 13: Foto do reservatório de gelo da Muller para o "Ice Harvester" com capacidade de armazenar $11.356 \mathrm{~m}^{3}$ de gelo.(Fonte (Paul Mueller Company, 2000)) 


\subsubsection{Resfriamento por ciclo térmico de absorção}

O resfriamento por ciclo térmico de absorção, que abreviamos por CTA, funciona de maneira similar ao CTC. Água gelada resfriada em um chiller passa por uma serpentina na entrada da turbina resfriando o ar (figura 14). A diferença está no fato do chiller de compressão acionado por motor elétrico ser substituído por um chiller de absorção.

A figura 15 mostra como opera o ciclo de absorção usado no chiller de absorção. O fluído de trabalho do ciclo é a água. Ela evapora no evaporador a baixa pressão e temperatura $\left(4^{\circ} \mathrm{C}\right.$ e $0,83 \mathrm{kPa}$ na figura), resfriando a água gelada que vai para a serpentina na entrada da turbina. O diferencial de concentração de água entre o evaporador e o absorvedor faz com que o vapor gerado no evaporador flua para o absorvedor. No absorvedor, a água é absorvida numa solução concentrada de LiBr em água. A absorção dilui a solução de LiBr em água. Esta solução diluída é coletada no fundo do absorvedor. A pressão do absorvedor é a mesma do evaporador. A solução diluída é bombeada para o gerador tendo a sua pressão elevada de $0,83 \mathrm{kPa}$ para $8 \mathrm{kPa}$. A energia elétrica consumida para esta elevação de pressão é menor do que a do ciclo de compressão pois a solução é um líquido e tem volume específico pequeno. No gerador: vapor, água quente ou óleo térmico aquecido fornece energia para o ciclo. O calor fornecido faz parte da água da solução diluída evaporar. A solução mais concentrada retorna ao absorvedor por diferença de pressão, passando por um resfriador para baixar a sua temperatura até uma temperatura compatível com o processo de absorção. O vapor de água obtido no gerador vai para o condensador, onde é condensado pelo resfriamento, que normalmente é água de resfriamento que circula por uma torre de resfriamento. No condensador a pressão e temperaturas são $45^{\circ} \mathrm{C}$ e $8 \mathrm{kPa}$. A água flui por diferença de pressão para o evaporador. Ao passar pelo aspersor no topo do evaporador a água sofre redução de pressão e evapora novamente em 
contato com a água gelada da serpentina, reiniciando o ciclo. O calor extraído no ciclo é retirado pelo sistema de resfriamento no condensador e absorvedor. O resfriamento da solução de LiBr concentrada entre o gerador e o absorvedor é regenerativo. A solução de $\mathrm{LiBr}$ diluída que flui do absorvedor para o gerador é usada no resfriamento. A figura 16 mostra 5 chillers de capacidade 5,8 $\mathrm{MW}$ de refrigeração cada usados no resfriamento de ar de entrada das turbinas de uma termelétrica (PUNWANI et al., 5-8 Novembro 2001).

A vantagem do CTA sobre o CTC é o consumo muito menor de energia elétrica. Enquanto o CTC consome em torno de 0,25kW de eletricidade por $\mathrm{kW}$ de resfriamento do ar de entrada da turbina, essa taxa é três vezes menor no CTA, ou seja, 0,08kW/kW. No entanto o consumo total de energia, considerando a energia térmica e a elétrica, é igual ou maior que a do CTC. Além disso é necessário instalar um trocador de calor ou caldeira de recuperação na exaustão da turbina, ou, quando já houver uma caldeira de recuperação, disponibilidade de vapor de baixa pressão para alimentar o chiller de absorção. O CTA, devido ao fato de usar água como fluído de trabalho, pode resfriar o ar até $10^{\circ} \mathrm{C}$ no mínimo (CHACARTEGUI et al., 2008). O CTA pode aproveitar a energia térmica dos gases de exaustão das turbinas de ciclo aberto. O investimento para instalação do CTA é de U\$386/kW de carga de resfriamento do ar (CHACARTEGUI et al., 2008). 


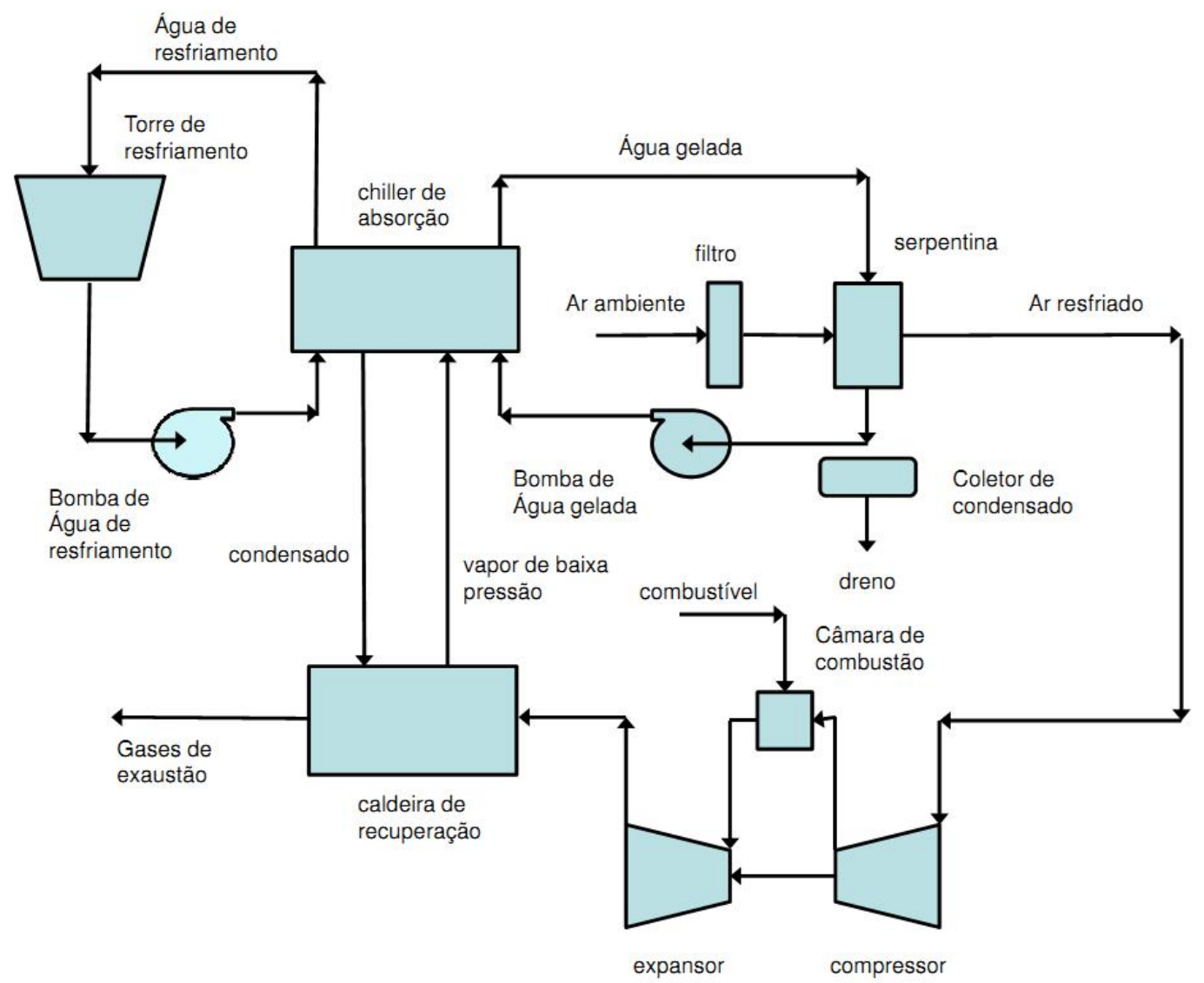

Figura 14: Diagrama do sistema de resfriamento de ar de entrada da turbina por ciclo de absorção 


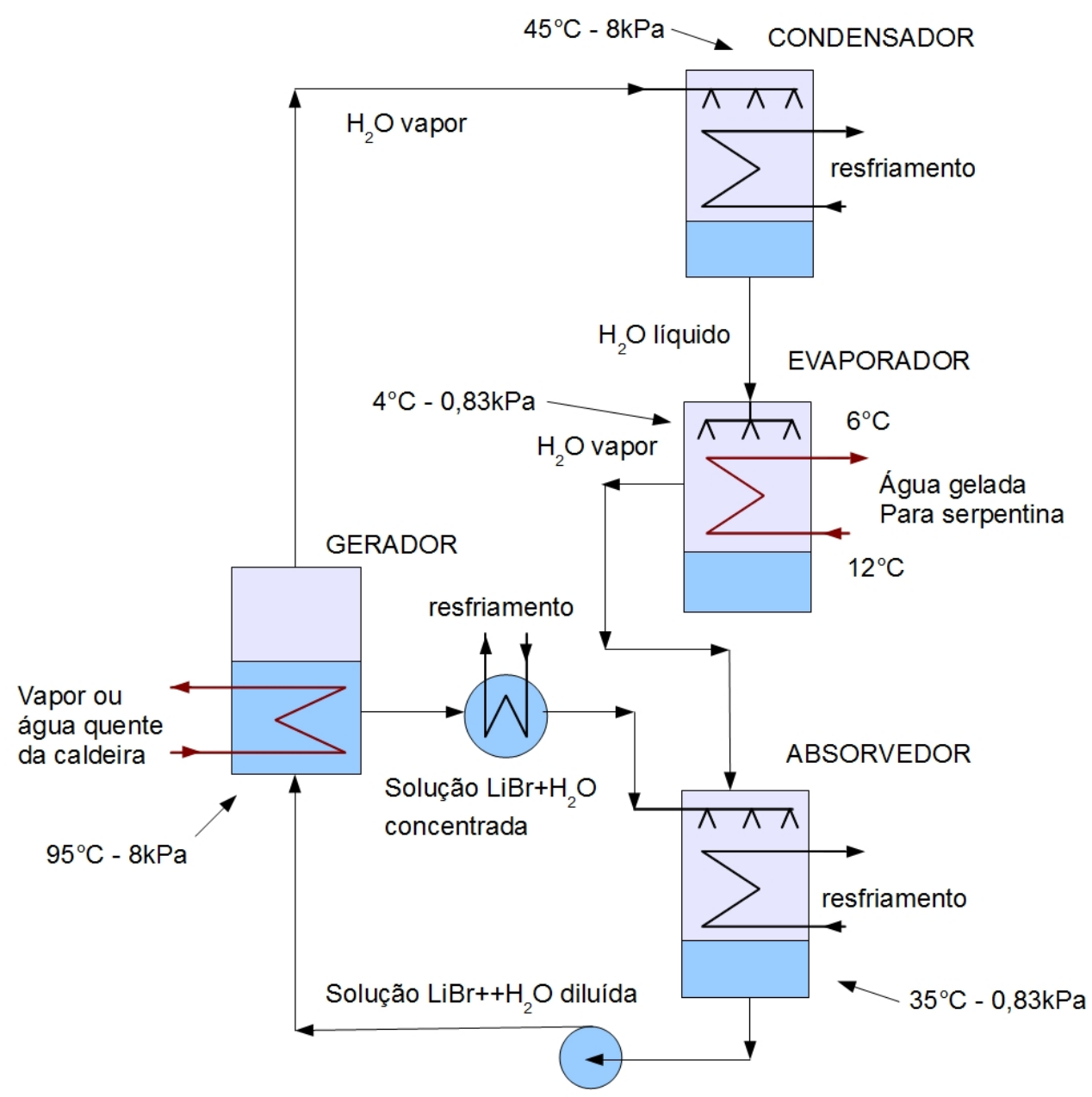

Figura 15: Diagrama simplificado do ciclo do chiller de absorção. 


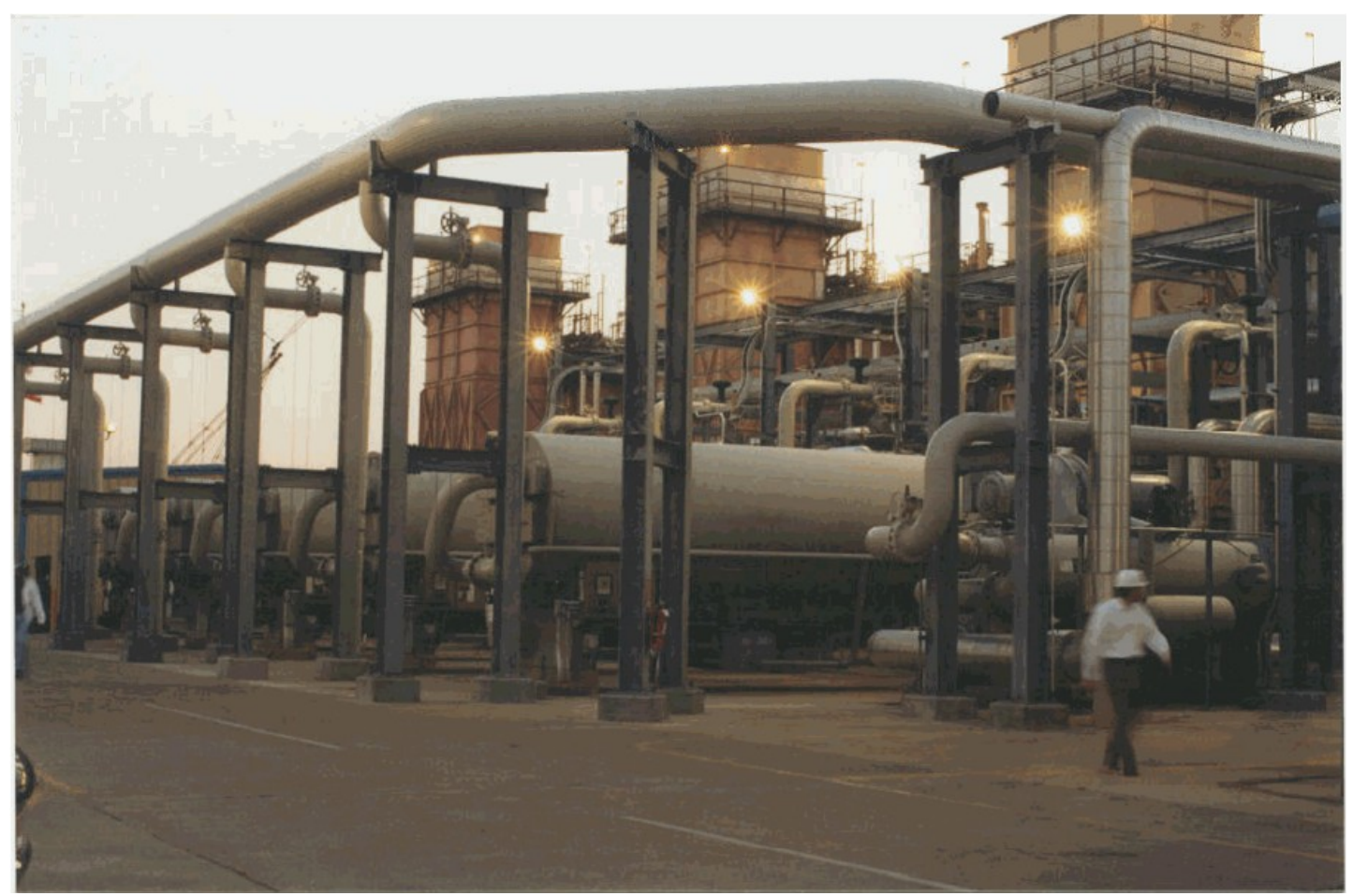

Figura 16: Foto de 5 chillers de absorção de capacidade 5,8 MW de refrigeração cada usados no resfriamento de ar de entrada de turbinas. (Fonte (PUNWANI et al., 5-8 Novembro 2001)) 


\subsection{Objetivos}

Dois métodos de resfriamento são estudados neste trabalho: o resfriamento evaporativo por meio rígido (EMR) e o resfriamento por ciclo térmico de compressão (CTC). O EMR é o paradigma para os dois tipos de resfriamento evaporativo em termos de influência climática e implementação. Da mesma forma o CTC é o paradigma para o os resfriamentos para ciclos térmicos. O CTC e o EMR também são os sistemas de resfriamento de ar de turbinas que requerem menor capital para a implementação e, no caso do CTC, implicam em menor modificação do ciclo térmico das turbinas a gás.

Os objetivos deste trabalho são:

- Avaliar o potencial dos métodos evaporativo e por ciclo térmico aplicados ao resfriamento do ar de entrada nas turbinas a gás do parque gerador brasileiro pela análise dos ganhos de geração e eficiência de cada método em função das condições climáticas na maioria dos centros de consumo de energia no Brasil.

- Desenvolver um modelo capaz de avaliar os efeitos do resfriamento do ar de entrada das turbinas a gás na geração termelétrica brasileira.

- Estudar parâmetros climáticos que indiquem a conveniência da instalação de sistemas de resfriamento em locais no Brasil.

\subsection{Metodologia}

Os passos para a realização do estudo proposto são os seguintes:

- Desenvolvimento de modelo de turbina a gás que simula a resposta da turbina a mudanças nas condições do ar de entrada. Este modelo é desenvol- 
vido baseado em princípios fundamentais da termodinâmica. Os parâmetros necessários para aplicação do modelo são os geralmente encontrados nos catálogos de turbinas a gás.

- Levantamento dos dados climáticos representativos para o estudo de resfriamento de 27 localidades brasileiras, para a simulação de operação das turbinas.

- Desenvolvimento de modelo de resfriamento evaporativo do tipo EMR.

- Simulação da turbina com e sem o modelo do EMR e avaliação do aumento de energia produzida, volume de água consumido em um ano de operação.

- Desenvolvimento de modelo de resfriamento por ciclo térmico do tipo CTC.

- Simulação da turbina com e sem o modelo do CTC e avaliação do aumento de energia produzida, aumento de consumo de gás e volume de água consumido em um ano de operação.

- Análise dos resultados e avaliação das condições de aplicação de cada tipo de sistema.

Nota: Nas análises econômicas da aplicação dos os preços de equipamentos e insumos são convertidos para dólares americanos usando as taxas de conversão da data de sua publicação usando o conversor fornecido em (Banco Central do Brasil, 2012). O valor em dólares é então atualizado para 2012 usando o atualizador de preços fornecido em (United States Department of Labor, 2012). Os preços de equipamentos são ainda corrigidos em 13,68\% para levar em consideração a maior carga tributária do Brasil em relação aos Estados Unidos (NOBLE; SOUZA; de Almeida, 2006). 


\section{REVISÃO BIBLIOGRÁFICA}

\subsection{Resfriamento do ar de entrada de turbinas a gás}

(JOHNSON, 1989) descreve a teoria e operação de resfriadores evaporativos com meio rígido.São apresentados os parâmetros de operação do resfriador: eficiência,operação com recirculação e sem recirculação, mapas de operação no diagrama psichrométrica. Também são apresentados o parâmetros de projeto do equipamento com uma descrição completa de cada componente do sistema, vazão de recirculação, vazão de dreno, velocidade permissíveis do ar no sistema. $\mathrm{O}$ artigo inclui uma lista de causa e efeito para possíveis problemas de operação e especificação da qualidade da água a ser usada no resfriador.

(ONDRYAS et al., 1991) apresenta um estudo técnico econômico do resfriamento por ciclo de absorção (chiller de absorção), ciclo mecânico (chiller elétrico) e sistema híbrido combinando absorção e mecânico. É apresentada uma tabela com detalhes dos equipamentos dos sistemas: consumos de energia e água, aumento de energia esperado da turbina, custos de capital, receitas e tempo de retorno de capital para cada tipo de sistema. (LUCIA; BRONCONI; CARNEVALE, 1994) discute a aplicação de resfriamento por absorção em turbinas usadas em vários setores industriais. Um modelo climático baseado na incidência de radiação solar é apresentado. É feita uma análise econômica das aplicações levando-se em conta preços diferenciados conforme o horário de consumo em conjunto com a variação de temperaturas ao longo do ano. 
(KITCHEN; EBELING, 5-8 Junho 1995) discute os ganhos de geração de energia para diferentes tipos, marcas e modelos de turbinas acionadas com gás natural e óleo diesel com resfriamento de ar de entrada usando sistemas de resfriamento não evaporativos. A relação entre carga de resfriamento de 38 para $4^{\circ} \mathrm{C}$ do $\operatorname{ar}$ de entrada das turbinas dividido pelo aumento de potência das turbinas é usado como indicador da efetividade do resfriamento na turbina. É feita uma tentativa de relacionar o indicador com a eficiência da turbina; taxa de compressão e a relação vazão de ar-potência da turbina não resulta em boa correlação.

(LINDEN; SEARLES, 10-13 Junho 1996) discute a aplicação de resfriamento evaporativo e por chiller elétrico (ciclo mecânico) em climas secos e úmidos. O resfriamento evaporativo tem menor custo de capital mas está limitado pela temperatura de bulbo úmido do ar ambiente. O resfriamento por chiller tem maior custo de capital mas é capaz de resfriar o ar até a temperatura limite de congelamento na entrada da turbina. Portanto pode aumentar mais a potência da turbina que o resfriamento evaporativo. A razão potência por vazão de ar na turbina é indicada como fator de avaliação da efetividade da aplicação do resfriamento do ar da turbina. Quanto maior a razão, menor a carga de resfriamento e maior o ganho de potência pela aplicação do resfriamento do ar da turbina. O aumento de carga no gerador e a necessidade de aumentar o resfriamento deste componente são mencionados.

(NAJJAR, 1996) faz um estudo detalhado da aplicação de um ciclo de absorção no resfriamento do ar da turbina. A implementação do sistema inclui a colocação de uma caldeira de recuperação na exaustão da turbina para fornecer vapor ao chiller de absorção. São relacionados os custos dos componentes do sistema e feito um estudo de viabilidade econômica. Um aumento de $21 \%$ na potência gerada e de $38 \%$ na eficiência da turbina são previstos quando a temperatura de entrada do ar é reduzida de 40 para $7^{\circ} \mathrm{C}$. 
(JOLLY et al., 9-11 Dezembro 1997) descreve a implantação do resfriamento por compressão (chiller elétrico) em uma turbina industria 7AE da GE nos EUA. O sistema de resfriamento consiste de chiller elétrico, torre de resfriamento e serpentina. O projeto considera condições em um dia de cada uma das estações do ano. A viabilidade econômica do projeto é estudada em termos de valor presente. O projeto é otimizado estudanto o seu valor para diferentes capacidades de resfriamento do chiller. O valor ótimo é de 2000TR (7 MW). Após a implantação, o ganho de potência, perda de carga na entrada da turbina e consumo de energia do sistema de resfriamento são medidos. É conseguido um aumento médio de $7 \mathrm{MW}$ para a turbina de potência nominal de $165 \mathrm{MW}$. A perda de carga do ar nas serpentinas fica em torno de $0,1 \mathrm{kPa}$.

(MCNEILLY, 8-11 Maio 2000) discute a aplicação de resfriamento evaporativo. O impacto do clima do local de aplicação dos sistemas evaporativos é enfatizado. Estatísticas climáticas dos locais de aplicação ( frequências cumulativas de depressão de bulbo úmido e temperaturas de bulbo seco e bulbo úmido) são apresentadas.

(MEHER-HOMJI; MEE III, 8-11 Maio 2000) descreve o resfriamento evaporativo do ar da turbina por névoa (fogging). O resfriamento por fogging é comparado ao resfriamento evaporativo por meio rígido. A teoria dos processos de transferência e de calor e massa do fogging é apresentada. Comparativamente ao resfriamento por meio rígido, fogging tem eficiência maior, consome menos água, não causa perda de pressão no ar de entrada da turbina, a sua instalação requer interrupção menor da operação da turbina. Em compensação o sistema requer água desmineralizada e bocais especialmente desenhados na sua operação. É possível também usar o fogging para resfriar o ar nos estágios intermediários do compressor. Neste caso, é gerada névoa em excesso que é engolida pelo compressor e evapoa-se nos estágios intermediários. Também é explicado a importância do uso de dados cli- 
máticos estatisticamento significativos na previsão da efetividade da aplicação de sistemas de resfriamento evaporativo. A diferença entre as temperaturas de bulbo seco e bulbo úmido também tem a sua importância ressaltada.

(PUNWANI et al., 5-8 Novembro 2001) apresenta o estudo de viabilidade econômica para implantação de um sistema híbrido com ciclo de absorção assistido por ciclo de compressão em uma planta de cogeração no Texas, EUA. A planta, onde o sistema está instalado, tem turbinas Westinghouse, cada uma de 105 MW, e exporta vapor gerado pelos gases de exaustão das turbinas. O estudo analisa as opções de ciclos evaporativos de névoa e meio rígido, ciclos de compressão acionados por eletricidade e vapor, ciclos de absorção acionados por água quente e queima direta e finalmente um sistema híbrido combinando absorção acionada por água quente e compressão acionada por eletricidade. A otimização da taxa de retorno interna anual resulta na escolha do sistema híbrido. Custos de investimento e operação típicos são apresentados para cada tipo de sistema. No sistema híbrido escolhido o ciclo de absorção resfria a água da serpentinas até $6^{\circ} \mathrm{C}$, devido a limitações do ciclo, e o ciclo de compressão resfria a água de 6 a $3^{\circ} \mathrm{C}$, que é a temperatura requerida pela otimização das serpentinas.

(CHAKER et al., 2003) faz um estudo da aplicabilidade do resfriamento por névoa (fogging) em 122 localidades dos EUA. O estudo apresenta a aplicação do conceito de horas graus de resfriamento equivalentes (equivalent cooling degree hours), HGRE, à previsão de resfriamento evaporativo. A determinação das HGRE de cada localidade são feitas com base em estatísticas de 30 anos de dados climáticos. Estas estatísticas são apresentadas na forma da anos de médias climáticas e são normalmente usados em projetos de refrigeração e ar condicionado. Também é enfatizado que mesmo em locais de alta umidade as horas de temperaturas mais altas geralmente correspondem a horas de baixa umidade, tornando mais efetivo a aplicação de resfriamento evaporativo nestes locais. 
(CASTRO; PIMENTA, 29 Novembro 3 Dezembro 2004) apresenta um modelo para a transferência de calor, massa e momento dos painéis evaporativos do tipo usado no resfriamento do ar de turbinas no resfrimanto evaporativo por meio rígido. O modelo é desenvolvido usando princípios termodinâmicos e relações empíricas de transferência de massa e calor e perda de carga. Os resultados do modelo são comparados com dados de painéis comerciais.

(GARETA; ROMEO; GIL, 2004) apresenta a metodologia para avaliar a viabilidade de sistemas de resfriamento de ar da turbina em ciclos combinados. É estudada a viabilidade de sistemas evaporativos, ciclo de compressão com chiller elétrico, ciclo de absorção e armazenamento térmico. Um modelo simples do sistema considerando curvas de desempenho da turbina em função das condições de entrada é usado. Custos de investimento em cada tipo de sistema de resfriamento são relacionados. Condições climáticas e de mercado de energia com variações de preços de gás e eletricidade da Espanha são consideradas.

(CHAKER; MEHER-HOMJI, 2006) refaz o estudo apresentado em (CHAKER et al., 2003) sobre a viabilidade do resfriamento evaporativo por névoa para locais fora dos EUA. No estudo estão inclusas as cidades brasileiras de Belém e Rio de Janeiro.

(CARVALHO, 2006) desenvolve um modelo para traçar mapas de operação de turbinas a gás a partir de dados de operação de projeto, que normalmente são fornecidos em catálogos.

(JABER; JABER; KHAWALDAH, 2007) apresenta o desenvolvimento do modelo de uma turbina e a simulação do resfriamento do ar de entrada da turbina por processo evaporativo de meio rígido e por ciclo de compressão com chiller elétrico. É feita a comparação dos dois meios de resfriamento. Custos de implementação de cada sistema são relacionados. O custo do sistema evaporativo é estimado por kW instalado das turbinas. Dados climáticos usados são para a Jordânia (clima 
seco).

(CHACARTEGUI et al., 2008) apresenta a aplicação dos métodos de resfriamento evaporativo (meio rígido e fogging), por ciclo mecânico (chiller movido por motor elétrico, de combustão e turbina a vapor), por ciclo de absorção (LiBr) e com armazenamento de gêlo e água em uma planta na Espanha com ciclo combinado e queima complementar. Consumos de energia e custos de investimento em cada tipo de sistema de resfriamento são apresentados. O ciclo combinado é modelado a partir de regressão sobre os dados de operação da planta. É feita uma revisão dos métodos de resfriamento de ar nas turbinas a gás. Uma análise financeira do retorno do investimento nos diferentes métodos de resfriamento também é feita. Os resultados do trabalho indicam que o uso de chillers elétricos e sistemas que combinam sistemas de absorção e chillers elétricos apresentam os melhores retornos de capital.

(BOONNASA; NAMPRAKAI, 2008) estuda a viabilidade tecnico-financeira da aplicação de resfriamento por ciclo de absorção em uma planta da Tailandia. O clima do local da planta é quente e úmido. A planta considerada é de ciclo combinado e vapor de baixa pressão fornece energia ao chiller de absorção. O balanço de energia indica ganho na potência da turbina a gás e redução na potência gerada pela turbina a vapor numa relação 5:1.

(GUIRARDI, 2008) estuda o uso do resfriamento evaporativo por meio rígido e por ciclo de absorção em uma turbina de 5MW. O modelo desenvolvido para o estudo inclui também emissões de $\mathrm{NO}_{x}$ e $\mathrm{CO}_{2}$. É feita uma comparação entre o efeito dos sistemas de resfriamento no verão e no inverno em Curitiba e Belém. Uma avaliação exergética da turbina com os dois sistemas de resfriamento é apresentada. O trabalho conclui que a aplicação de resfriamento tem maior impacto em Belém do que em Curitiba, tanto do ponto de vista de viabilidade econômica como do ponto de vista exergético. 
(AL-IBRAHIM; VARNHAM, 2010) faz uma revisão completa da literatura sobre métodos de resfriamento de ar de entrada de turbinas a gás e discute sua aplicação na clima quente e seco da Arábia Saudita. No artigo, é mencionado que a primeira aplicação do resfriamento de ar de entrada de turbinas a gás aconteceu em 1987 na termelétrica Battle Creek nos Estados Unidos.

(SANAYE; FARDAD; MOSTAKHDEMI, 2011) estuda a otimização de um sistema resfriamento com chiller elétrico e armazenamento de gêlo. É feito o estudo termoeconômico do sistema aplicado a uma turbina operando com potências de 25 a 100MW. A destruição de exergia no sistema é considerada. Os dados climáticos usados são de Ahvaz no Irã.

(FARZANEH-GORD; DEYMI-DASHTEBAYAZ, 2011) apresenta a aplicação de resfriamento pela expansão do gás natural em uma refinaria do Irã. Gás natural é expandido da pressão de processamento (70 bar) até a pressão de distribuição na refinaria (14 bar). A expansão é feita em um turbo-expansor, gerando energia elétrica. O gás tem sua temperatura reduzida na expansão e por sua vez resfria o ar de entrada das turbinas da refinaria através de trocadores de calor colocados na entrada das turbinas. O sistema é comparado favoravelmente com sistemas evaporativos e sistemas de ciclo de compressão. No entanto só pode ser aplicado a turbinas de baixa potência (no artigo 7,5 MW), devido à carga de resfriamento requerida pelo ar de entrada.

\subsection{Modelos de turbinas a gás}

(LAPINA, 1982) explica como analisar o efeito de alterações na condição de entrada de compressores centrífugos na sua operação usando as curvas de desempenho dos compressores.

(ROWEN; HOUSEN, 1983) discute o controle da temperatura e vazão de gases 
de exaustão de turbinas de um e dois eixos para a otimização da recuperação de calor. A manipulação dos ângulos da aletas guia de entrada permite operar as turbinas em carga parcial com aumento de vazão e temperatura do vapor gerado em caldeiras de recuperação. Os resultados do estudo também indicam que a redução da temperatura do ar de entrada das turbinas aumenta a energia gerada nas caldeiras de recuperação.

(ROWEN, 1983) descreve o sistema de controle das turbinas a gás da GE e apresenta um modelo simplificado do controle e turbina. O objetivo do artigo é descrever um modelo dinâmico que pode ser aplicado no estudo de sistemas motores e de geração elétrica. O controle de potência-rotação e temperatura na entrada do expansor é relacionado à vazão de combustível quando a turbina opera na condição de projeto.

(ROWEN, 1988) discute as características do controle de turbinas industriais. Partida, controle de velocidade, controle de temperatura, controle de carga, operação de pico, e atuação de aletas guia de entrada (IGV) são explicados em detalhe. Características de operação de várias turbinas GE são relacionadas. O controle de emissões pela injeção de água e vapor é discutido. É explicado que a potência gerada pela turbina é função do calor liberado pela combustão na câmara de combustão, que, por sua vez, é função da vazão de combustível. Os limites de operação normal da turbina são dados pelas temperaturas de operação normal e de pico.

(FLACK, 3-6 Junho 2002) explica o casamento dos componentes das turbinas a gás: compressor, câmara de combustão e expansor. Equações e mapas de desempenho de cada componente são mostradas. Um algoritmo para seleção dos componentes é apresentado.

(XIAO et al., 2007) mostra o efeito das aletas guias de entrada nas curvas de desempenho de compressores. 
(YEE; HUGHES; MILANOVIC, 24-28 Junho 2007) compara o modelo de Rowen (ROWEN, 1983) com o modelo IEEE. O modelo de Rowen, baseado nas turbinas da GE, requer menor esforço computacional, mas requer as curvas características da turbina modelada, informação nem sempre disponível. O modelo IEE requer apenas dados de catálogo da turbina: vazão e temperatura de exaustão e potência porém requer mais esforço computacional. Além disso o modelo IEE simula o controle das emissões da turbina pela atuação das aletas guias de entrada (IGV).

(TAVAKOLI; VAHIDI, 2009) demonstra a aplicação do modelo de Rowen (ROWEN, 1983) para simulação dinâmica de uma turbina.

(LEE; KANG; KIM, 2011) desenvolve um modelo modular para avaliar o desempenho de turbinas a gás. O modelo é construído de blocos menores representando estágios do compressor e do expansor. O modelo também tem blocos para a câmara de combustão e regenerador. Estes blocos são combinados para simular diferentes modelos de turbinas. O modelo requer informações construtivas da turbina modelada. O estudo apresenta a simulação de turbinas de ciclo simples, regenerativo e com reaquecimento e compara as variações de desempenho em função da temperatura de entrada do ar simuladas com dados das turbinas. 


\section{ESTUDO DO SISTEMA EVAPORATIVO}

Neste capítulo estudamos a operação do resfriamento por sistema evaporativo do tipo EMR. Inicialmente apresentamos o modelo da turbina. Em seguida apresentamos o modelo do resfriamento evaporativo, levantamento dos dados meteorológicos das localidades brasileiras. Finalizamos com a apresentação dos resultados das simulações feitas para 27 localidades brasileiras e a discussão destes resultados.

\subsection{Modelo da turbina a gás}

Há diferentes configurações de turbinas a gás quanto ao número de eixos e ciclo termodinâmico. O parque gerador brasileiro tem em operação vários modelos de turbina operando em ciclo simples e combinado. A tabela 1 apresenta uma relação de dados das turbinas instaladas em termelétricas brasileiras de potência total maior que 50 MW (Agência Nacional de Energia Elétrica, 2008). Consideramos as características desta população de turbinas na escolha do modelo de turbina desenvolvido neste trabalho. Uma parcela maior do que $99 \%$ da energia gerada em termelétricas com turbinas a gás no Brasil é gerada por turbinas instaladas nestas termelétricas (Agência Nacional de Energia Elétrica, 2008). A tabela 1 apresenta ainda dados relativos aos sistemas de resfriamento de ar de entrada de turbinas desta população de turbinas.

Com base na tabela 1 temos as seguintes estatísticas da população de turbi- 


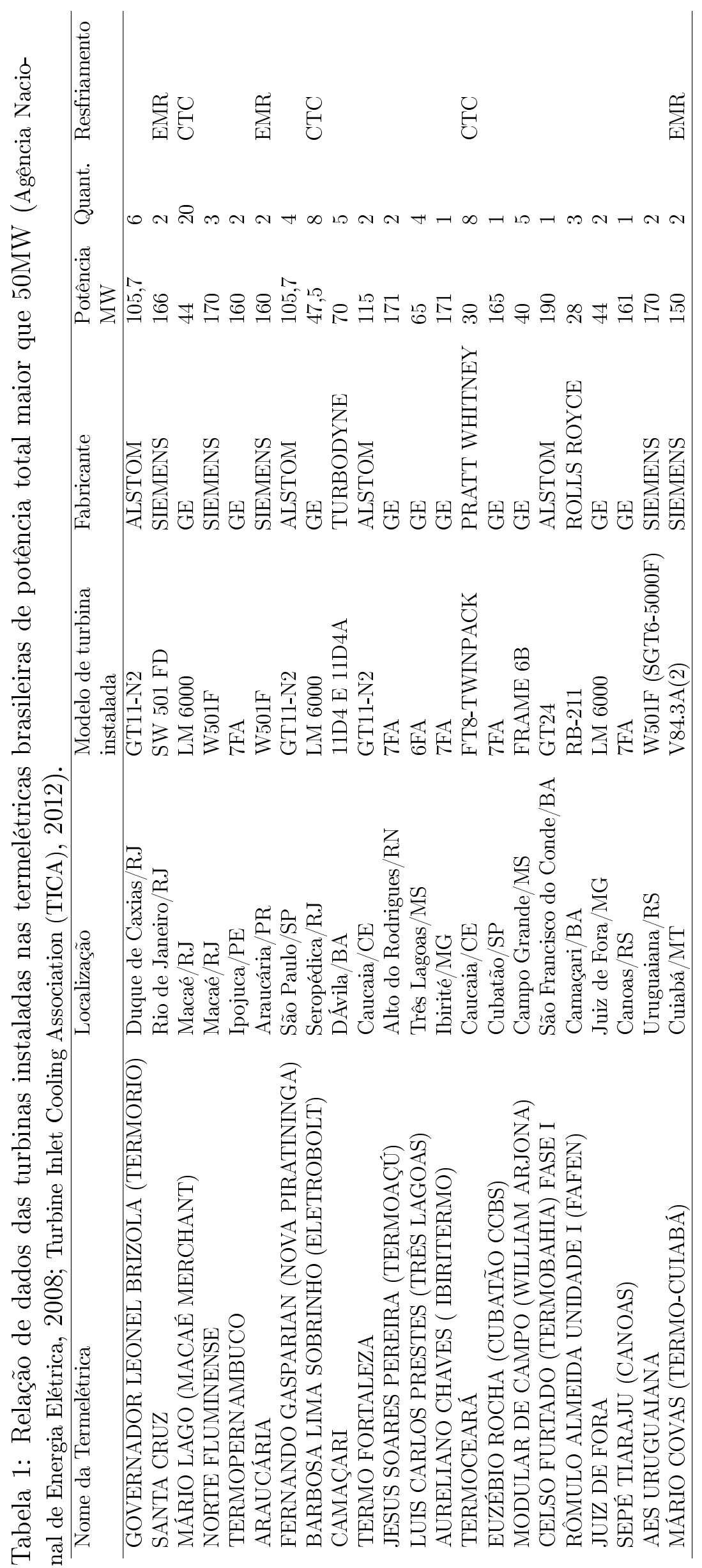




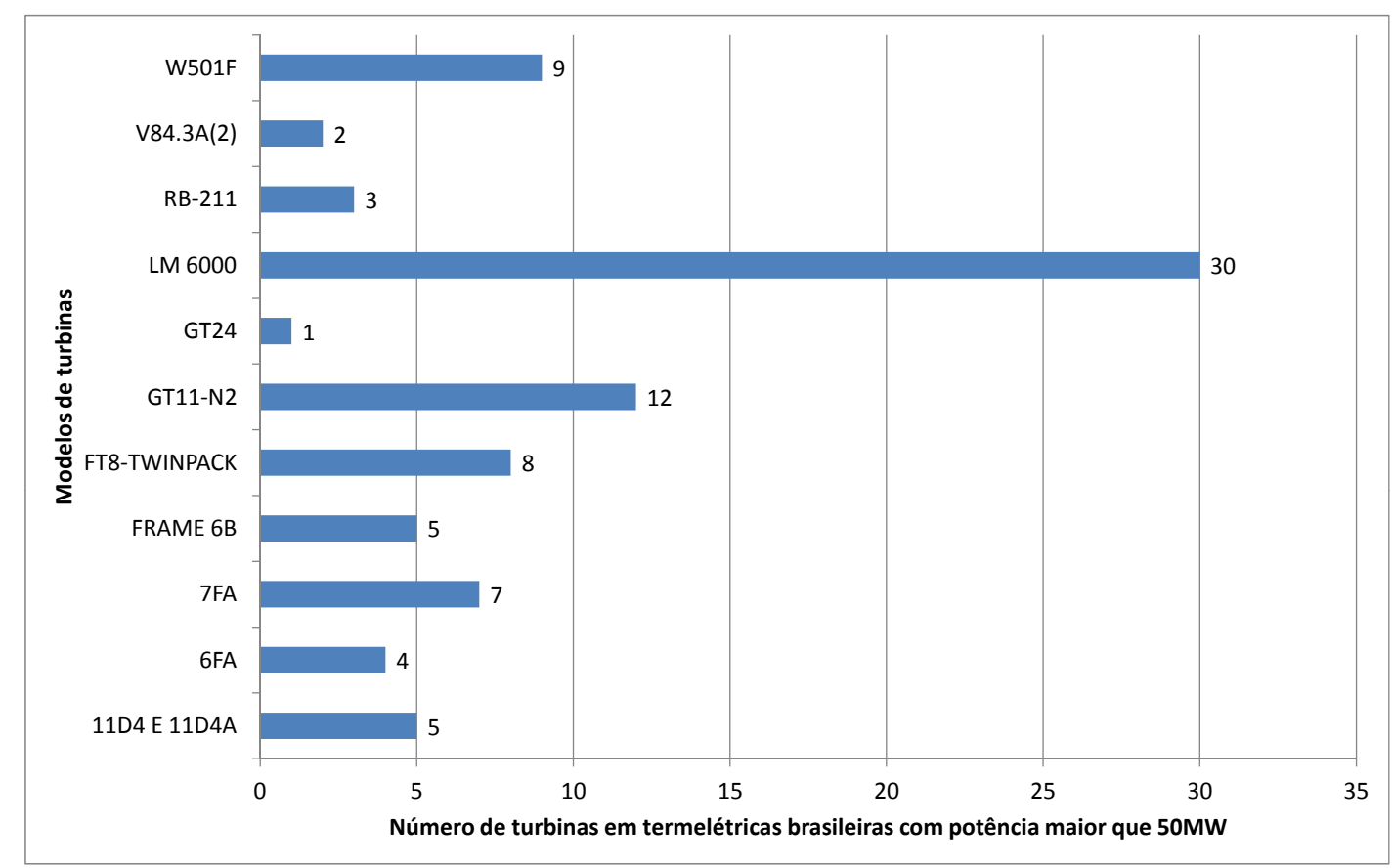

Figura 17: Quantidade de turbinas por modelo nas termelétricas brasileiras com potência maior que $50 \mathrm{MW}$.

nas instaladas nas termelétricas brasileiras de mais de $50 \mathrm{MW}$ : a quantidade de turbinas de cada modelo e a potência gerada por cada modelo. A figura 17 mostra a quantidade de cada tipo de turbina instalada nesta população. A turbina instalada em maior número é a LM 6000 da General Electric. Esta turbina é uma turbina aeroderivada de dois eixos. Um eixo comum ao compressor e à turbina de baixa pressão, que gira a $3600 \mathrm{rpm}$, aciona diretamente o gerador (BADEER, 2000). Os modelos de turbina que aparecem em seguida em ordem de frequência na população são a GT11 da Alstom e a W501F da Siemens. Estas turbinas são turbinas industriais de eixo único operam com ciclo térmico sem regeneração. Com este mesmo tipo de construção as turbinas 7FA da General Electric aparecem com a quinta maior frequência.

Quando consideramos a potência total instalada na população estudada das termelétricas brasileiras, as turbinas industriais de eixo único, sem regeneração e injeção de água ou vapor representam a maior parcela de potência instalada. 


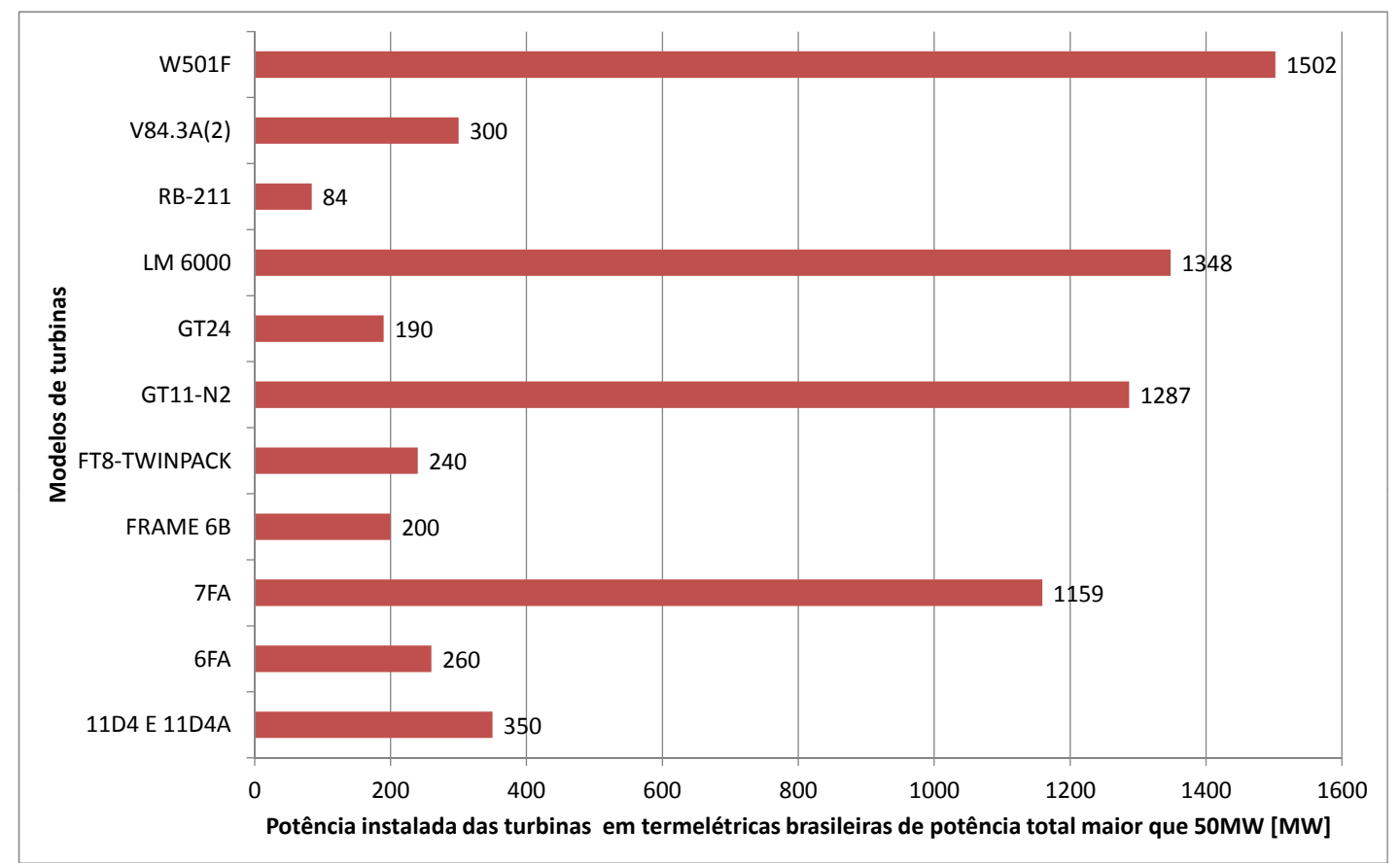

Figura 18: Potência instalada por modelo de turbina nas termelétricas brasileiras com potência maior que $50 \mathrm{MW}$.

Tabela 2: Condições de operação conforme (ISO, 1997)

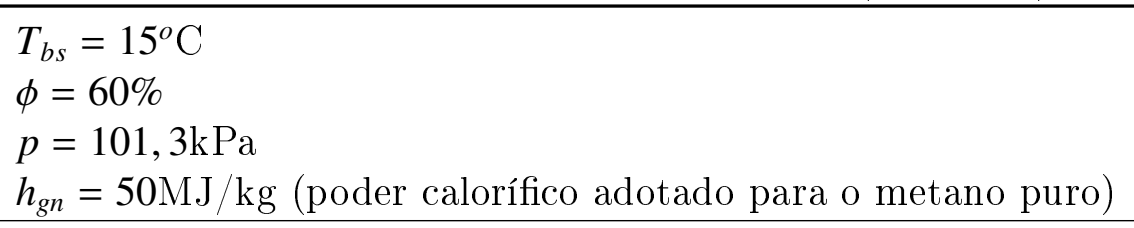

A figura 18, também baseada na tabela 1, mostra as potências instaladas dos diferentes modelos de turbinas. Podemos observar que as turbinas industriais W501F, GT11 e 7FA representam a maior parcela da potência instalada.

A potência de uma turbina a gás varia com as condições do ar de entrada. A principal influência na potência gerada pela turbina é a temperatura do ar de entrada na turbina. Outras propriedades também alteram a potência: pressão do ar e umidade. Os fabricantes de turbinas a gás listam a potência e eficiência de suas máquinas para operação nas condições ISO (ISO, 1997). Estas condições são listadas na tabela 2 .

Para levar em conta as condições atmosféricas do local de instalação, que em 
geral diferem das condições ISO, são fornecidas curvas da turbina que indicam a variação da potência, eficiência, vazão e temperatura do gás de exaustão do equipamento em função de temperatura, pressão e umidade do ambiente (DRBAL; WESTRA, 1996). As ordenadas destas curvas são os fatores de correção para as condições dadas, $f$. Os fatores $f$ são definidos por:

$$
f=\frac{\text { valor da resposta da turbina na condição de operação }}{\text { valor da resposta da turbina na condição ISO }}
$$

Neste trabalho, usamos os fatores apresentados na tabela 3.

Tabela 3: Fatores de correção para a condição de operação da turbina usados neste trabalho.

\begin{tabular}{llll}
\hline \hline Condição alterada & \multicolumn{3}{l}{ Variável da resposta da turbina afetada } \\
\hline$T$ & $W$ & $H R$ & mex \\
$\omega$ & $f_{W T}$ & $f_{H R T}$ & $f_{m e T}$ \\
$\delta p$ & $f_{W \omega}$ & $f_{H R \omega}$ & - \\
$Z$ & $f_{W \delta p}$ & $f_{H R \delta p}$ & - \\
\hline
\end{tabular}

A resposta das turbinas industriais de eixo único, sem regeneração ou injeção de água ou vapor à variação da temperatura do ar de entrada é similar conforme mostrado na figura 19 (BROOKS, 2000; SIEMENS, 2008). A turbina aeroderivada LM 6000 de dois eixos apresenta uma resposta mais pronunciada à temperatura do ar de entrada. No caso da LM 6000 é maior o ganho de potência pelo uso de um sistema de resfriamento de ar de entrada de turbina. Conforme observado na tabela 1, o resfriamento de ar de entrada é adotado em termelétricas com turbinas LM 6000.

Turbinas de um único eixo, sem regeneração e injeção de vapor ou água operando em ciclo aberto, por serem as de maior representatividade no parque gerador brasileiro em termos de potência, são usadas no estudo comparativo de sistemas de resfriamento no Brasil. A figura 20 mostra o diagrama da turbina 


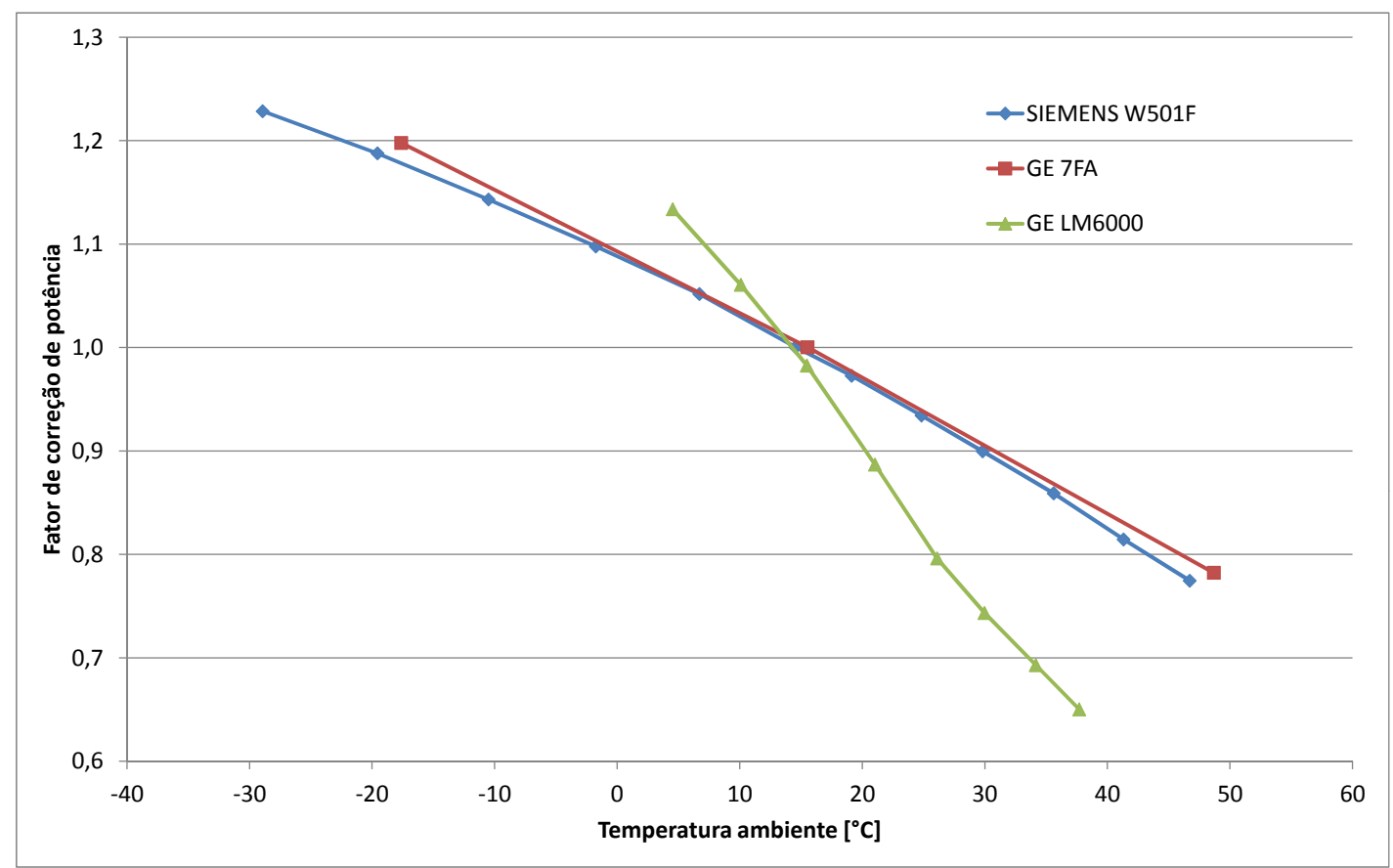

Figura 19: Fator de correção de potência para a temperatura do ar de entrada da turbina , $f_{W T}$, para os modelos de turbinas com maior participação nas termelétricas brasileiras. (Adaptado de (BROOKS, 2000; SIEMENS, 2008; BADEER, 2000).)

modelada. Ar do ambiente no estado 1 é aspirado pelo compressor, C, e comprimido até o estado 2 na entrada do câmara de combustão, CC. Gás natural de 5 é injetado na câmara de combustão misturando-se ao ar de 2 e sofrendo combustão. A mistura aquecida de ar e gases de combustão em 3 expande-se no expansor, E,até o estado 4. A potência gerada do expansor é suficiente para acionar o compressor e um gerador elétrico. A figura 21 mostra o Ciclo Brayton percorrido pelo ar neste tipo de turbina. A área definida pelas linhas conectando os pontos 1-2-3-4 representa o trabalho fornecido à turbina por unidade de massa de ar que flui através da turbina.

Desenvolvemos em seguida um modelo de regime permanente de turbina a gás que é capaz de aproximar as curvas dos fabricantes de turbinas e ao mesmo tempo fornecer um entendimento de como se dá a influência das condições ambientes na operação do equipamento. Este modelo é baseado nas leis fundamentais da 


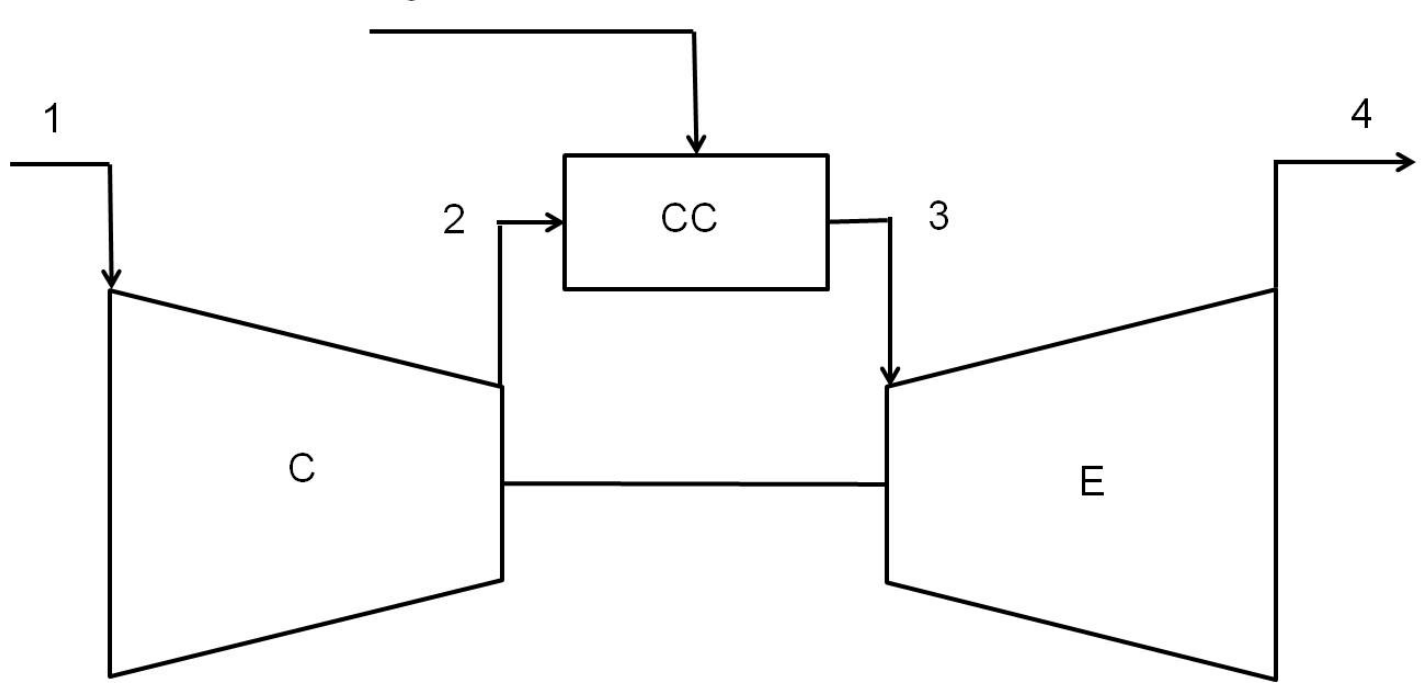

Figura 20: Diagrama de turbina a gás. Componentes: C - compressor; CC câmara de combustão; E - expansor. Pontos de processo: 1 - entrada da turbina (compressor); 2 - descarga do compressor (entrada da câmara de combustão; 3 entrada do expansor (descarga da câmara de combustão); 4 - descarga do expansor (descarga da turbina); 5 - entrada de gás natural na câmara de combustão.

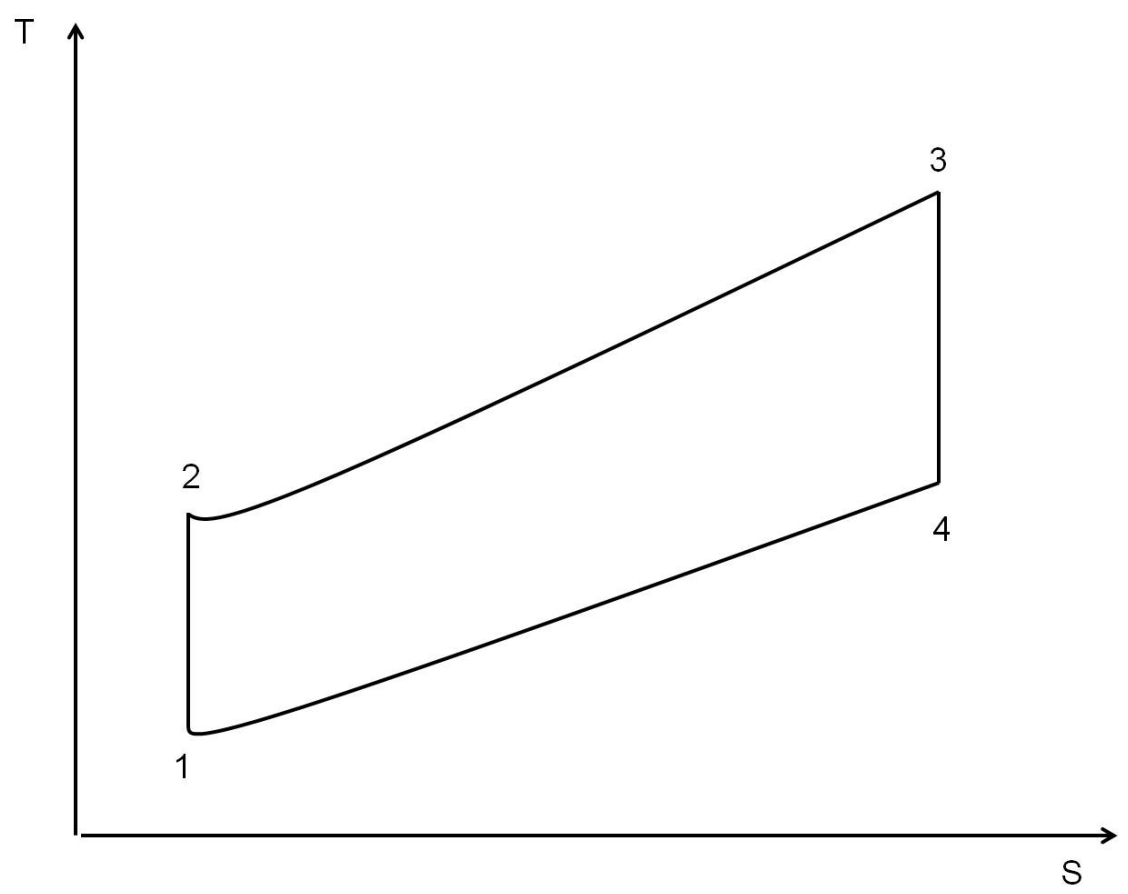

Figura 21: Diagrama do Ciclo Brayton percorrido pelo ar na turbina modelada. 
termodinâmica.

O primeiro processo que ocorre na turbina é a compressão do ar pelo compressor. Este processo é modelado como uma compressão politrópica (CSANADY, 1964). A equação que relaciona a energia transferida ao ar por unidade de massa, $e_{c}$, conhecida como energia politrópica, é:

$$
e_{c}=\frac{1}{\alpha_{c}} \frac{p_{1}}{\rho_{1}}\left[1-\left(\frac{p_{2}}{p_{1}}\right)^{\alpha_{c}}\right]
$$

Que também pode ser escrita como:

$$
e_{c}=\frac{1}{\alpha_{c}} R_{a} T_{1}\left[1-\left(\frac{p_{2}}{p_{1}}\right)^{\alpha_{c}}\right]
$$

Onde o coeficiente $\alpha_{c}$ é:

$$
\alpha_{c}=\frac{n_{c}-1}{n_{c}}
$$

O expoente politrópico do compressor, $n_{c}$, é definido como uma função da eficiência politrópica, $\eta_{c}$, deste componente da turbina:

$$
n_{c}=\frac{\eta_{c} k_{c}}{\eta_{c} k_{c}-k_{c}+1}
$$

O processo politrópico determina a relação entre as temperaturas e pressões do ar na entrada e saída do compressor, ou seja, as condições nas seções 1 e 2 do compressor (figura 20).

$$
\frac{T_{2}}{T_{1}}=\left(\frac{p_{2}}{p_{1}}\right)^{\alpha_{c}}
$$

O próximo componente da turbina a ser modelado é a câmara de combustão. 
Na câmara de combustão o gás natural é misturado ao ar e queimado. A energia fornecida à mistura ar-combustível, $\dot{Q}_{c c}$, é:

$$
\dot{Q}_{c c}=\eta_{c c} \dot{m}_{g n} h_{g n}
$$

Onde $\eta_{c c}$ é a eficiência da câmara de combustão.

Considerando que:

- O calor específico dos produtos de combustão é igual ao calor específico do ar na mesma temperatura $T_{3}$.

- O gás natural entra na câmara de combustão com temperatura igual a de entrada do ar, $T_{2}$, e é aquecido até a temperatura dos produtos de combustão.

A temperatura, $T_{3}$, na entrada do expansor é:

$$
T_{3}=T_{2}+\frac{\dot{Q}_{c c}}{\dot{m}_{1} c_{p c c}+\dot{m}_{g n} c_{p g n}}
$$

A pressão, $p_{3}$, na entrada do expansor,desprezando a perda de carga na câmara de combustão, é:

$$
p_{3}=p_{2}
$$

O processo no expansor é modelado por uma expansão politrópica (CSANADY, 1964). A energia extraída por unidade de massa do ar, $e_{e}$, chamada de energia politrópica do expansor, é:

$$
e_{e}=\frac{1}{\alpha_{e}} R_{a} T_{3}\left[1-\left(\frac{p_{4}}{p_{3}}\right)^{\alpha_{e}}\right]
$$


Onde:

$$
\alpha_{e}=\frac{n_{e}-1}{n_{e}}
$$

e

$$
n_{e}=\frac{k_{e}}{k_{e}-\eta_{e} k_{e}+\eta_{e}}
$$

$\eta_{e}$ é a eficiência politrópica do expansor (CSANADY, 1964).

A temperatura na descarga do expansor é:

$$
T_{4}=T_{3}\left(\frac{p_{4}}{p_{3}}\right)^{\alpha_{e}}
$$

As energias politrópicas do compressor e do expansor são relacionadas às vazões volumétricas nos componentes, nas condições de entrada de cada componente, $\dot{V}_{1}$ e $\dot{V}_{3}$, pelas curvas características do componente respectivo (CSANADY, 1964; LAPINA, 1982). Estas curvas são informações proprietárias e, normalmente, não são divulgadas pelos fabricantes.

As curvas do compressor e do expansor devem ser relacionadas no sentido de que as razões de compressão e vazões em massa em cada componente devem ser aproximadamente as mesmas. A figura 22 mostra curvas típicas de ambos os componentes, ressaltando a sua relação.

A potência gerada no expansor é:

$$
\dot{W}_{e}=\left(\dot{m}_{1}+\dot{m}_{g n}\right) e_{e}
$$




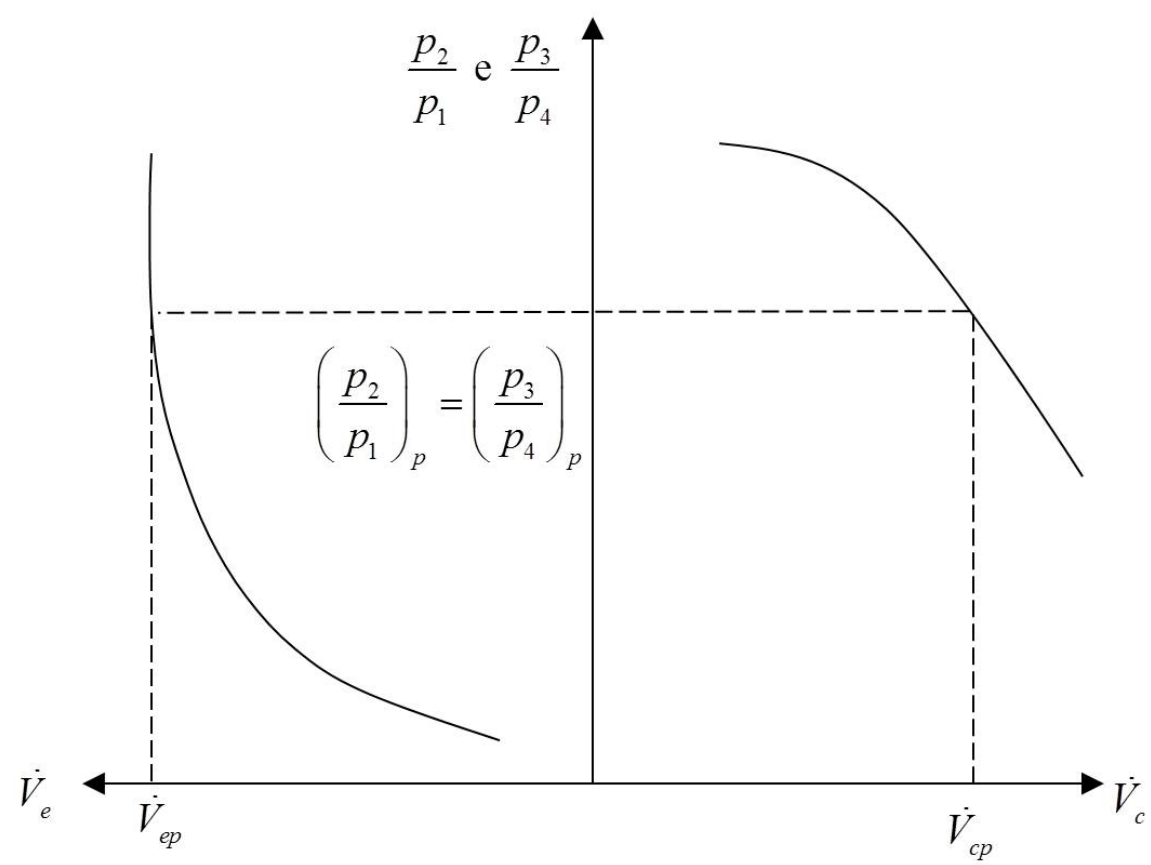

Figura 22: Combinação das curvas características do compressor e expansor de uma turbina a gás (CSANADY, 1964).

Igualmente a potência gerada no compressor é:

$$
\dot{W}_{c}=\dot{m}_{1} e_{c}
$$

As curvas características do compressor e do expansor são obtidas durante o desenvolvimento da turbina pelo fabricante. A sua aplicação na predição de variações na energia politrópica para variações da vazão volumétrica em torno do ponto de operação de projeto é questionável devido às incertezas na medição das variáveis de processo em plantas industriais. Este fato e a indisponibilidade pública das curvas, nos leva a adotar o mesmo procedimento de (LAPINA, 1982) ao modelar a operação tanto do compressor, quanto do expansor da turbina: as variações de pressão, temperatura e umidade do ar não afetam a vazão volumétrica, $\dot{V}_{c}$, no compressor e no expansor que por sua vez não alteram a energia politrópica e a eficiência politrópica dos componentes da turbina isoladamente. 
Observando que $e_{c}$ é negativa, a potência gerada pela turbina é:

$$
\begin{aligned}
\dot{W}_{t g} & =\dot{W}_{e}+\dot{W}_{c} \\
& =\dot{m}_{1}\left[\left(1+\frac{\dot{m}_{g n}}{\dot{m}_{1}}\right) e_{e}+e_{c}\right]
\end{aligned}
$$

Substituindo as equações $3.3,3.10$ na equação 3.16 temos:

$$
\dot{W}_{t g}=\dot{m}_{1}\left(1+\frac{\dot{m}_{g n}}{\dot{m}_{1}}\right)\left\{\frac{1}{\alpha_{e}} R_{a} T_{3}\left[1-\left(\frac{p_{4}}{p_{3}}\right)^{\alpha_{e}}\right]+\frac{1}{\alpha_{c}} R_{a} T_{1}\left[1-\left(\frac{p_{2}}{p_{1}}\right)^{\alpha_{c}}\right]\right\}
$$

A vazão em massa do ar de entrada, $\dot{m}_{1}$, explicitada em termos de densidade e vazão em volume é:

$$
\dot{m}_{1}=\rho_{1} \dot{V}_{1}
$$

A eficiência da turbina, que envolve as equações 3.7 e 3.17 , é calculada por:

$$
\eta_{t g}=\frac{\dot{W}_{t g}}{\dot{Q}_{c c}}
$$

A eficiência da turbina também pode ser expressa em termos de heat rate em MJ/MWh por:

$$
\mathrm{HR}=\frac{3600}{\eta_{t g}}
$$

Os valores dos parâmetros e variáveis das equações 3.17, 3.18, 3.19 e 3.20 são avaliados pelas seguintes considerações:

- As pressões de entrada, $p_{1}$, e de descarga da turbina, $p_{4}$, são determinadas pelas condições ambientes e perdas de carga na entrada e saída da turbina. 
- A pressão na descarga do compressor, $p_{2}$, é determinada a partir de $p_{1}$ pela taxa de compressão do compressor que é um dado listado pelos fabricantes de turbinas.

- A perda de carga na câmara de combustão é desprezível e a pressão na entrada do expansor, $p_{3}$, é igual a $p_{2}$.

- Os expoentes politrópicos, $\alpha_{e}$ e $\alpha_{c}$, são funções das eficiências politrópicas do compressor e do expansor da turbina e das propriedades do ar nestes componentes. As eficiências estão dentro de uma faixa de valores dada pela literatura $\left(\eta_{c}=0,85, \eta_{c c}=0,97, \eta_{e}=0,87\right)$ (KOSTYUK; FROLOV, 1988) e podem ser ajustadas para reduzir o erro de resposta do model. As propriedades do ar são consideradas constantes no compressor, expansor e câmara de combustão.

- A temperatura de entrada do ar, $T_{1}$, é dada pela condição ambiente e sistema de resfriamento de ar da turbina usado.

- A densidade de entrada do ar, $\rho_{1}$, também é dada pelas condições ambientes e sistema de resfriamento através de $T_{1}$ e $p_{1}$.

- A vazão volumétrica do ar, $\dot{V}_{1}$, é considerada constante igual à vazão na condição ISO, seguindo (LAPINA, 1982).

- A vazão de gás para a turbina, $\dot{m}_{g n}$, e a temperatura de entrada no expansor, $T_{3}$, são relacionados pelas equações 3.7 e $3.8 . T_{3}$ e $\dot{m}_{g n}$ são parâmetros de controle da turbina e a escolha de seus valores é discutida adiante.

A densidade do ar é determinada pelas relações psicrométricas que seguem (WYLEN; SONNTAG; BORGNAKKE, 1995). 
A pressão parcial do vapor, $p_{v}$, no ar em função da umidade relativa, $\phi$, é:

$$
p_{v}=p_{\text {sat }} \frac{\phi}{100}
$$

A umidade relativa do ar, $\phi$, é parte dos dados climáticos medidos disponíveis no local de instalação da turbina. Estes dados também incluem a pressão atmosférica, $p_{a t}$, temperatura de bulbo seco, $T_{b s}$ e temperatura de bulbo úmido, $T_{b u}$.

A pressão de saturação da água, $p_{v}$, na temperatura de bulbo seco do ar, $T_{b s}$, é obtida pela equação de Arden Buck (BUCK, 1981):

$$
p_{s a t}=0,61121 \exp \left[\left(18,678-\frac{T_{b s}}{234,5}\right)\left(\frac{T_{b s}}{257,14+T_{b s}}\right)\right]
$$

Na equação $3.22 T_{b s}$ é dada em ${ }^{\circ} \mathrm{C}$ e $p_{\text {sat }}$ em $\mathrm{kPa}$.

A umidade absoluta é dada por:

$$
\omega=0,622 \frac{p_{v}}{p_{a t}-p_{v}}
$$

A densidade do ar é dada por:

$$
\rho=(1+\omega) \frac{p_{a t}-p_{v}}{R_{a} T_{b s}}
$$

A equação 3.24, quando substituída na equação 3.18, explicita a influência das condições do ar de entrada (presssão, umidade e temperatura) na potência gerda pela turbina , $W_{t g}$ (equações 3.17 e 3.18 ).

Sob a perspectiva de controle, as condições do ar de entrada da turbina são perturbações, a variável manipulada é a vazão de combustível, $\dot{m}_{g n}$, e a principal 
Tabela 4: Parâmetros de operação da turbina GE 7FA na condição ISO (BROOKS, 2000)

\begin{tabular}{ll}
\hline Parâmetro & Valor \\
\hline Potência $(\mathrm{MW})$ & 171,7 \\
Heat rate $(\mathrm{kJ} / \mathrm{kWh})$ & 9936 \\
Razão de compressão & 15,5 \\
Vazão de exaustão $(\mathrm{kg} / \mathrm{s})$ & 432 \\
Temperatura de exaustão $\left({ }^{\circ} \mathrm{C}\right)$ & 602 \\
\hline
\end{tabular}

variável controlada é a potência da turbina, $\dot{W}_{t g}$. A temperatura de entrada dos produtos de combustão no expansor, $T_{3}$, é também função da vazão de combustível. Dada uma condição do ar de entrada, a potência é determinada pela vazão de combustível. A potência aumenta com o aumento da vazão de combustível. A temperatura na entrada do expansor, $T_{3}$, também aumenta. Quanto maior a temperatura mais curta a vida útil dos componentes do expansor, resultando em menores intervalos entre manutenções e maior custo de operação. A potência de operação é limitada por um compromisso com os intervalos de manutenção do expansor (ROWEN, 1983; ROWEN, 1988). Turbinas industriais operam com temperaturas entre 900 e $1500^{\circ} \mathrm{C}$ na entrada do expansor.A figura 23 mostra a curva de resposta da temperatura $T_{3}$ de uma turbina de eixo único sem regeneração à vazão do combustível e os limites de operação contínua e operação de pico. Para simular o controle da turbina em potência máxima fixamos uma temperatura na faixa de operação (figura 23) e calculamos a vazão de combustível. Este procedimento fornece a potência gerada pela turbina, a energia consumida na forma de gás natural e a sua eficiência quando mudam as condições do ar de entrada, determinando as equações 3.17 e 3.18 .

Para validar o modelo desenvolvido de turbinas a gás, usamos parâmetros de uma turbina GE, modelo 7FA, mostrados na tabela 4, na simulação das curvas de resposta a variações de temperatura, umidade e pressão do ar de entrada. Baseado nos dados para operação ISO da turbina da tabela 4 e nas eficiências 


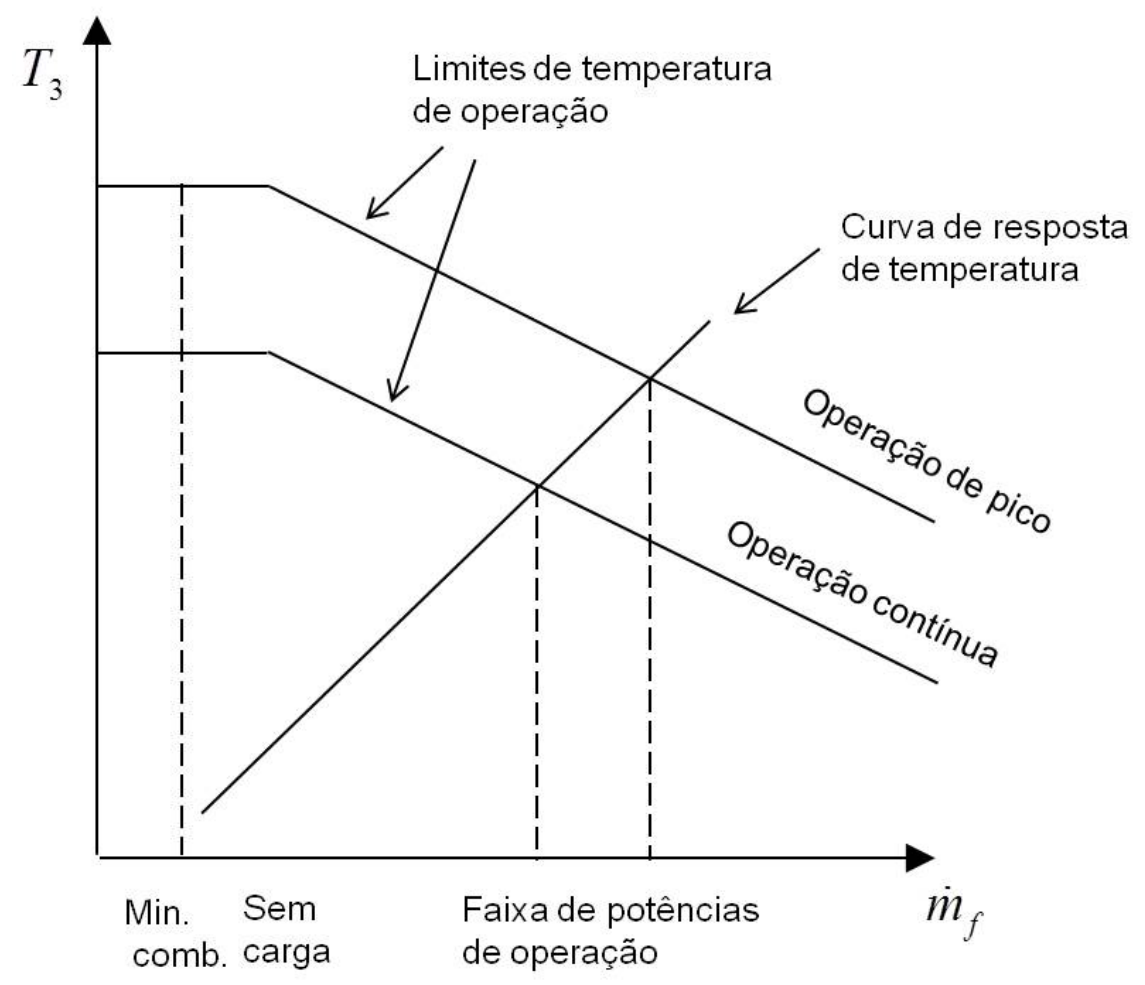

Figura 23: Curvas de controle de uma turbina a gás. (ROWEN, 1983; ROWEN, 1988)

típicas sugeridas para turbinas a gás por (KOSTYUK; FROLOV, 1988) $\left(\eta_{c}=0,85\right.$, $\left.\eta_{c c}=0,97, \eta_{e}=0,87\right)$ calculamos os dados complementares necessários para a simulação. A tabela 5 lista estes dados e as propriedades do ar de entrada. Os calores específicos do ar e do vapor obtidos de tabelas termodinâmicas (WYLEN; SONNTAG; BORGNAKKE, 1995) apresentados na tabela 5 são os empregados na simulação dos componentes da turbina (BROOKS, 2000). Comparamos os resultados destas simulações com as curvas fornecidas pelo fabricante da turbina (BROOKS, 2000).

As figuras 24, 25, 26, 27, mostram os resultados da simulação do modelo para a GE 7FA juntamente com as curvas fornecidas pelo fabircante (BROOKS, 2000). Na faixa de condições climáticas que ocorrem normalmente no Brasil, o modelo simula de maneira consistente a resposta da turbina. 


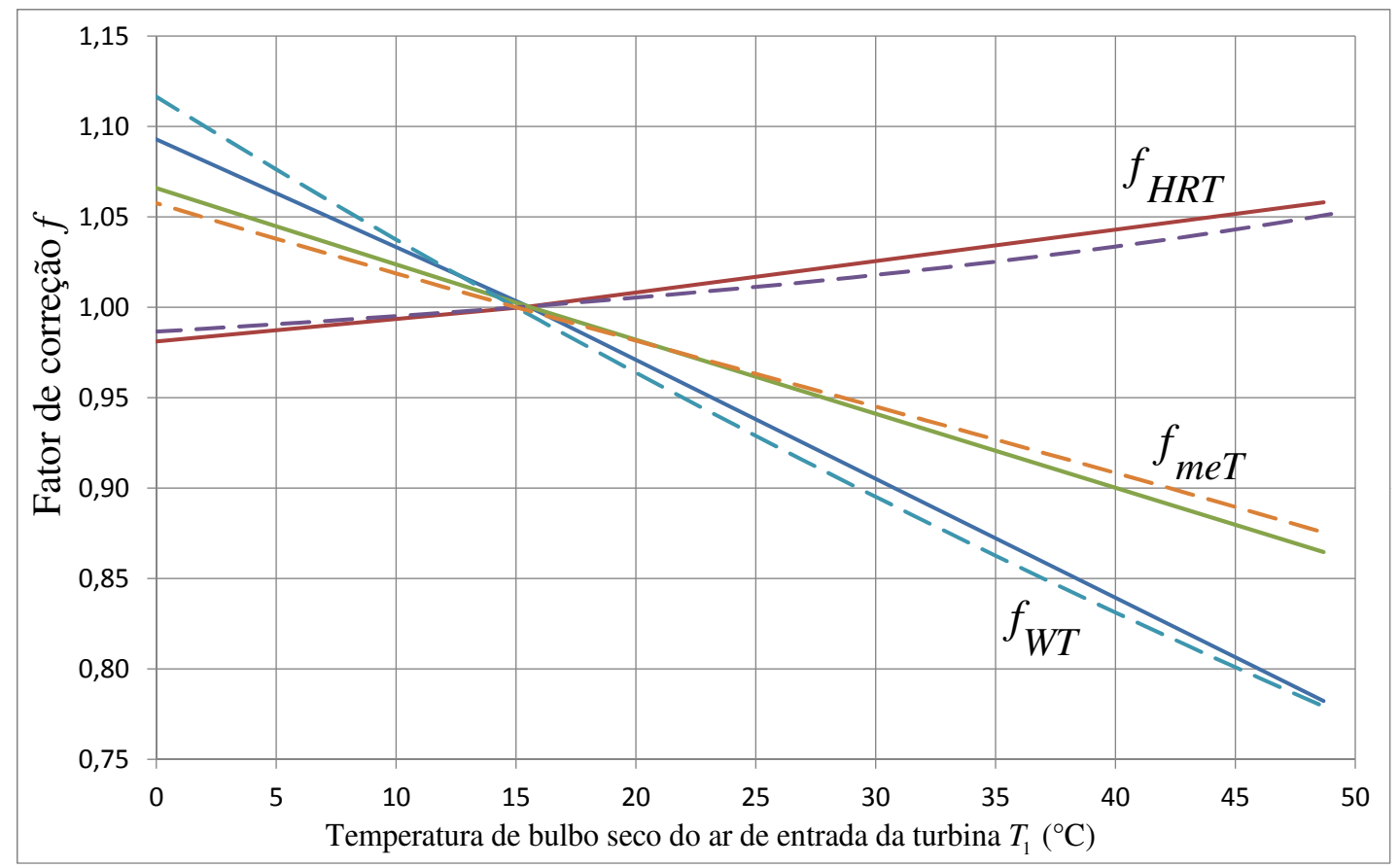

Figura 24: Resposta da turbina a temperatura de bulbo seco do ar de entrada $T_{1}\left({ }^{\circ} \mathrm{C}\right): f_{W T}$ fator de potência; $f_{H R T}$ fator e heat rate; $f_{m e T}$ fator de vazão de exaustão da turbina(linhas contínuas representam dados do fabricante; linhas pontilhadas indicam resultados do modelo).

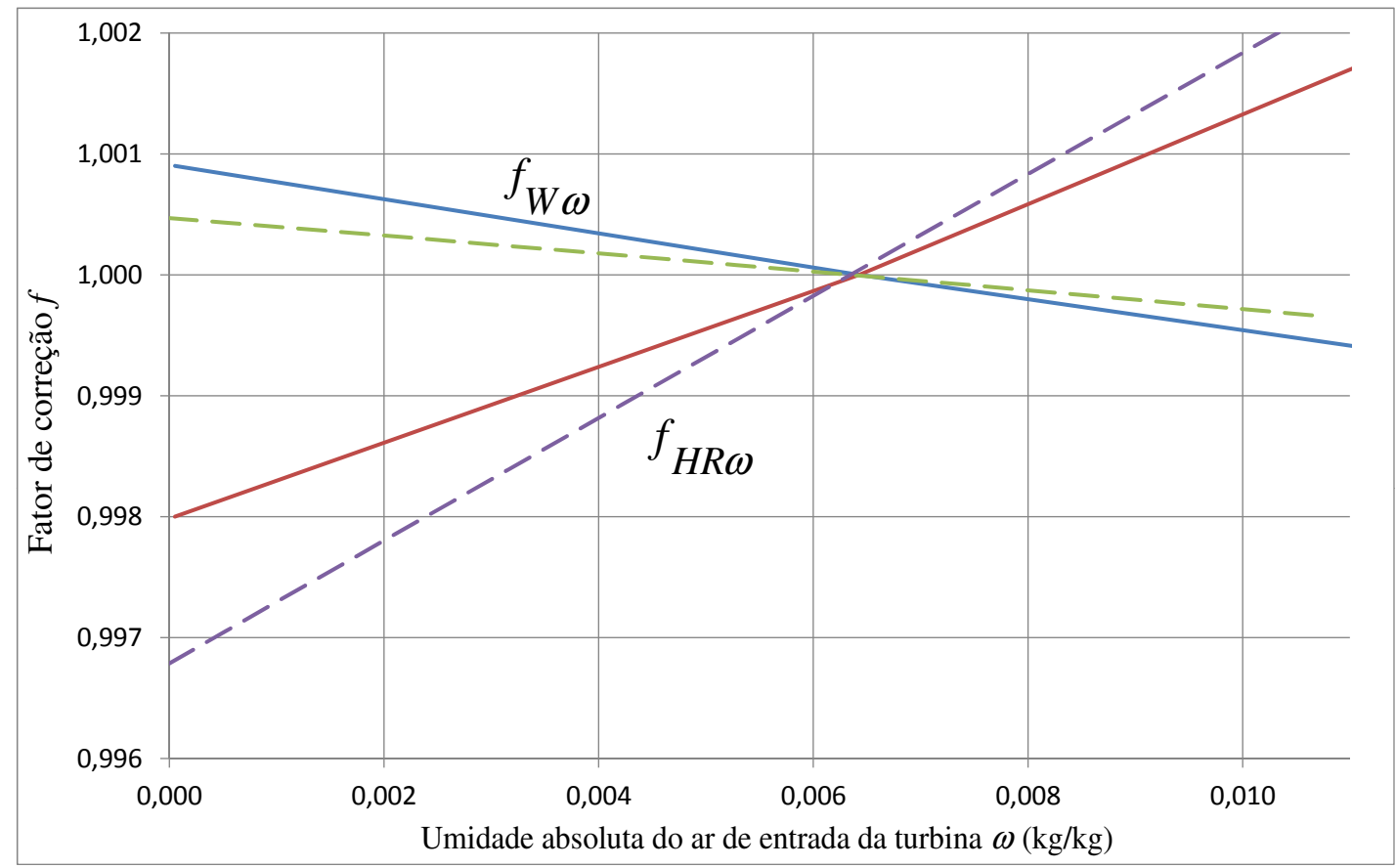

Figura 25: Resposta da turbina a umidade absoluta do ar de entrada $\omega_{1}(\mathrm{~kg} / \mathrm{kg})$ : $f_{W \omega}$ fator de potência; $f_{H R \omega}$ fator e heat rate (linhas contínuas representam dado dos fabricantes; linhas pontilhadas indicam resultados do modelo). 


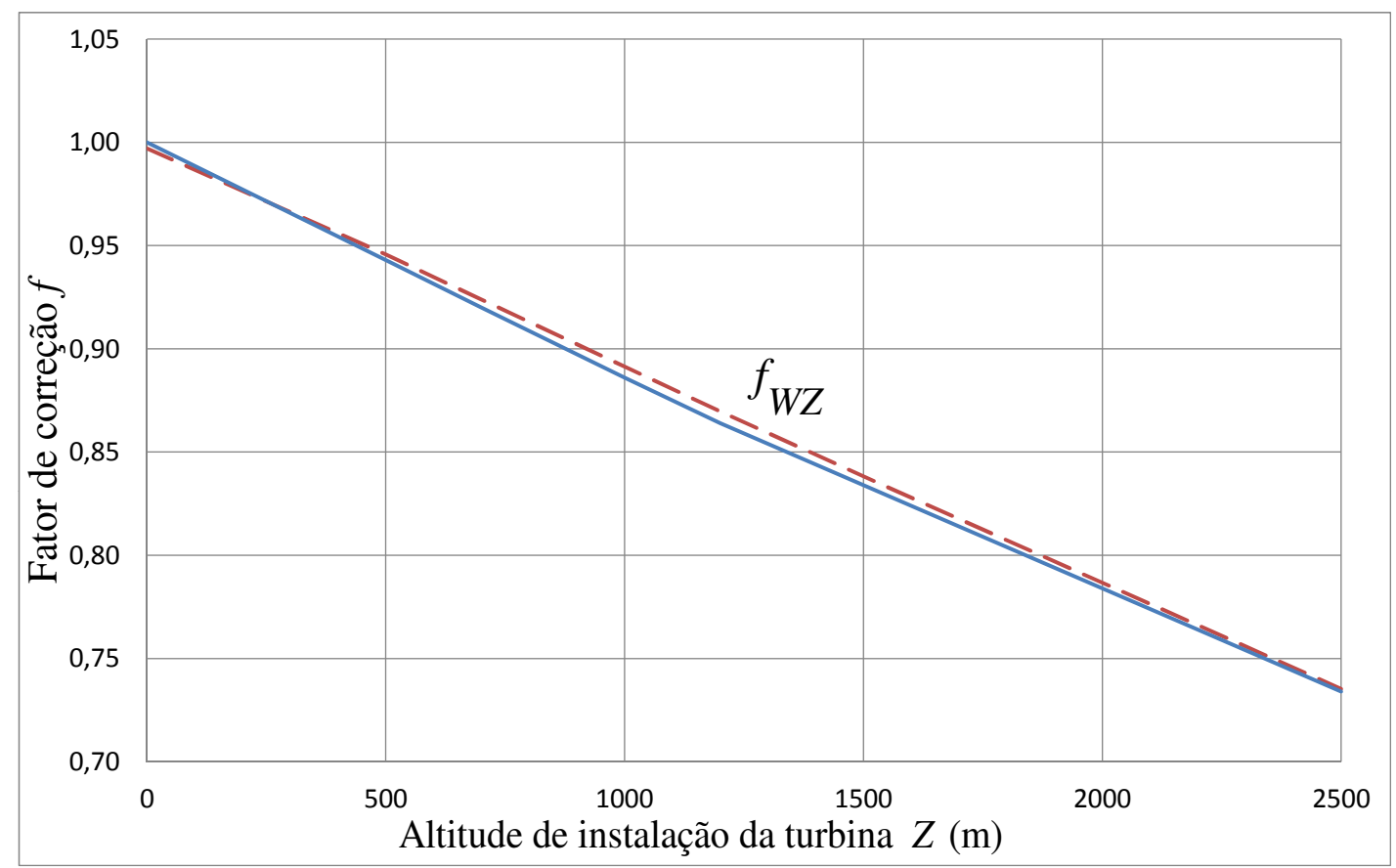

Figura 26: Resposta da turbina a altitude de operação $Z(\mathrm{~m}): f_{W Z}$ fator de potência (linha contínua representa dados dos fabricantes; linha pontilhada indica resultado do modelo).

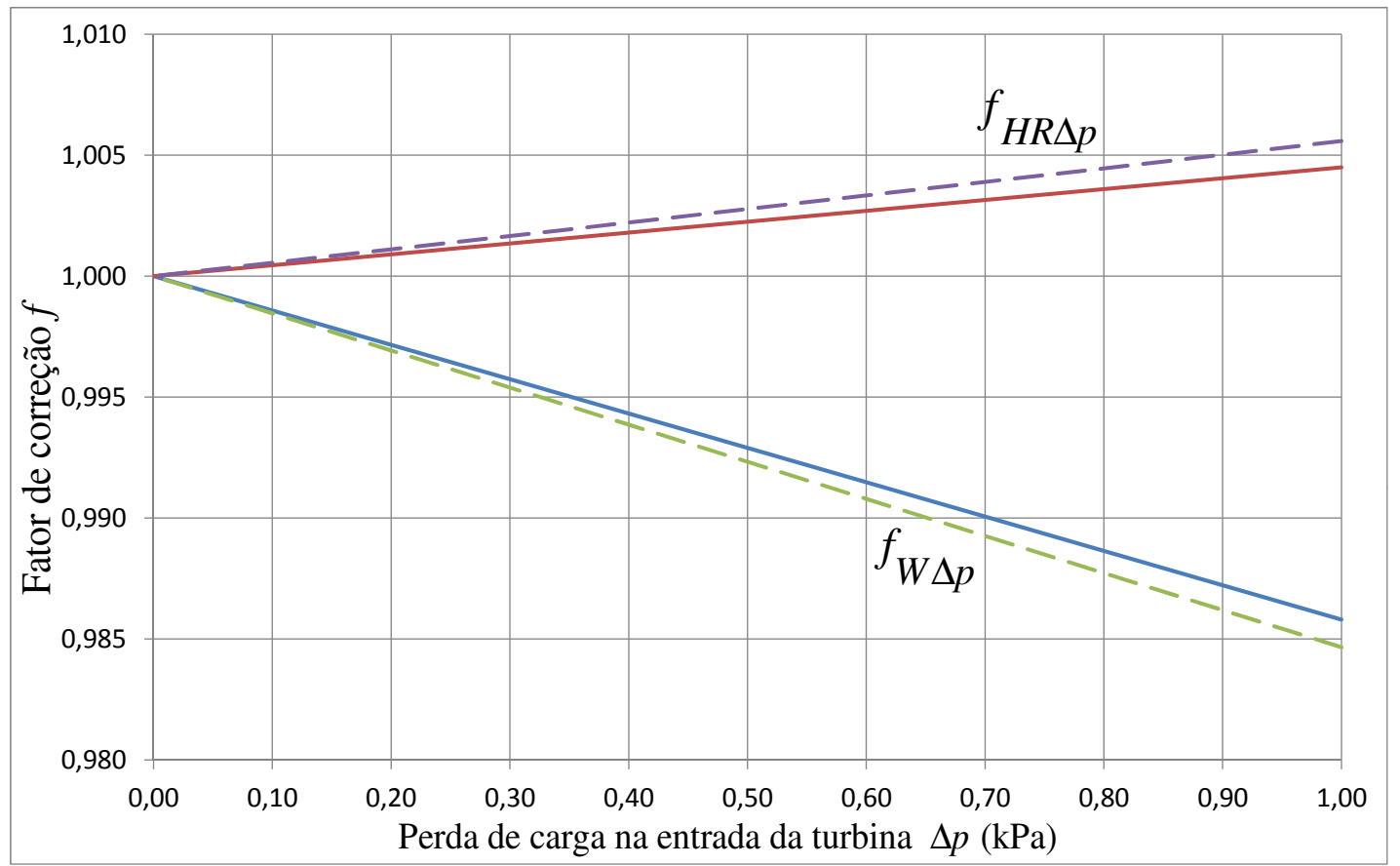

Figura 27: Resposta da turbina a perda de carga na entrada $\Delta p(\mathrm{kPa}): f_{W \Delta p}$ fator de potência; $f_{H R \Delta p}$ fator e heat rate (linhas contínuas representam dado dos fabricantes; linhas pontilhadas indicam resultados do modelo). 
Tabela 5: Parâmetros complementares da turbina MS0017FA e propriedades do ar e vapor

\begin{tabular}{lllll}
\hline Seção da turbina $^{1}$ & $\begin{array}{l}\mathrm{Ar} \\
c_{p a} \\
(\mathrm{~kJ} / \mathrm{kg} \mathrm{K})\end{array}$ & $\begin{array}{l}c_{p v} \\
(\mathrm{~kJ} / \mathrm{kg} \mathrm{K})\end{array}$ & $\left.\mathrm{T}^{2} \mathrm{C}\right)$ & $\mathrm{p}^{2}$ \\
& 1,029 & 2,10 & 15 & 101,3 \\
\hline 1- Entrada do compressor & 1,175 & 2,00 & 438 & 1570 \\
2- Entrada da câmara de comustão & 1,188 & 2,45 & 1423 & 1570 \\
3- Entrada do expansor & 1,45 \\
\hline
\end{tabular}

${ }^{1}$ Ver figura 20.

${ }^{2}$ As temperaturas e pressões são derivadas de dados na tabela 4. 


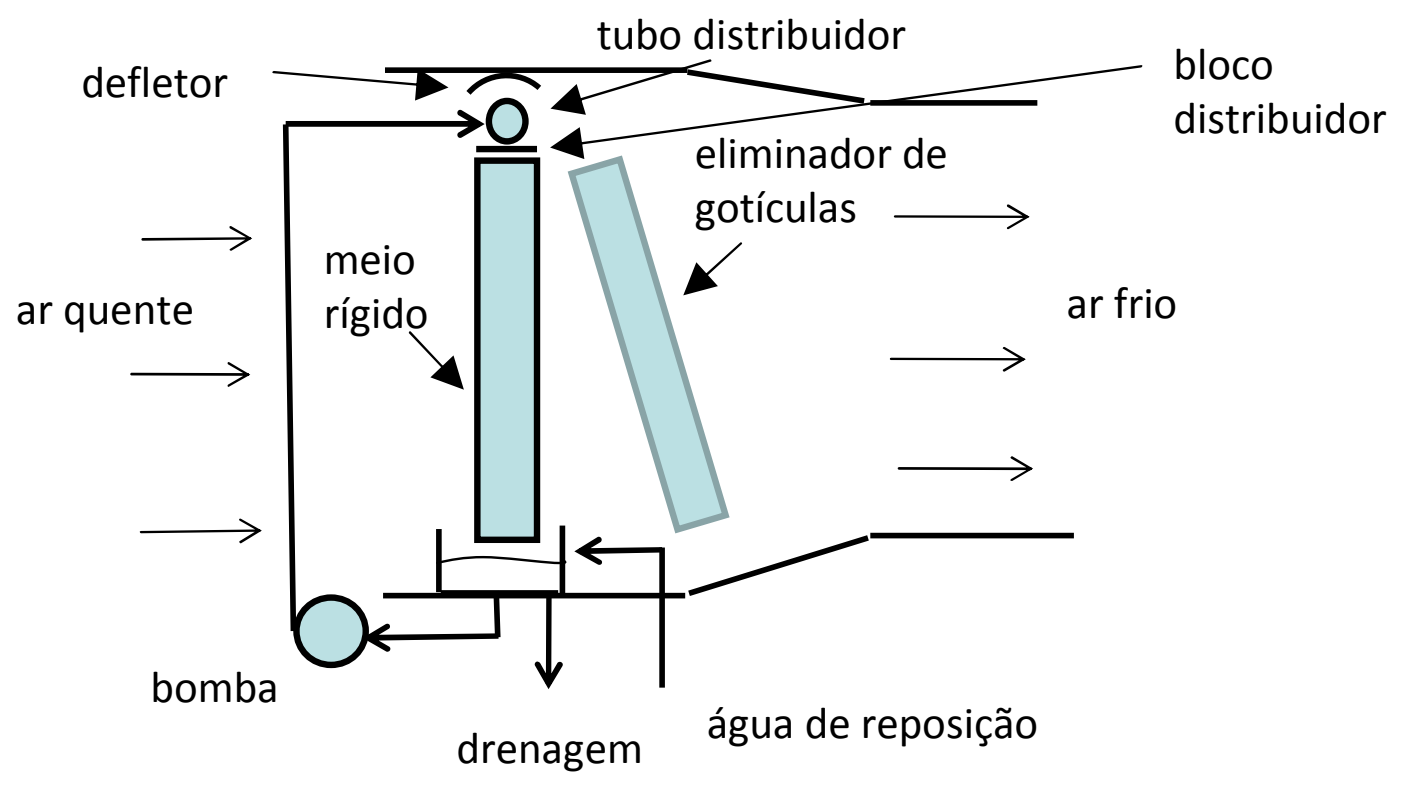

Figura 28: Diagrama do sistema de resfriamento com meio evaporativo rígido (EMR).

\subsection{Modelo do sistema de resfriamento evaporativo}

A redução da temperatura de entrada de ar no compressor aumenta a eficiência da turbina, conforme mostrado na figura 24. O sistema de resfriamento de ar de entrada que requer menor investimento inicial é o resfriamento com meio evaporativo rígido (EMR) (CHACARTEGUI et al., 2008).

A figura 28 mostra o diagrama de um sistema EMR ((JOHNSON, 1989)). O sistema é instalado na entrada de ar da turbina, após os filtros. Todo o ar filtrado passa através do meio rígido molhado. O meio rígido consiste de um bloco poroso. Água do tubo distribuidor no topo do meio rígido é dirigida para o meio por um defletor.A água defletida cai sobre um bloco distribuidor que uniformiza o fluxo de água para o meio molhado. A água flui então para baixo no meio molhado por gravidade.O ar que passa pelo meio molhado sofre um processo de saturação adiabática: água no meio molhado evapora, saturando o ar e retirando calor deste. O resultado é o abaixamento da temperatura de bulbo sêco do ar e a sua saturação pelo vapor de água. Um eliminador de gotículas 
evita que estas sejam transportadas até as palhetas dos primeiros estágios do compressor, danificando-as. O excesso de água no meio molhado e as gotículas capturadas no eliminidor, são coletadas em um tanque embaixo do resfriador. A água deste tanque é recirculada por uma bomba até o tubo de distribuição no topo do meio. A concentração de minerais na água é mantida dentro de limites que não danifiquem o meio molhado e a turbina pela drenagem. A água do sistema de resfriamento é perdida por evaporação e drenagem. O volume de água no sistema é mantido pela água de reposição injetada no tanque de acúmulo (JOHNSON, 1989).

No processo ideal de saturação abiabática o ar sai do resfriamento saturado com temperatura igual a temperatura de bulbo úmido do ar de entrada. No EMR a saturação não é completa e ar deixa o resfriador com temperatura de bulbo sêco, $T_{b s 1}$, levemente acima da temperatura de bulbo úmido do ar atmosférico, $T_{b u 0}$. Na prática, este efeito é modelado pelo uso do fator de eficiência do resfriamento, $\eta_{e v}$, no cálculo da temperatura de saída do resfriador (JOHNSON, 1989).

$$
T_{b s 1}=T_{b s 0}-\eta_{e v}\left(T_{b s 0}-T_{b u 0}\right)
$$

A figura 29 mostra o processo de resfriamento do ar na carta psicrométrica. Ar ambiente com umidade relativa menor que $100 \%$ entra no meio molhado na condição indicada pelo ponto 0 . O processo ocorre ao longo da linha de entalpia constante 0-1. Se o ar deixasse o meio molhado na condição saturada, a sua condição seria indicada pelo ponto s. No processo real, ele deixa o meio numa condição próxima à saturação indicada pelo ponto 1 .

Dadas as condições ambientes em 0: pressão atmosférica $\left(p_{a t}\right)$, temperatura de bulbo seco $\left(T_{b s 0}\right)$ e umidade realtiva $\left(\phi_{0}\right)$ e a temperatura de bulbo seco do ar que deixa o meio molhado em $1\left(T_{b s 1}\right)$, a umidade absoluta do ar que deixa o 


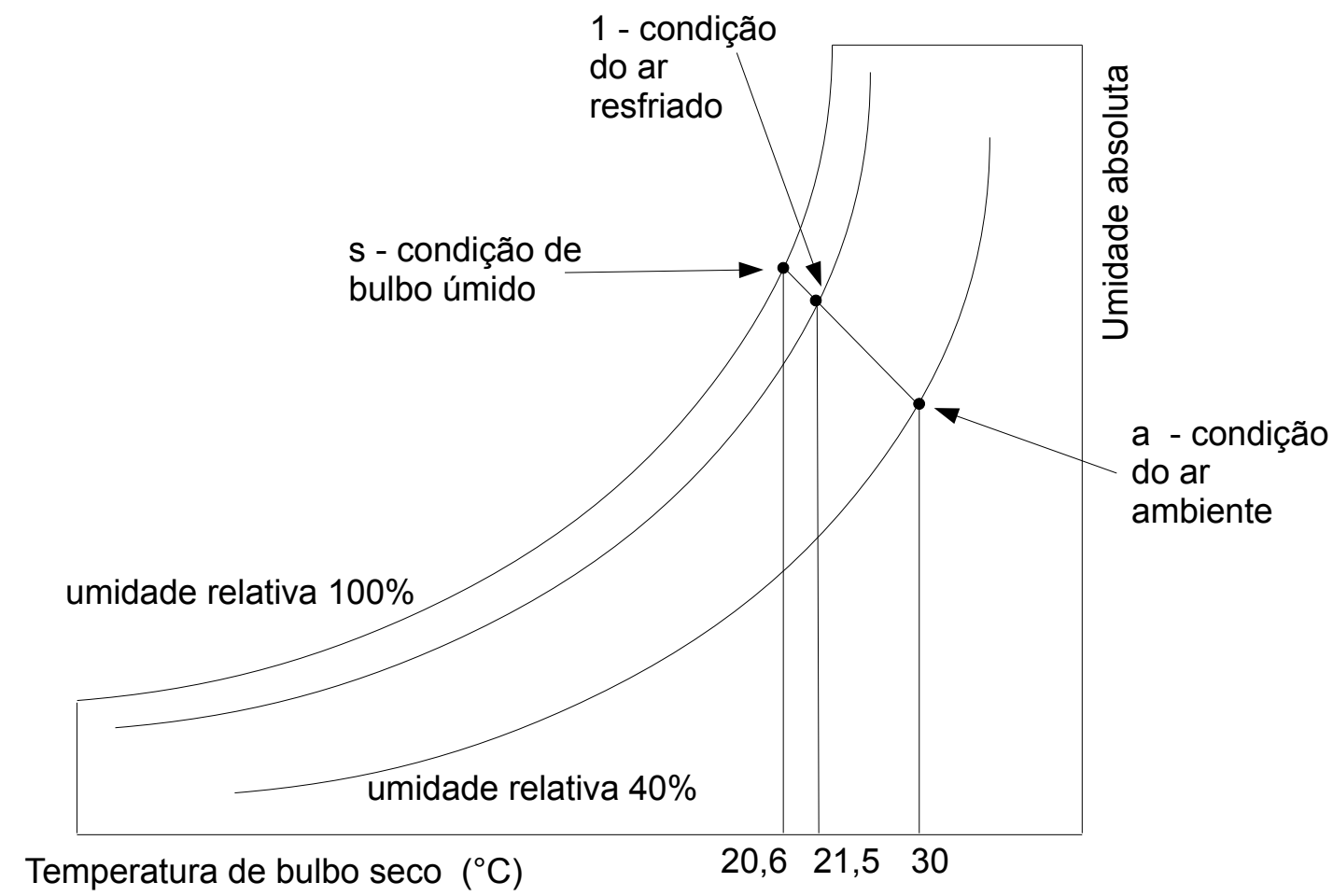

Figura 29: Diagrama psicrométrico do resfriamento no EMR.

meio molhado $\left(\omega_{1}\right)$ é obtida por:

$$
\omega_{1}=\frac{c_{p a r}\left(T_{b u 0}-T_{b s 1}\right)+\omega_{s} h_{l v s}}{h_{v 1}-h_{l s}}
$$

Como a entalpia de evaporação da água, $h_{l v s}$, pouco varia nas condições atmosféricas encontradas no Brasil, adotamos $h_{l v}=2430 \mathrm{~kJ} / \mathrm{kg}$ (WYLEN; SONNTAG; BORGNAKKE, 1995).

O balanço de massa da água no EMR começa pela massa de água evaporada no resfriador, $\dot{m}_{\text {agev }}$ :

$$
\dot{m}_{\text {agevap }}=\dot{m}_{a s 0}\left(\omega_{1}-\omega_{0}\right)
$$


Onde,

$$
\dot{m}_{a s 0}=\frac{\dot{m}_{a u 0}}{1+\omega_{0}}
$$

A vazão de drenagem da água no reservatório do EMR, $\dot{m}_{a g d}$, é calculada em função da dureza de projeto da água de resfriamento, $c_{d p}$, da dureza da água de alimentação, $c_{\text {dalim }}$ e da vazão de água evaporada, $\dot{m}_{\text {agevap }}$, (JOHNSON, 1989).

$$
\dot{m}_{\text {agd }}=\frac{1}{\frac{c_{d p}}{c_{d a l i m}}-1} \dot{m}_{\text {agevap }}
$$

A referência (JOHNSON, 1989) apresenta dados da prática industrial para a vazão de drenagem que são consistentes com uma dureza da água de resfriamento de projeto no reservatório, $c_{d p}$, de $187,5 \mathrm{ppm}$ de $\mathrm{CaCO}_{3}$. A dureza da água de alimentação, $c_{\text {dalim }}$, adotada é de 100 ppm de $\mathrm{CaCO}_{3}$, valor que está dentro da faixa da faixa recomendada para torres de resfriamento. A vazão de água de alimentação deve repor as perdas por evaporação e drenagem:

$$
\dot{m}_{\text {agalim }}=\dot{m}_{\text {agevap }}+\dot{m}_{\text {agd }}
$$

A área total da seção transversal do meio rígido do evaporador é derivada da velocidade recomendada do ar no meio, que é de $2,5 \mathrm{~m} / \mathrm{s}$, e da vazão em volume de ar na turbina na condição ISO, $\dot{V}_{1}$ (JOHNSON, 1989). Das tabelas 2 e 4 e equações $3.7,3.20$ e 3.24 temos $\dot{V}_{1}=346 \mathrm{~m}^{3} / \mathrm{s}$. A seção transversal do meio rígido é $143 \mathrm{~m}^{2}$. A casa de filtros na entrada da turbina normalmente é quadrada, resultando em um meio rígido com aproximadamente $12 \mathrm{~m}$ de lado. A espessura do meio rígido é 0,36 m (Pneumafil Corporation, 2011).

A vazão de água de recirculação no resfriador, isto é, da água bombeada do reservatório para o distribuidor no topo do meio molhado, é obtida dos valores 
recomendados pelos fabricantes do equipamento. A faixa de vazões recomendadas varia de 2,5 a $5,0 \mathrm{~m}^{3} / \mathrm{h}$ por $\mathrm{m}^{2}$ de área do bloco de distribuição (figura 28). Na simulação dos sistemas EMR adotamos $3,65 \mathrm{~m}^{3} / \mathrm{h}$ por $\mathrm{m}^{2}$. O comprimento do bloco de distribuição é igual à largura do meio rígido, $12 \mathrm{~m}$. A largura do bloco de distribuição é igual à espessura do meio rígido, 0,36 m, resultando numa área de $2,13 \mathrm{~m}^{2}$. Como adotamos um fluxo de $3,65 \mathrm{~m}^{3} / \mathrm{h}$ por $\mathrm{m}^{2}$ de área do bloco de distribuição, a vazão total circulada no EMR é $7,78 \mathrm{~m}^{3} / \mathrm{h}$. A potência de bombeamento de recirculação é obtida considerando a altura de bombeamento igual ao lado do meio rígido, 12 m, e a eficiência da bomba 50 \% (KSB, 2009).

A potência de bombeamento da água de alimentação é calculada usando $\dot{m}_{\text {agalim }}$ e considerando a altura de bombeamento aproximdamente igual à altura do meio rígido, $12 \mathrm{~m}$, conforme observação de plantas existentes pelo autor. A eficiência da bomba de alimentação é assumida como sendo $50 \%$ também.

A fórmula usada para calcular a potência de bombeamento é:

$$
\dot{W}_{b}=\frac{\gamma_{a g} \dot{V}_{a g} H_{b}}{\eta_{b}}=\frac{\dot{m}_{a g} H_{b}}{\eta_{b}}
$$

Onde o peso específico da água, $\gamma_{a g}$, é $10.000 \mathrm{~N} / \mathrm{m}^{3}$.

A potência total consumida pelo bombeamento no resfriamento EMR, $\dot{W}_{\text {bresf }}$ é a soma das potências de bombeamento de recirculação, $\dot{W}_{\text {brec }}$, e de bombeamento de alimentação, $\dot{W}_{\text {balim }}$. 


\subsection{Dados Climáticos}

O método estabelecido de lidar com a incerteza do clima em projeto de sistemas de resfrigeração é usar médias dos dados climáticos tomados sobre 20 anos (CHAKER et al., 2003). Estes dados são disponíveis em (U.S. Department of Energy, 2011) para locais nos Estados Unidos e alguns locais fora daquele país. Dados dos locais brasileiros estão disponíveis principalmente no Laboratório de Eficiência Energética em Edificações da Universidade Federal de Santa Catarina (LABEEE - Laboratório de Eficiência Energética em Edificações, 2011) e no Solar and Wind Energy Resource Assessment (SWERA) (Solar and Wind Energy Resource Assessment (SWERA), 2011). Dois tipos de dados estão disponíveis:

- Arquivos TMY - Dados do ano metereológico típico (Typical metereological year data) - Estes dados são gerados selecionando 12 meses típicos de até 12 anos diferentes em uma base de dados de 20 anos.

- Arquivos TRY - Dados do ano teste de referência (Test reference year) Estes dados são gerados pela eliminação de anos com temperaturas extremas sobre uma base de dados de longa duração, até que reste um único ano, o ano de referência.

Os dois tipos de arquivos fornecem dados com intervalos de uma hora sobre 365 dias do ano de referência. Estes dados são coletados em estações metereológicas e incluem: temperatura de bulbo seco, umidade relativa e pressão ambiente. No Brasil estes dados estão disponíveis para 27 locais, que representam todos os tipos de climas brasileiros. A tabela 6 relaciona dados gerais dos locais das estações metereológicas.

A figura 30 mostra os dados do arquivo TMY relativos a um mês em Belo Horizonte. Estes dados incluem: temperatura de bulbo seco,umidade relativa e 


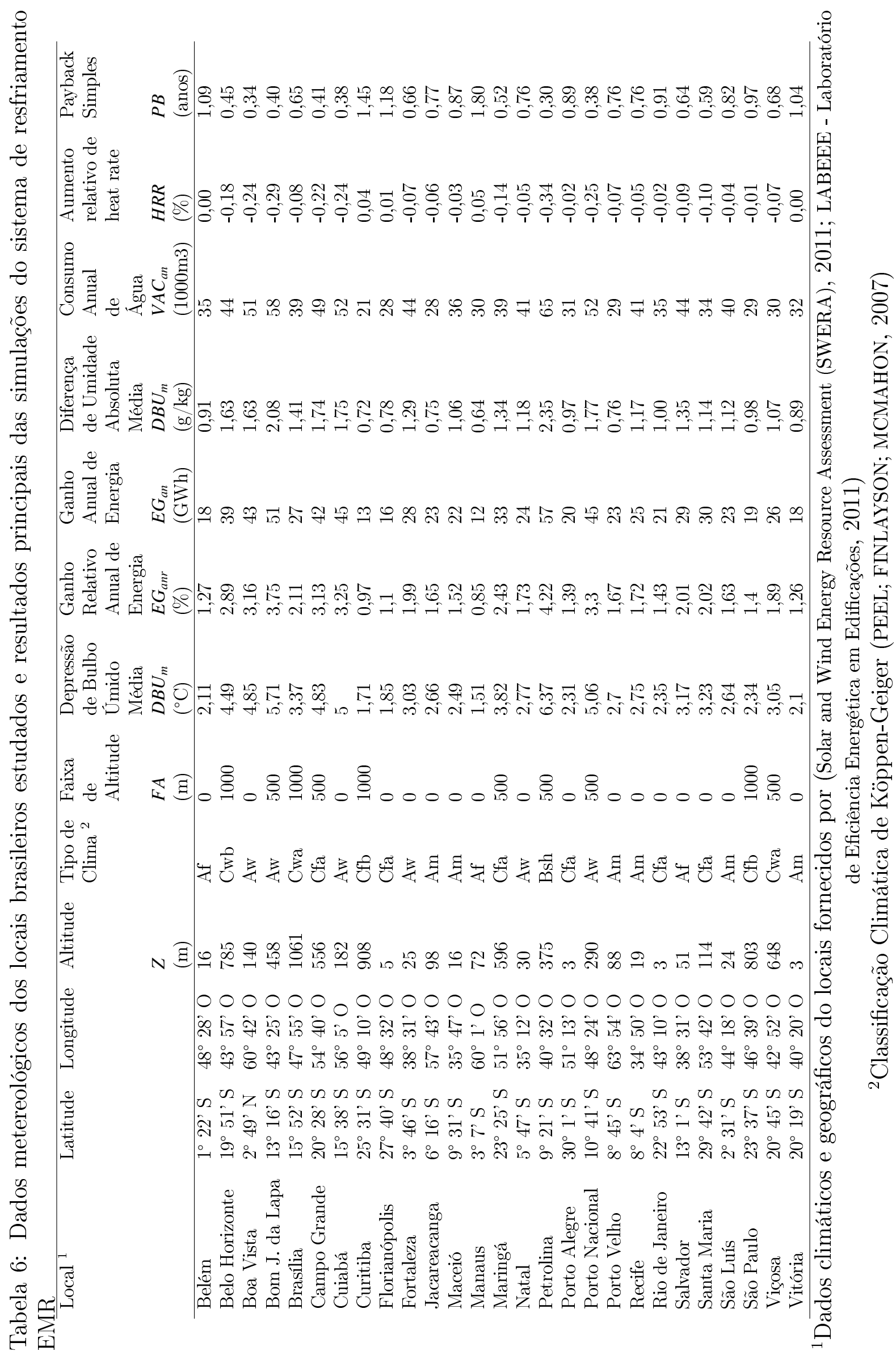




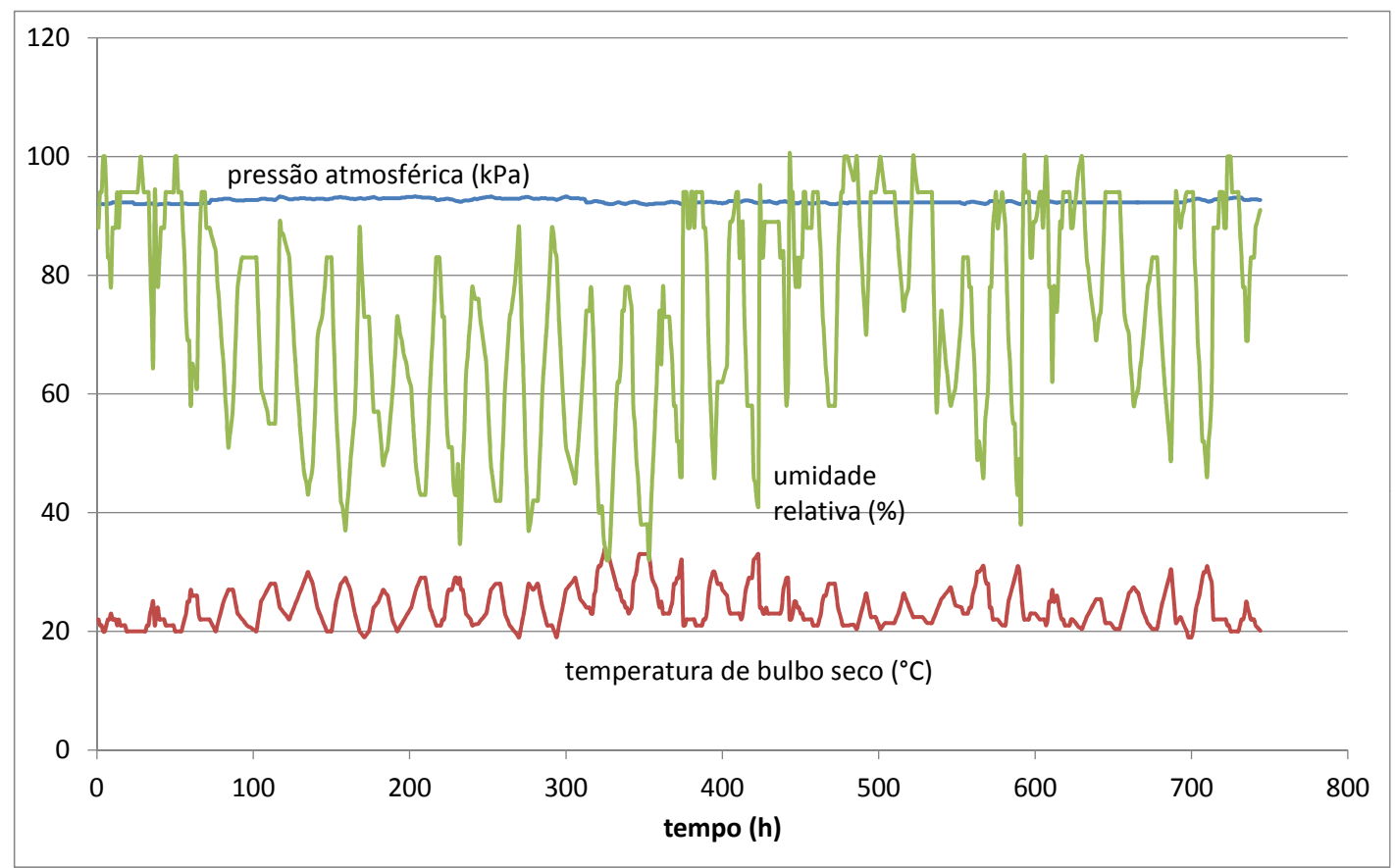

Figura 30: Gráfico dos dados de um mês do arquivo TMY de Belo Horizonte apresentando $p_{a t}$, ur e $T_{b s}$.

pressão atmosférica. A partir destes dados calculamos as temperaturas de bulbo úmido e umidade absoluta para uso nas simulações.

Dois conceitos são usados pela literatura no estudo do resfriamento evaporativo do ar de entrada de turbinas (CHAKER et al., 2003):

- Depressão de bulbo úmido, $D B U$, é a diferença entre as temperaturas de bulbo seco e úmido do ar ambiente. Ela determina o potencial de resfriamento do ar de entrada na turbina por métodos evaporativos (EMR e por névoa). A equação da depressão de bulbo úmido é:

$$
D B U=T_{b s}-T_{b u}
$$

- Horas graus de resfriamento evaporativo, $H G R E$, é a soma dos produtos das depressões de bulbo úmido pelo número de horas em que são prevalentes sobre um determinado período. Neste estudo adotamos 1 ano como o pe- 
ríodo considerado, $\tau$. Este conceito é proposto em (CHAKER et al., 2003) e pode ser facilmente entendido se considerarmos o seu equivalente contínuo:

$$
H G R E=\int_{0}^{\tau}\left(T_{b s}-T_{b u}\right) d t
$$

A figura 24 indica uma relação quase linear entre a temperatura de entrada do ar na turbina e a temperatura gerada por esta. Considerando também a equação 3.25 , verificamos que a energia gerada em um ano pela turbina é proporcional a HGRE.

No estudo do resfriamento evaportivo no Brasil substituímos HGRE do ano típico fornecido pelas séries de dados climáticos, TMY ou TRY, pela média da $D B U$ no ano, $D B U_{m}$. A relação entre $H G R E$ e $D B U_{m}$, considerando um ano de 8760 horas, é dada por:

$$
H G R E=8760 D B U_{m}
$$

A tabela 6 apresenta as altitudes dos locais brasileiros relacionados. Para facilitar o estudo do efeito da altitude de instalação da turbina tanto no resfriamento evporativo EMR quanto no resfriamento por ciclo térmico CT, as altitudes foram agrupadas em faixas. As faixas de altitude, $F A$, são definidas da seguinte forma:

- altitudes de 0 a $250 \mathrm{~m}-F A=0 \mathrm{~m}$

- altitudes de 250 a $750 \mathrm{~m}-F A=500 \mathrm{~m}$

- altitudes de 750 a $1250 \mathrm{~m}-F A=1000 \mathrm{~m}$

O diferencial de altitudes entre diferentes faixas é $500 \mathrm{~m}$. Este diferencial corresponde a variações de $5 \%$ no fator de correção de potência por altitude, $f_{W Z}$ 
(figura 26).

Finalmente, a tabela 6 apresenta o tipo climático de cada local de acordo com a classificação de Köppen-Geiger. Esta classificação climática usa conjuntos de até três letras para caracterizar os tipos climáticos (T. Ambrizzi, 2010; PEEL; FINLAYSON; MCMAHON, 2007). O significado das letras usadas na classificação Köppen-Geiger é o seguinte (T. Ambrizzi, 2010):

- Zonas climáticas principais

- A. Tropical

- B. Seco

- C. Baixas latitudes médias

- D. Altas latitudes médias

- E. Polar

- Modificadores adicionais em letras maiúsculas

- S. Semi-árido

- W. Árido

- T. Tundra

- F. Calota polar

- H. Montanhosa

- Modificadores em letras minúsculas

- a. verões quentes e longos

- b. verões quentes e curtos

- c. verões frescos e curtos 
$-\mathrm{d}$. verões e invernos frios

- f. precipitação todos os meses

- w. inverno seco

- s. verão seco

- m. precipitação de monção

- h. quente e seco, temperatura média de todos os meses acima de $0^{\circ} \mathrm{C}$

- k. frio e seco, pelo menos um mês com temperatura média abaixo de $0^{\circ} \mathrm{C}$

- n. nevoeiro frequente

- n'. nevoeiro não frequente, mas alta umidade

As classificações começam sempre pela zona climática principal seguidas por modificadores em letras minúsculas e maiúsculas. Por exemplo, "Af" indica clima tropical com precipitação todos os meses; "Cwa" significa clima de baixas latitudes médias com inverno sêco e verões longos; "BSh" significa clima seco, semi-árido, quente e seco. As classificações apresentadas na tabela 6 para os locais brasileiros vêm de (PEEL; FINLAYSON; MCMAHON, 2007). 


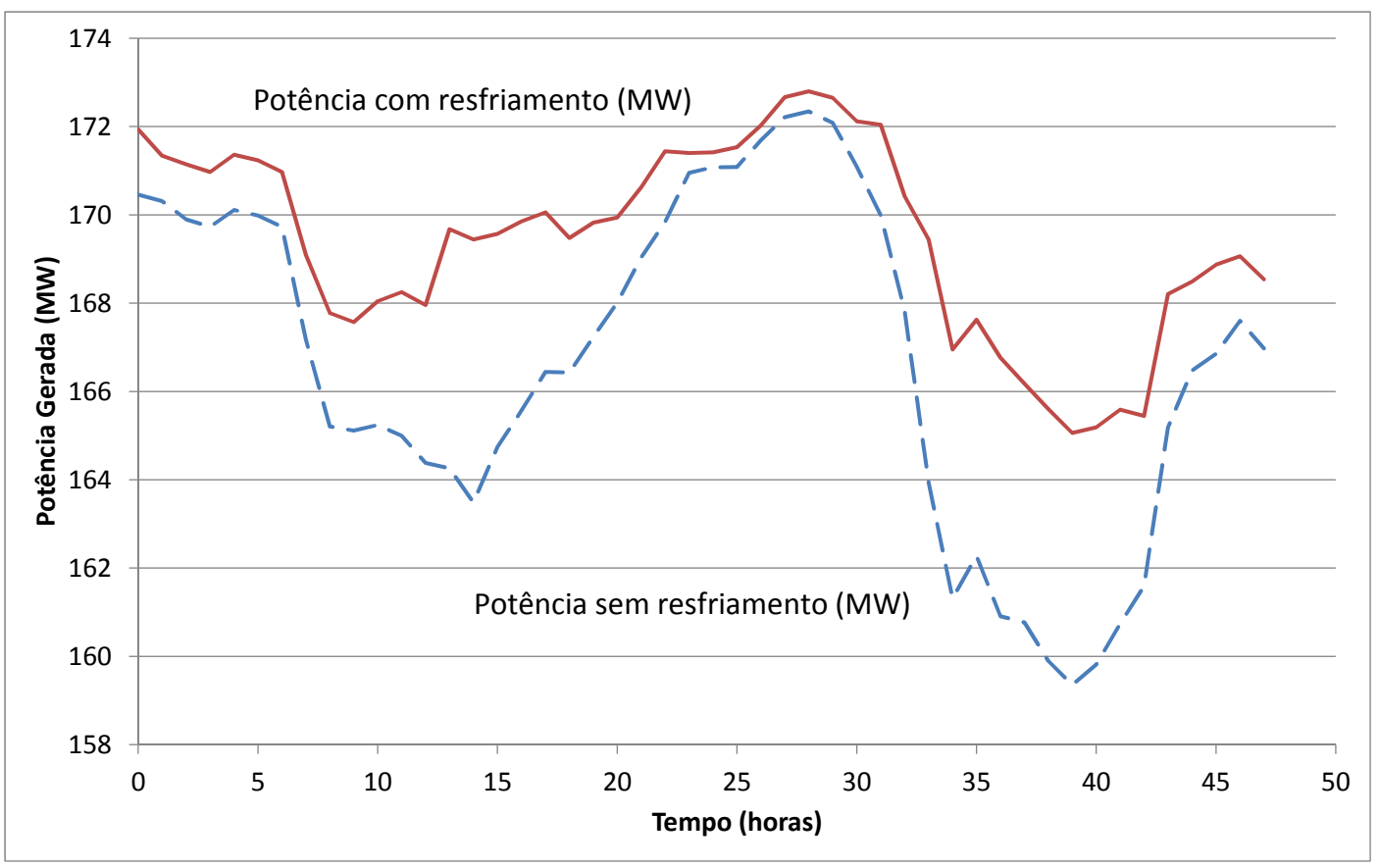

Figura 31: Potência gerada em Vitória (MW) por uma turbina GE 7FA com resfriamento EMR (linha contínua) e sem resfriamento (linha tracejada) de ar de entrada num período de 2 dias (48 horas).

\subsection{Simulação dos Modelos com Dados Climáticos}

A figura 31 mostra a potência gerada por uma turbina GE 7FA (4) ao longo de 2 dias em Vitória - ES com e sem resfriador EMR do ar de entrada. A figura 32 mostra a diferença entre as potências geradas com e sem resfriador ou ganho de potência, $W G$, e a depressão de bulbo úmido, $D B U$, nos dois dias. Estas duas figuras mostram que o aumento de potência na turbina dado pelo resfriamento evaporativo ocorre durante o dia, período de pico de consumo, e que o ganho de potência é uma função da depressão de bulbo úmido.

Na análise dos resultados das simulações comparamos a operação da turbina com e sem resfriamento do ar de entrada. O parâmetro principal usado nesta comparação é o ganho de energia gerada e um ano típico (TMY ou TRY)por 


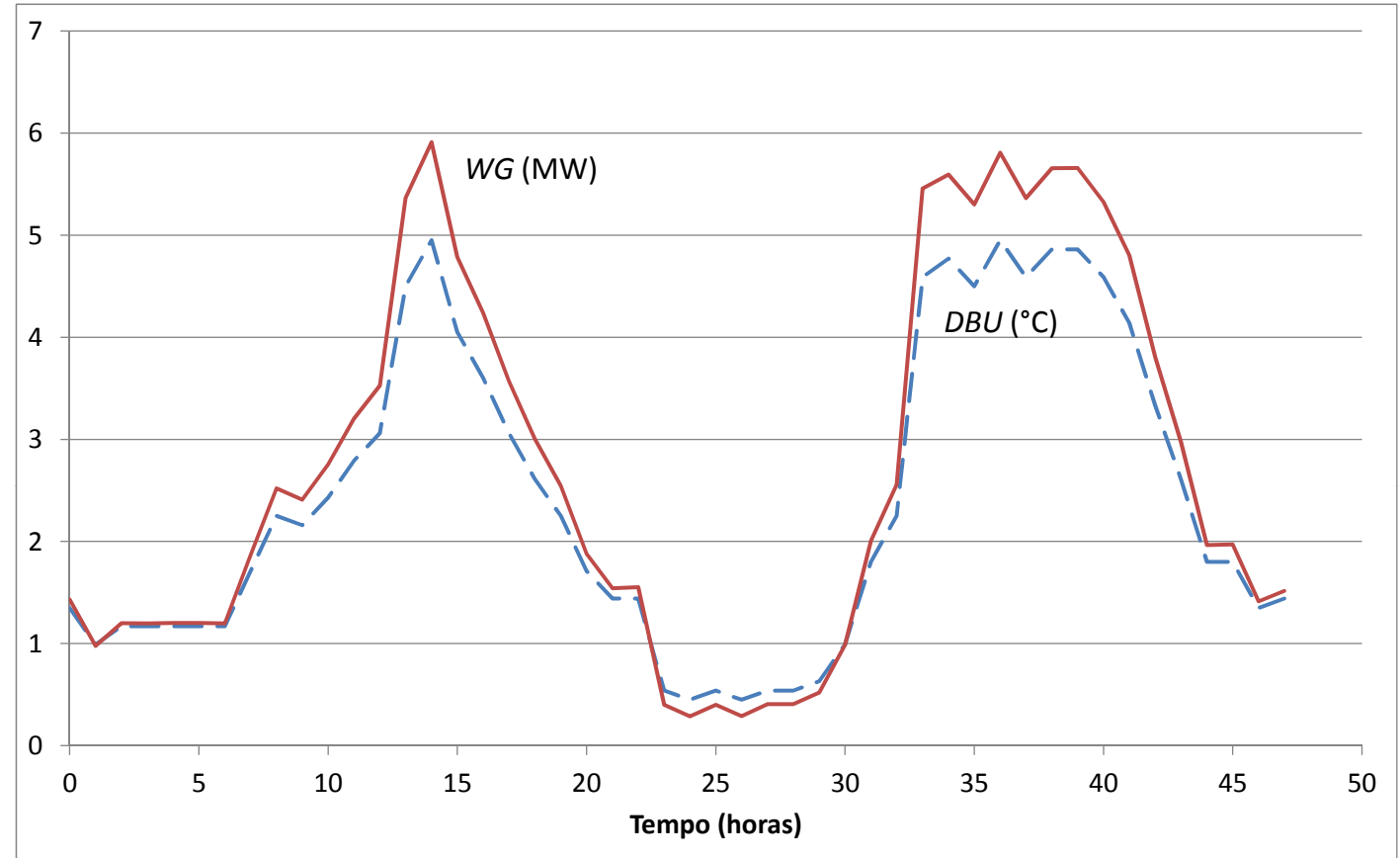

Figura 32: Ganho de potência ( $W G$ em MW) de uma turbina GE 7FA com o uso de EMR (linha contínua) e depressão de bulbo úmido $\left(D B U\right.$ em $\left.{ }^{\circ} \mathrm{C}\right)$ (linha tracejada) em Vitória no mesmo período mostrado na figura 31.

uma turbina GE 7FA, $E G_{a n}$, definido por:

$E G_{a n}=($ energia gerada em um ano pela turbina com resfriamento)

- (energia gerada pela turbina em um ano sem resfriamento)

Definimos o ganho relativo de energia em um ano de geração:

$$
E G_{a n r}=\frac{E G_{a n}}{\text { energia gerada pela turbina em um ano sem resfriamento }}
$$

Também verificamos a variação relativa do heat rate da turbina, $H R R$, defi- 


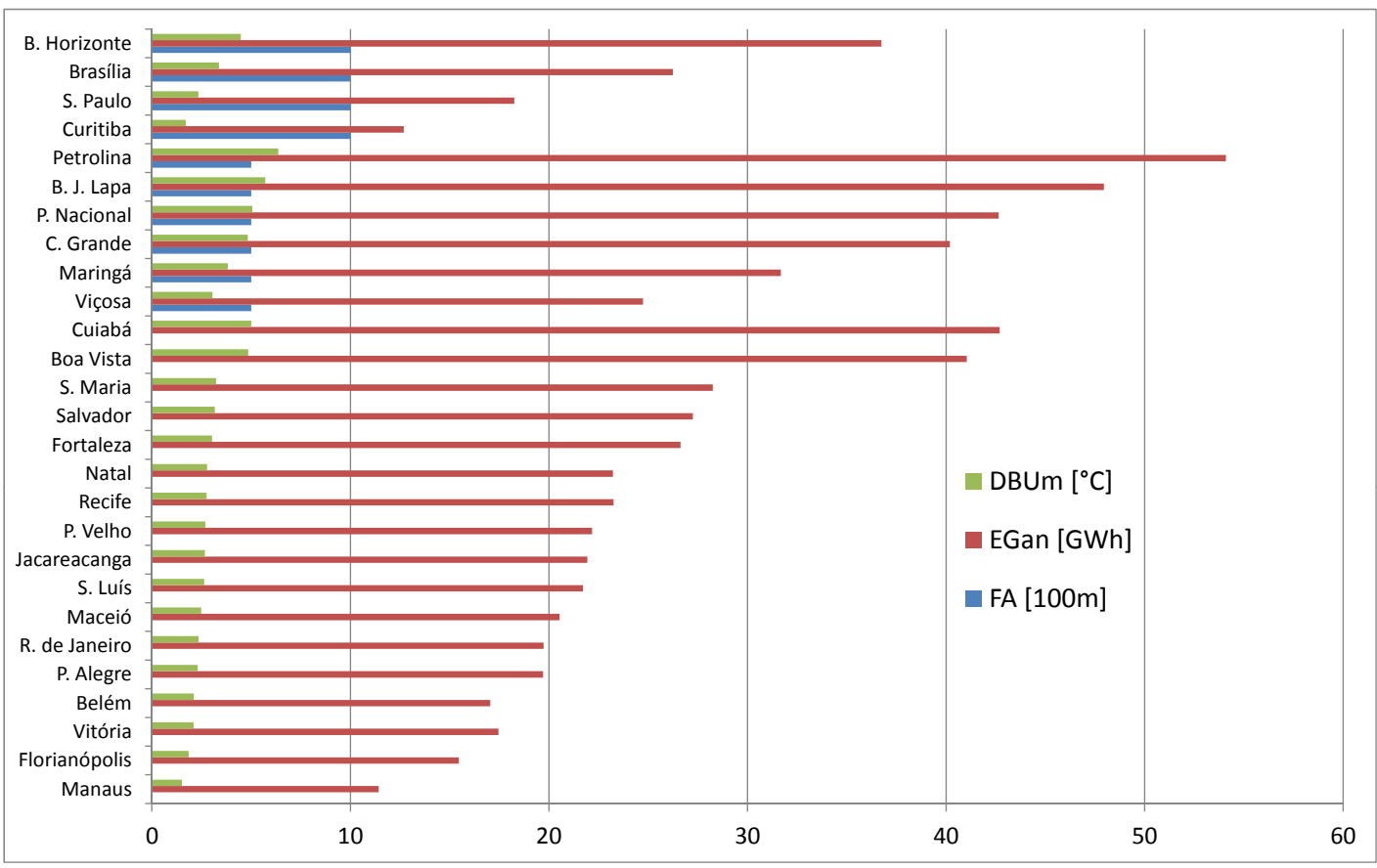

Figura 33: Ganho de energia anual $\left(E G_{a n}\right)$ ordenada por depressão de bulbo úmido média anual $\left(D B U_{m}\right)$ e faixa de altitude $(F A)$ para localidades brasileiras.

nida da seguinte maneira:

$H R R=100 \frac{H R \text { para operação com resfriamento }-H R \text { para operação sem resfriamento }}{H R \text { para operação sem resfriamento }}$

A figura 33 mostra o ganho de energia no período de um ano, $E G_{a n}$, para as localidades brasileiras da tabela 6. (Os valores estão listados na própria tabela também.) Na figura 33 os dados foram ordenados pela depressão de bulbo úmido média anual do local, $D B U_{m}$, também mostrada no gráfico e listada na tabela. As localidades também são classificadas por faixa de altitude, $F A$ : 0 metros (0-250m); 500 metros $(250-750 \mathrm{~m})$ e 1000 metros $(750-1250 \mathrm{~m})$. Estas faixas são mostradas na tabela e no gráfico. Fica clara a relação do ganho de energia com a depressão de bulbo úmido média e com menor intensidade à faixa de altitude, $F A$. 


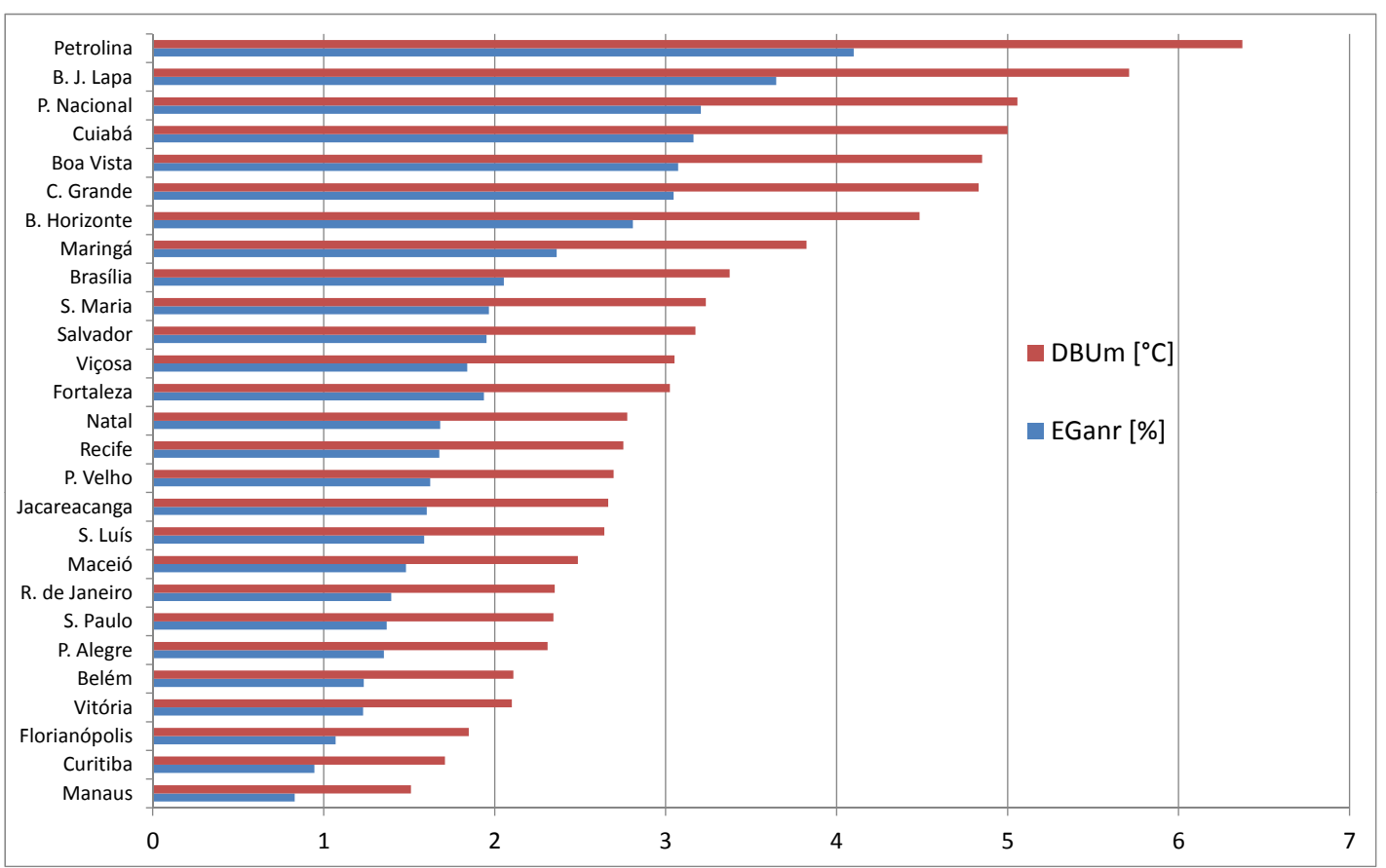

Figura 34: Ganho de energia anual relativo de uma turbina GE 7FA $\left(E G_{a n r}\right)$ e depressão de bulbo úmido anual média $\left(D B U_{m}\right)$ para localidades brasileiras.

A figura 34 mostrando o ganho de energia anual relativo de uma turbina GE $7 F A, E G_{a n r}$, e a depressão de bulbo úmido média e faixas de altitude para localidades brasileiras suporta o uso da $D B U_{m}$ na estimativa de $E G_{a n r}$. Isto pode ser observado mais claramente no gráfico $E G_{a n r}$ versus $D B U_{m}$, na figura 35 . Por ser fixa para cada localidade, a faixa de altitude, $F A$, não afeta $E G_{a n r}$.

A figura 36 mostra o volume consumido de água, $V A C_{a n}$, por resfriamento evaporativo de turbinas GE 7FA em locais brasileiros. $V A C_{a n}$ foi ordenado de acordo com faixas de altitude $F A$ dos locais e de acordo com a diferença média entre as úmidades absolutas médias e na condição média de ar saturado, $D U A_{m}$ :

$$
D U A_{m}=\omega_{\text {satm }}-\omega_{\text {atm }}
$$

A dependência de $V A C_{a n}$ em relação à $D U A_{m}$ é explicada pela equação 3.27 . A figura 37 mostra o efeito de $D U A_{m}$ e $F A$ em $V A C_{a n}$. 


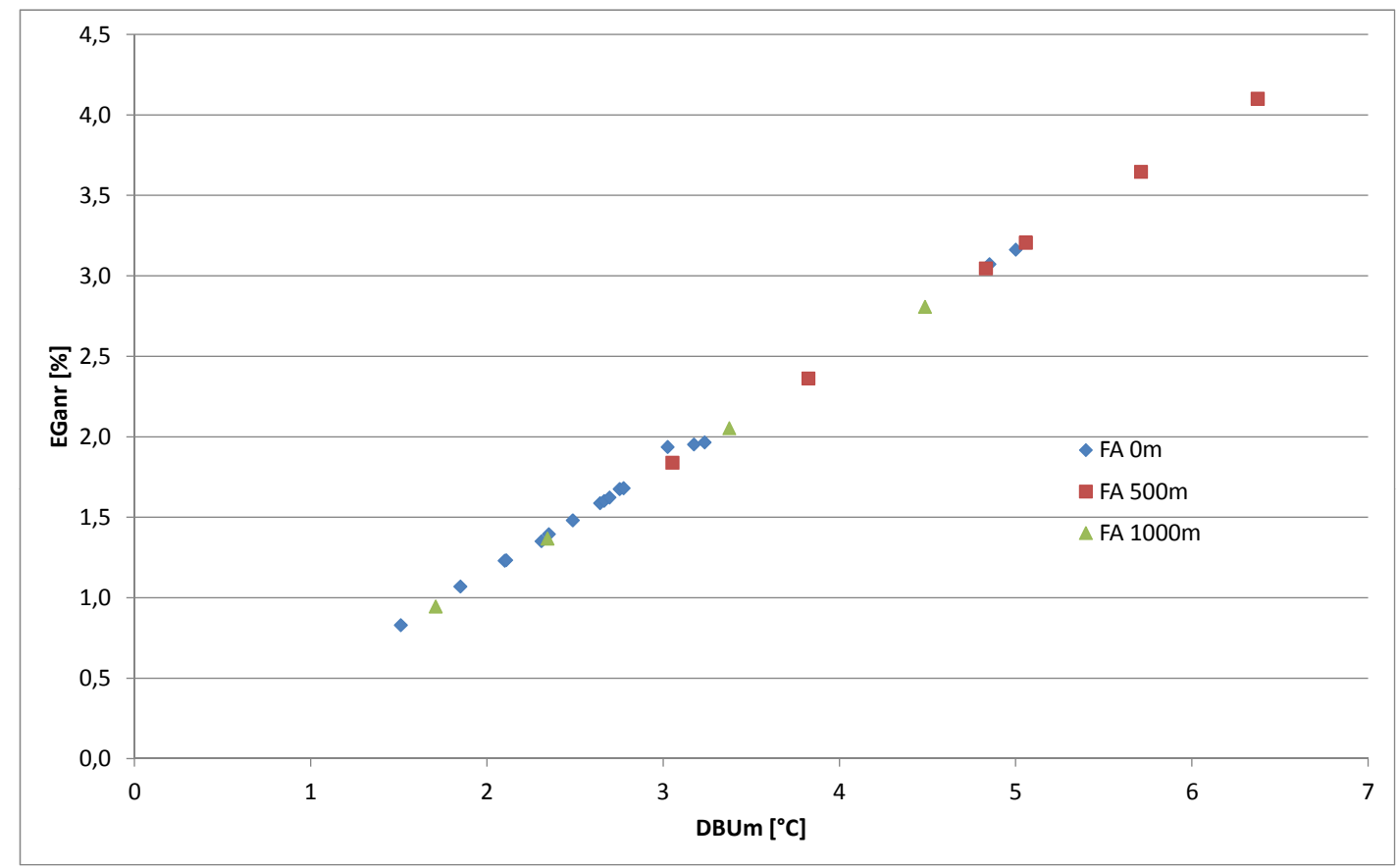

Figura 35: Ganho de energia anual relativo de uma turbina GE 7FA (EG anr $)$ versus depressão de bulbo úmido anual média $\left(D B U_{m}\right)$ para diferentes faixas de altitude $(F A)$.

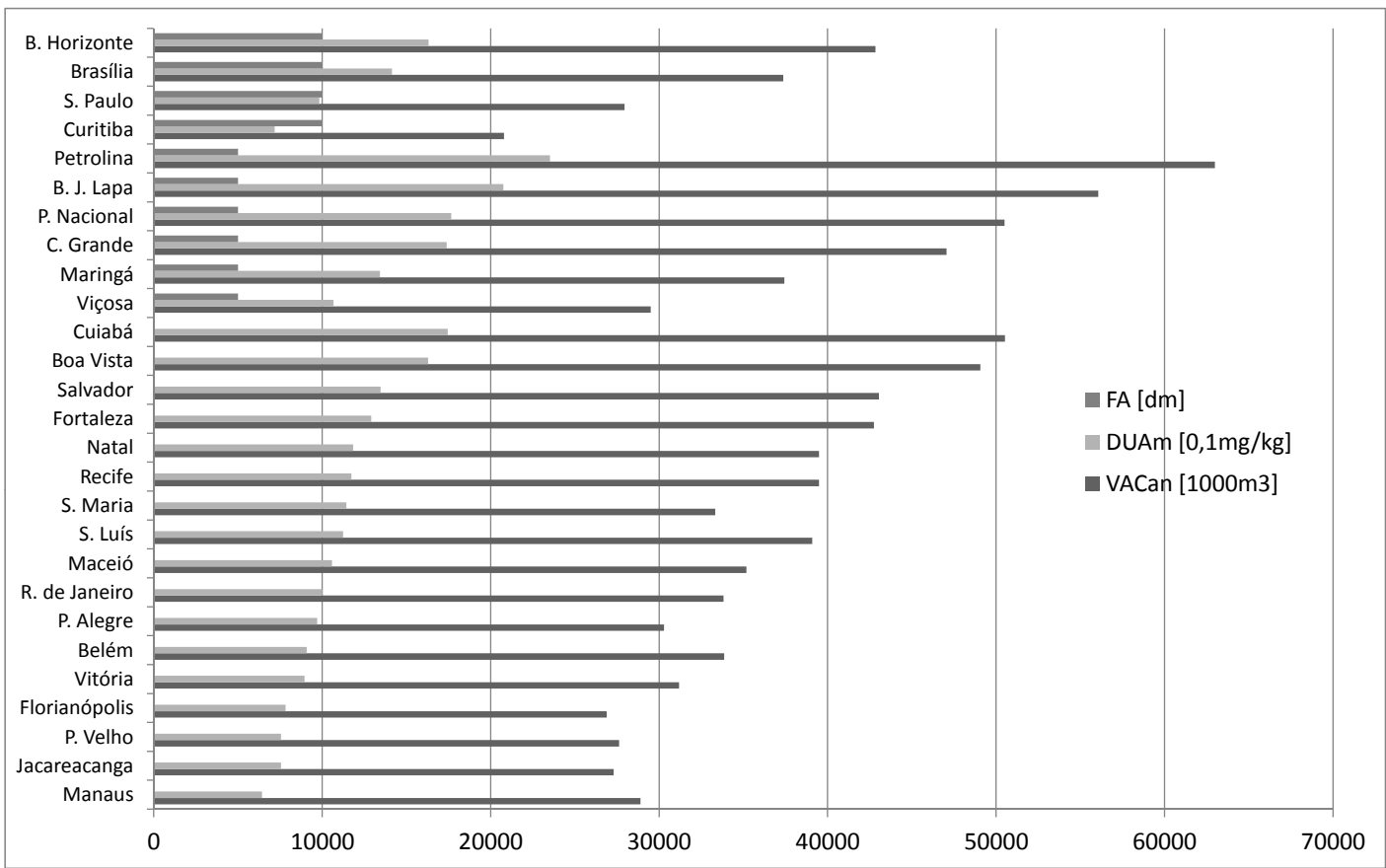

Figura 36: Volume de água consumido em um ano $\left(V A C_{a n}\right)$ pelo resfriamento evaporativo EMR pela turbina GE 7FA em locais brasileiros, indicando também o diferencial de umidade absoluta médio $\left(D U A_{m}\right)$ e faixa de altitude $(F A)$. 


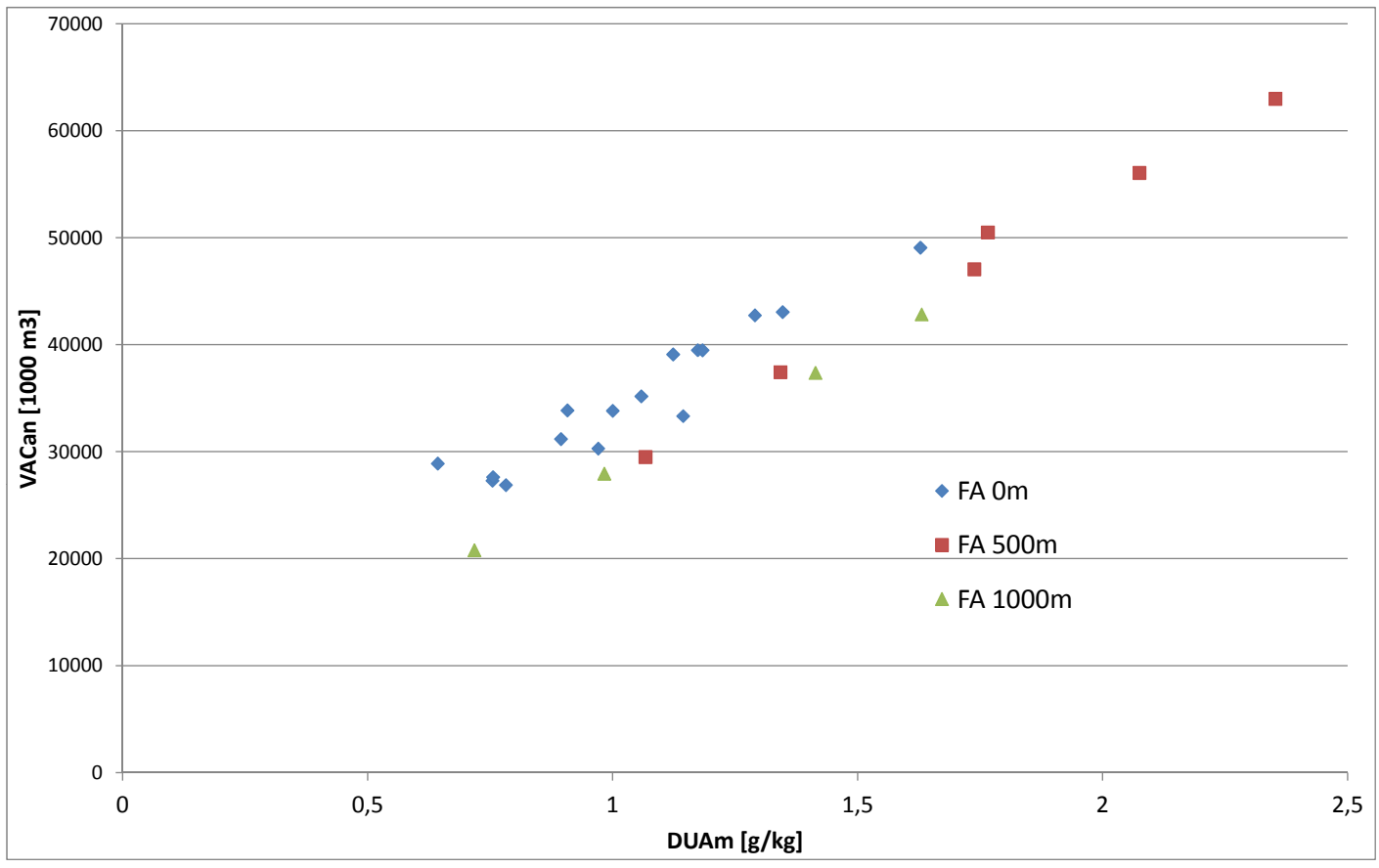

Figura 37: Volume de água consumido em um ano $\left(V A C_{a n}\right)$ pelo resfriamento evaporativo EMR pela turbina GE 7FA em função do diferencial de umidade absoluta médio $\left(D U A_{m}\right)$ para diferentes faixas de altitude $(F A)$.

A figura 38 mostra o ganho de energia anual relativo, $E G_{a n r}$, ordenado pela classificação climática de Köppen-Geiger e faixa de altitude, FA. Conforme esperado, os climas mais secos, de classificação BSh, apresentam os maiores potenciais para ganho de energia e o maior consumo de água nos sistemas de resfriamento evaporativo. Os climas mais úmidos, de classificação Af, apresentam os menores potênciais de ganho de energia e consumo de água. Além destes dois extremos, a classificação de climas de Köpper-Geiger não fornece claras indicações sobre o potencial do resfriamento evaporativo.

A variação de heat rate com a aplicação do resfriamento EMR é muito pequena e sempre no sentido de reduzir o heat rate, isto é, aumentar a eficiência, conforme indicado na tabela 6 . 


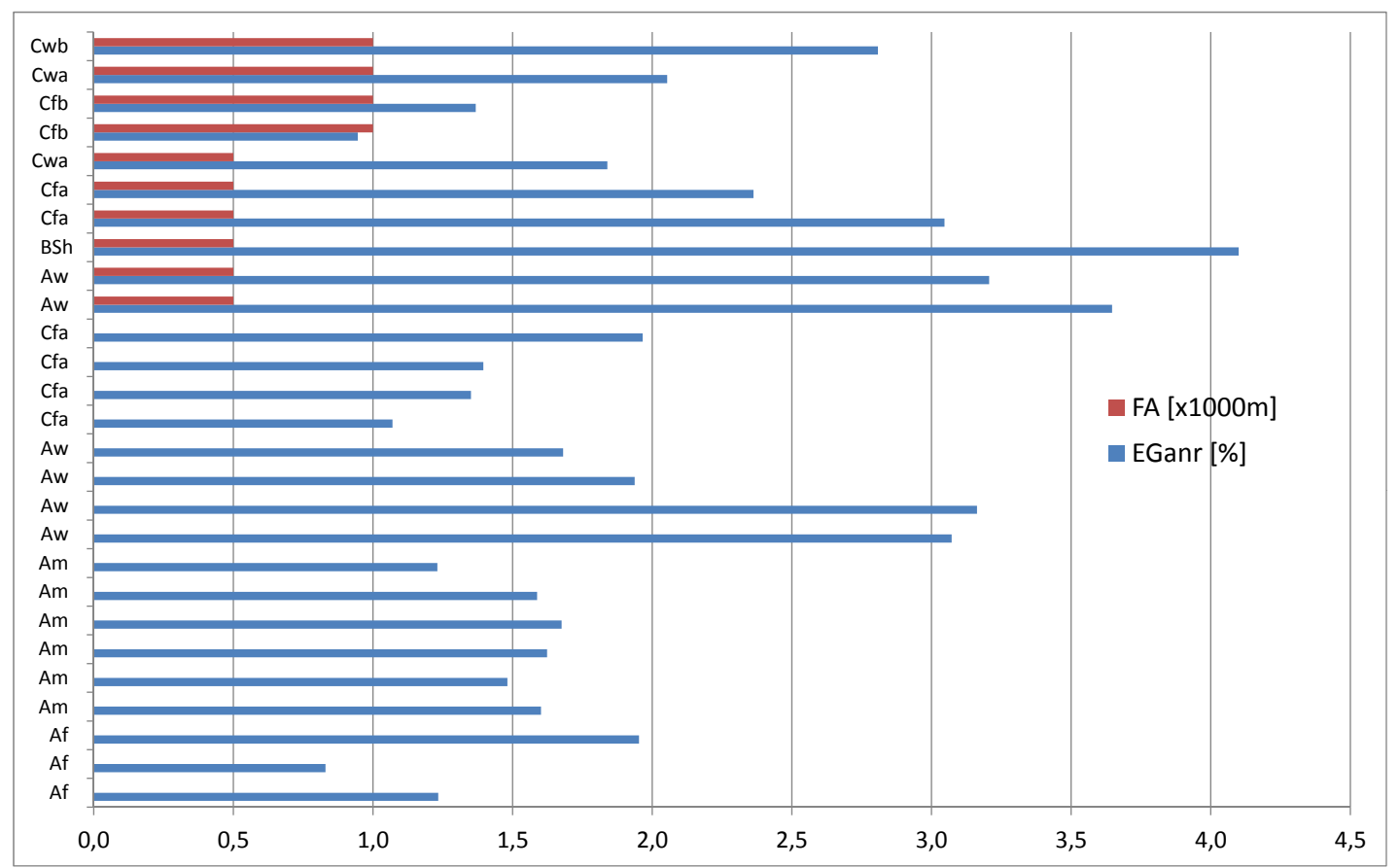

Figura 38: Ganho de energia anual relativo, $E G_{\text {anr }}$, ordenado pela classificação climática de Köppen-Geiger e faixa de altitude, $F A$.

\subsection{Análise Econômica do Resfriamento Evaporativo}

A análise econômica da aplicação do resfriamento EMR é feita usando o método do payback simples, que é o método adotado para avaliação preliminar de projetos em empresas como a Petrobras (FERRAZ, A. C. P. C.; GOMES, E.; PEREZ, J. M. G. T.; XAVIER, M. B.; BARCELLOS, W. J., 2006). A receita da aplicação do EMR é obtida da venda da energia adicional gerada pela turbina com resfriamento EMR, ou ganho de energia anual, $E G_{a n}$. Os custos considerados vêm das despesas operacionais: consumo adicional anual de gás natural e consumo adicional de água.

As termelétricas definem o valor de venda da sua energia elétrica por MWh gerado, chamado de Custo Variável Unitário, ou $C V U$, que é determinado de acordo com regras estabelecidas pelo Ministério de Minas e Energia. Este custo é a melhor aproximação que a termelétrica pode fornecer do valor de cada MWh gerado na planta. A base deste valor é o custo operacional da planta. Normalmente 
$80 \%$ deste valor é custo do combustível usado na geração de energia, o restante são custos de outros insumos: água, lubrificantes; energia elétrica consumida internamente; e o custo futuro das manutenções das turbinas devido às horas de operação da turbina e partidas realizadas (ONS - Operador Nacional do Sistema Elétrico , 2011; Ministério de Minas e Energia , 2007; Câmara de Comercialização da Energia Elétrica , 2011; SOARES; RAMOS, 24-28 Maio 2009). A referência (Ministério de Minas e Energia (Brasil), 2010) apresenta os valores de $C V U$ em 2010 para 11 termelétricas com turbinas a gás. A média destes valores é 188,59 R \$/MWh em 15 de abril de 2010. Este valor foi convertido para dólares daquela data usando o conversor do Banco Central do Brasil (Banco Central do Brasil, 2012) e o valor em dólares atualizado para 2012 usando o índice de preços ao consumidor dos Estados Unidos disponível na página do " United States Department of Labor" (United States Department of Labor, 2012). O valor final de venda de energia, $C V U$, usado na análise econômica é $113,20 \mathrm{U} \$ /$ MWh.

O preço do gás natural, $C E G N$, usado na análise econômica é o recomendado em 2012 por ( Empresa de Pesquisa Energética, 2012): 16,21 U\$/MWh de gás natural.

Normalmente as termelétricas têm o seus próprios sistemas de tratamento de água e o custo da água tratada é contabilizado internamente e não publicado. Preços da água distribuida no Brasil para usos industriais pelas empresas públicas variam com os locais no Brasil. Consideramos o preço de água para uso indutrial médio publicado pela SABESP em todas as regiões do Estado de São Paulo (SABESP, 2011) em 2011, 8,35R \$/ $\mathrm{m}^{3}$. Este valor é convertido para U $\$$ na data de publicação, 11 de setembro de 2011, usando (Banco Central do Brasil, 2012) e depois atualizado para 2012 usando (United States Department of Labor, 2012), resultando num custo específico da água de resfriamento, CEAG, de $5,09 \mathrm{U} \$ / \mathrm{m}^{3}$.

Os custos de manutenção e operação do sistema não relacionados ao consumo de água e gás adicional são desprezíveis de acordo com (OMIDVAR, 2001). 
O custo de investimento em um sistema de resfriamento evaporativo com meio rígido, CIEMR, é apresentado como sendo proporcional à potência em kW adicionados à turbina em (CHACARTEGUI et al., 2008; MUNTERS, 2011). Os valores apresentados vão de 27 a 81U\$/kW. Em (JABER; JABER; KHAWALDAH, 2007), o investimento em resfriamento evaporativo é apresentado como sendo proporcional à potência instalada da turbina a gás, com um valor específico de 10 a $15 \mathrm{U} \$ / \mathrm{kW}$ instalado. O custo refere-se à instalação do sistema na Jordânia. O problema de considerar o investimento em resfriamento evaporativo EMR como proporcional à potência adicionada à turbina é que o aumento de potência é dependente da condição do ar atmosférico. Considerar o investimento em resfriamento evaporativo como proporcional à potência instalada da turbina faz mais sentido, porque o tamanho do meio evaporativo é proporcional à vazão de ar succionada pelo compressor da turbina, que por sua vez é proporcional à potência ISO da turbina.

A referência (JONES; Jacobs III, 2000) indica um investimento de 1,4 milhões de U\$ como sendo necessário para instalar resfriadores evaporativos em duas turbinas GE 7FA. O ganho de potência em cada turbina é de 10MW quando o ar atmosférico está a $35^{\circ} \mathrm{C}, 45 \%$ e $101,3 \mathrm{kPa}$. O custo baseado na potência adicionada à turbina é $70 \mathrm{U} \$ / \mathrm{kW}$. Considerando o custo por potência instalada de cada turbina, 171,7MW ISO, temos 4,10U\$/kW. Neste estudo consideramos o valor $4,10 \mathrm{U} \$ / \mathrm{kW}$, corrigida para a inflação da data de publicação de (JONES; Jacobs III, 2000), 2000, para 2012, usando (United States Department of Labor, 2012) e para a diferença de carga de impostos dos Estados Unidos para o Brasil que é de 13,68\% (NOBLE; SOUZA; de Almeida, 2006), resultando em CIEMR $=6220,00 \mathrm{U} \$ / \mathrm{MW}$ de potência nas condições ISO da turbina. 
A receita líquida da operação do resfriamento EMR é:

$R L=$ receita da venda de energia elétrica adicional

- custo do gás adicional consumido - custo da água consumida no resfriamento $=E G_{a n} C V U-E G_{g n} C E G N-V A C C E A G$

O tempo de payback é calculado por:

$$
P B=\frac{\dot{W}_{t g I S O} C E I E M R}{R L}=\frac{C I E M R}{P B}
$$

Onde CIEMR é o investimento de instalação do resfriamento EMR na turbina GE7FA, U\$ 1.067.682,11.

A figura 39 mostra a dependência linear da receita do ganho de energia, $R E G$, custo do aumento do consumo de gás, $C G N$, custo do aumento de consumo de água, $C A G$, e da receita anual líquida, $R L$, com a depressão média de bulbo úmido do local de instalação da turbina, $D B U_{m}$. A figura 40 mostra claramente a dependência do tipo $1 / x$ do tempo de payback, $P B$, em relação a $D B U_{m}$. Esta dependência é esperada pelo fato de $R L$ ser função linear de $D B U_{m}$ e $C I E M R$ ser constante para uma dada turbina. 


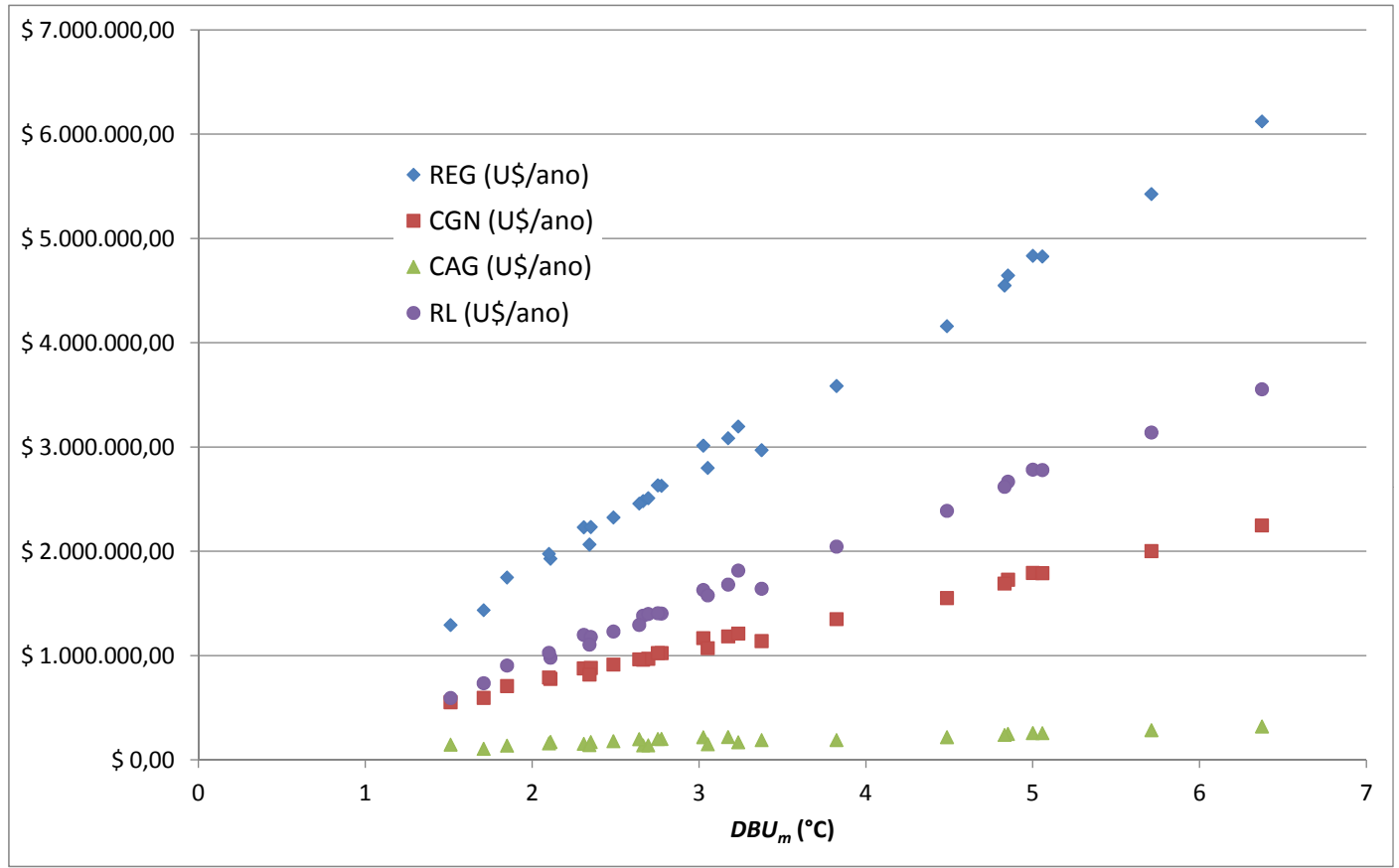

Figura 39: Ganho de energia, REG, custo do aumento do consumo de gás, $C G N$, custo do aumento de consumo de água, $C A G$,receita anual líquida, $R L$ em função da depressão de bulbo úmido, $D B U_{m}$.

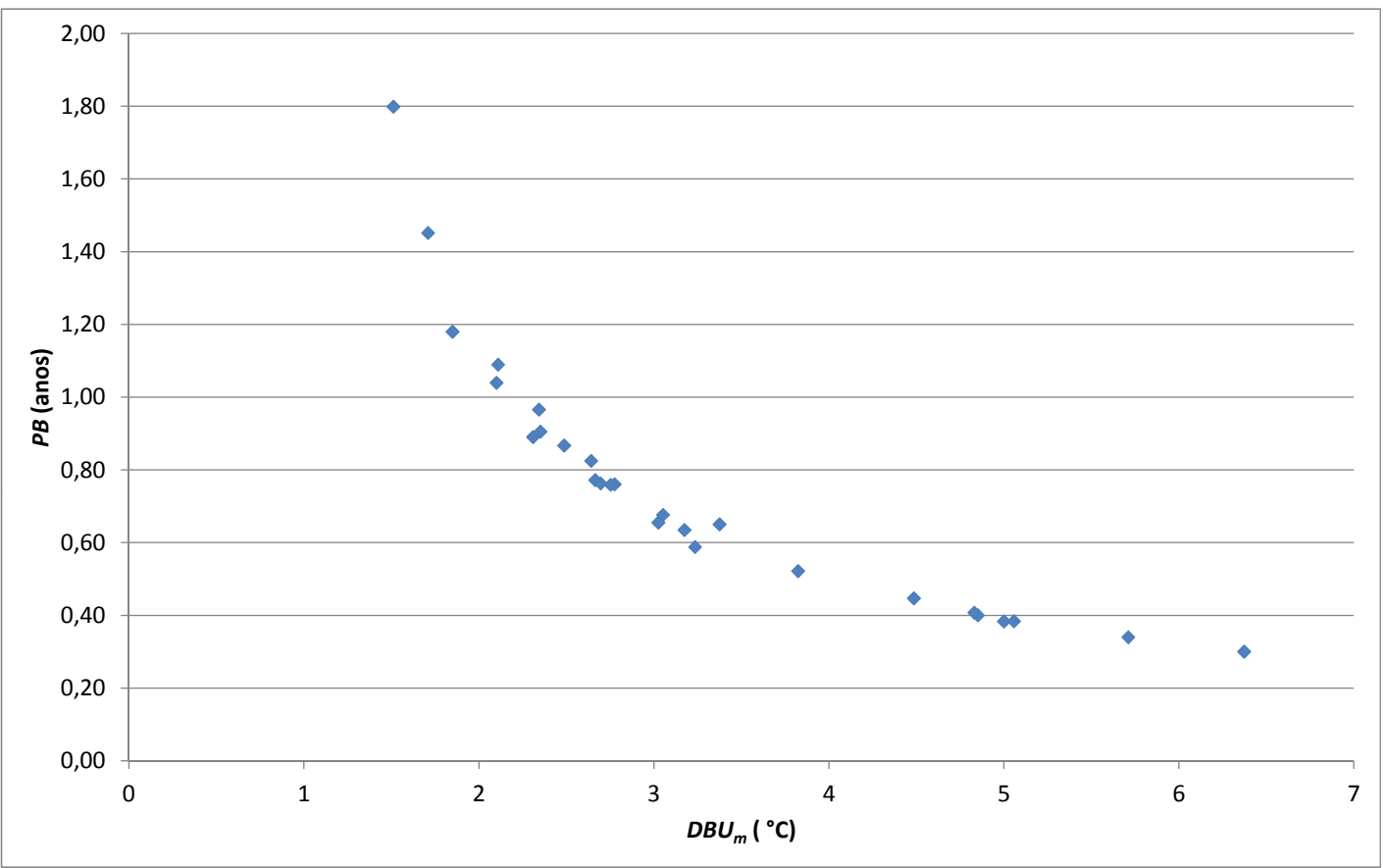

Figura 40: Payback, PB, em função. 


\section{ESTUDO DO RESFRIAMENTO POR CICLO TÉRMICO}

Neste capítulo estudamos o resfriamento por ciclo térmico de compressão com chiller acionado por motor elétrico. A tabela 1 indica que três termelétricas com potência acima de $50 \mathrm{MW}$ têm sistemas como este instalados. A descrição detalhada deste sistema é feita na seção 1.2.3. No sistema de resfriamento CTC estudado, a rejeição de calor do chiller para a atmosfera é feita por uma torre de resfriamento que é a prática mais comum no Brasil. Para facilitar o acompanhamento do desenvolvimento do modelo, repetimos aqui o diagrama do CTC na figura 41.O modelo de turbina a gás desenvolvido para o estudo do resfriamento evaporativo no capítulo 3 é usado no estudo do resfriamento por ciclo térmico. Os dados climáticos também são os mesmos do resfriamento evaporativo.

\subsection{Modelo do resfriamento por ciclo termodinâmico por compressão (CTC)}

Quando o resfriamento por ciclo térmico, seja ele de compressão (CTC) ou por absorção (CTA), é aplicado no resfriamento do ar de entrada de turbinas, a redução de temperatura do ar não está limitada pela depressão de bulbo úmido como no caso dos métodos evaporativos. (Ver o capítulo 1.) O limite de resfriamento é dado pela capacidade do sistema.

Quando o sistema de resfriamento tem capacidade suficiente para baixar a temperatura do ar até a temperatura desejada qualquer que seja a condição a 


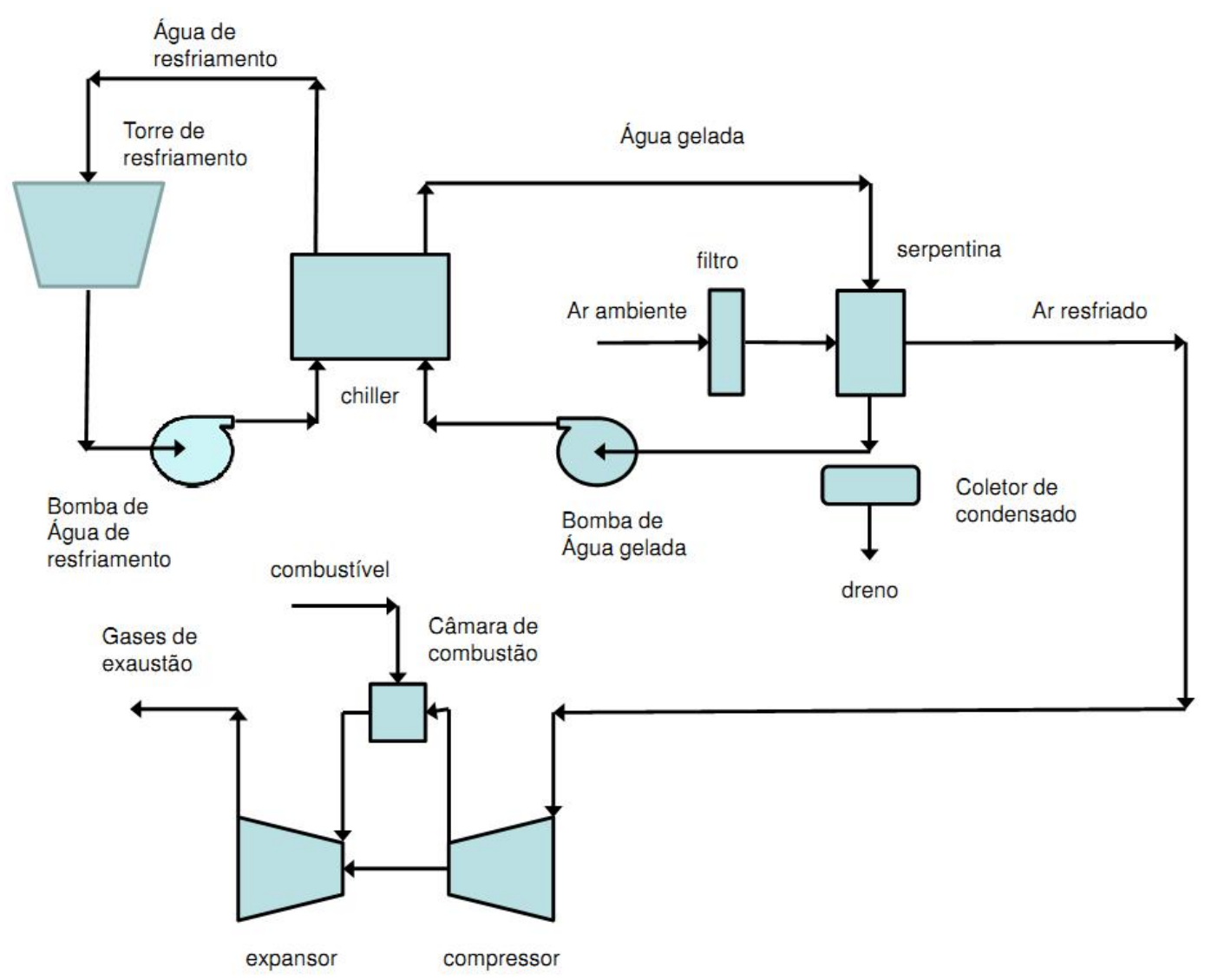

Figura 41: Diagrama do sistema de resfriamento de ar de entrada da turbina CTC.

temperatura do ar de entrada na turbina fica constante. Neste caso a potência máxima que pode ser gerada na turbina é constante, indepente da temperatura do ar ambiente. A figura 42 ilustra o que acontece sem resfriamento e com resfriamento com ciclo térmico com capacidade suficiente para regular a temperatura desejada, $T_{C}$, que é igual à temperatura $T_{1}$ das figuras 20 e 21.

Se a capacidade do sistema de resfriamento não for suficiente para resfriar o ar até a temperatura desejada nos períodos mais quentes do dia, haverá elevação da temperatura do ar de entrada e queda da potência máxima gerada nestes períodos. A figura 43 mostra o comportamento do sistema de resfriamento e turbina nesta condição. A potência máxima da turbina neste caso é disponível por um período que depende das condições ambientes e da capacidade de resfriamento.

Tendo em vista as considerações acima, estudamos os seguintes problemas: 


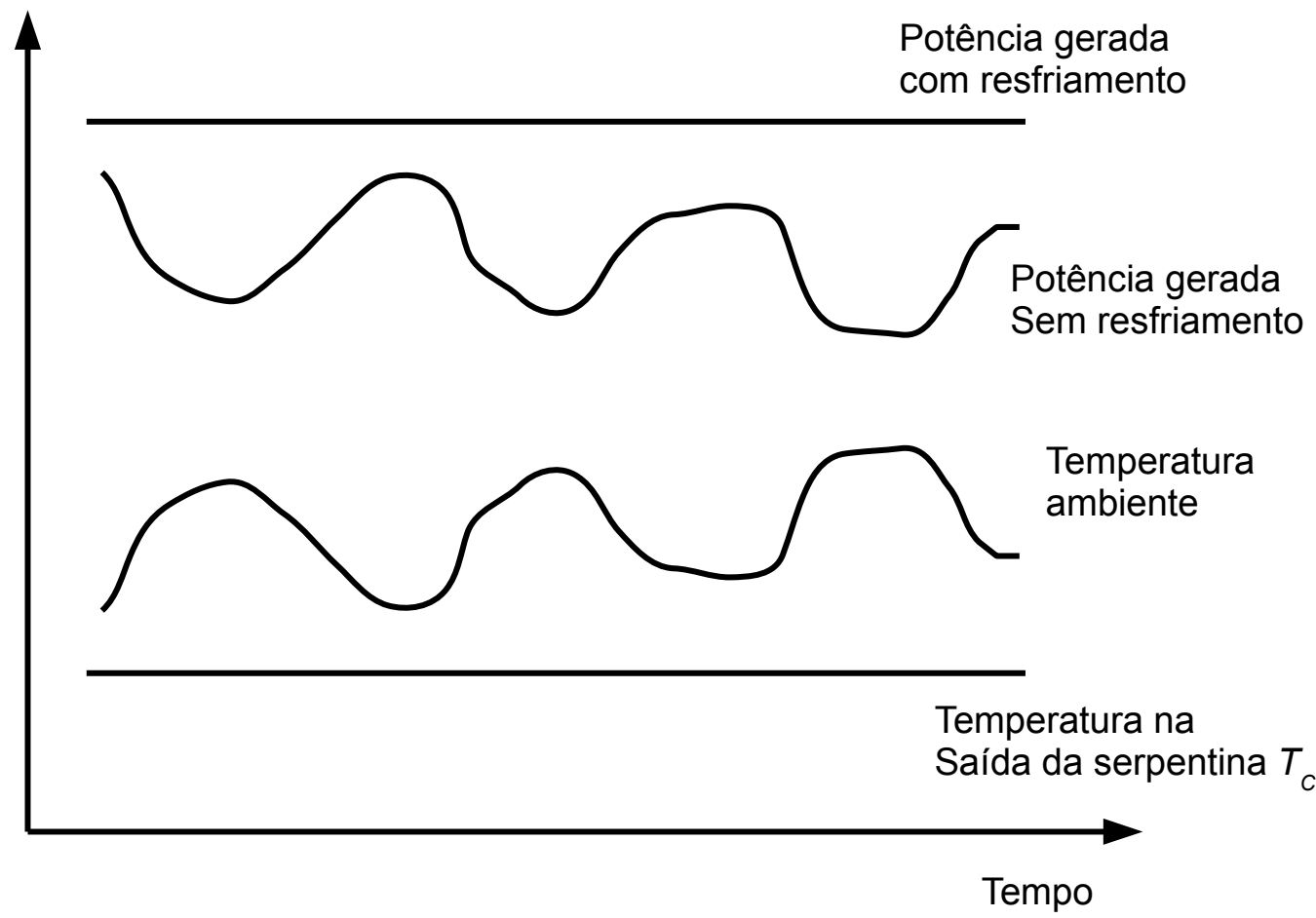

Figura 42: Efeito do resfriamento por ciclo térmico, CTC, do ar de entrada de turbina a gás quando o resfriamento tem capacidade suficiente para regular a temperatura do ar.

- Para cada localidade brasileira analisada, calculamos os ganhos de energia anual, $E G_{a n}$, e energia anual relativa, $E G_{a n r}$ conforme a temperatura de resfriamento do ar desejada e verificamos a relação deste ganho com relação às variáveis climáticas e geográficas do local: temperaturas de bulbo seco e úmido médias, umidade do ar média e faixa de altitude.

- Ao resolvermos o problema acima obtemos a capacidade necessária ao sistema de resfriamento para manter a temperatura de resfriamento do ar desejada qualquer que seja a condição ambiente. Uma vez que estatisticamente, extremos de temperatura e umidade ambientes ocorrem em períodos limitados do ano, as capacidades obtidas com a condição de manter a temperatura desejada em qualquer circunstância são superdimensionadas,resultando em custos de investimento desnecessários. Estudamos então o efeito de variar a capacidade de resfriamento para uma determinada temperatura de ar dese- 


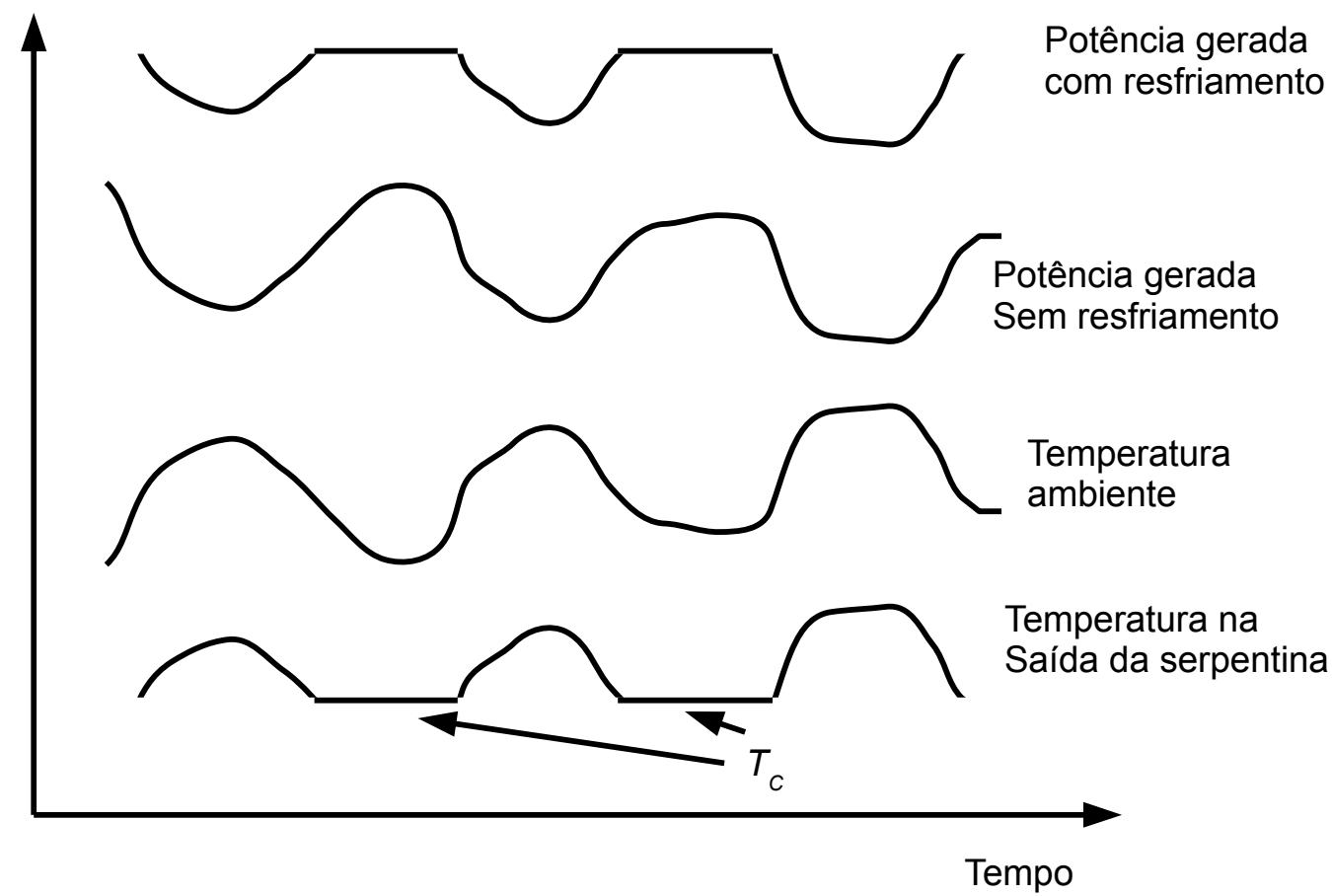

Figura 43: Efeito do resfriamento por ciclo térmico, CTC, do ar de entrada de turbina a gás quando o resfriamento não tem capacidade suficiente para regular a temperatura do ar.

jada em função das variáveis climáticas do local sobre os ganhos de energia obtidos com o CTC.

A discussão acima vale tanto para o CTC como o CTA. A diferença entre os dois sistemas do ponto de vista do balanço de energia é o fato da maior fonte de energia ser térmica no caso do CTA, enquanto que no CTC com chiller com motor elétrico a energia consumida é elétrica. Em termos de eficiência os dois sistemas são equivalentes (CHACARTEGUI et al., 2008). O CTC tem custo de instalação e manutenção menor que o CTA e implica em intervenção menor na turbina (CHACARTEGUI et al., 2008). (O CTA necessita da instalação de um trocador de calor na descarga da turbina.) Tendo em vista estes aspectos modelamos o CTC como representativo dos sistemas de resfriamento com ciclo térmico neste estudo.

O modelo do resfriamento CTC tem duas entradas: a temperatura desejada de resfriamento do ar de entrada, $T_{C}$, e a capacidade de resfriamento de projeto do 
CTC, $\dot{Q}_{\text {resfp. }}$. Quando simula o caso em que o CTC tem capacidade para regular a temperatura do ar não importando as condições ambientes, $\dot{Q}_{r e s f p}$ é fixado com um valor muito alto, por exemplo, igual à potência ISO da turbina. Nesta condição o modelo calcula a capacidade de resfriamento instantânea necessária, $\dot{Q}_{\text {resf }}$, para resfriar o ar até a temperatura desejada qualquer que seja a condição ambiente e os ganhos de energia, $E G_{a n}$ e $E G_{a n r}$, para a temperatura desejada, $T_{C}$. O valor máximo de $\dot{Q}_{\text {resf }}$ é a capacidade de resfriamento de recomendada para o dimensionamento do resfriamento CTC se desejarmos que este seja capaz de manter a temperatura $T_{C}$ em qualquer circunstância.

Quando a capacidade de resfriamento de projeto, $\dot{Q}_{\text {resfp }}$, tem um valor fixado abaixo da capacidade necessária para manter a temperatura desejada, $T_{C}$, as informações de interesse na saída do modelo são os ganhos de energia, $E G_{a n}$ e $E G_{a n r}$, que neste caso são funções também de $\dot{Q}_{r e s f p}$.

$\dot{Q}_{\text {resf }}$ é equivalente à diferença de entalpia no ar que atravessa a serpentina. (Repetimos aqui o diagrama psicrométrico do processo de resfriamento para facilitar o entendimento (figura 44).)

$$
\dot{Q}_{r e s f}=\dot{m}_{a s}\left(h_{t A}-h_{t C}\right)
$$

Onde (DOSSAT, 1980):

$$
\begin{gathered}
h=h_{a s}+\omega h_{v} \\
h_{a s}=c_{p a} T_{b s} \\
h_{v}=c_{p v} T_{b s}+h_{l v}
\end{gathered}
$$


Onde $c_{p a}$ e $c_{p v}$ tem os valores da entrada do compressor, dados na tabela 5 . O valor de $h_{l v}$ é o mesmo adotado na simulação do EMR, $2430 \mathrm{~kJ} / \mathrm{kg}$.

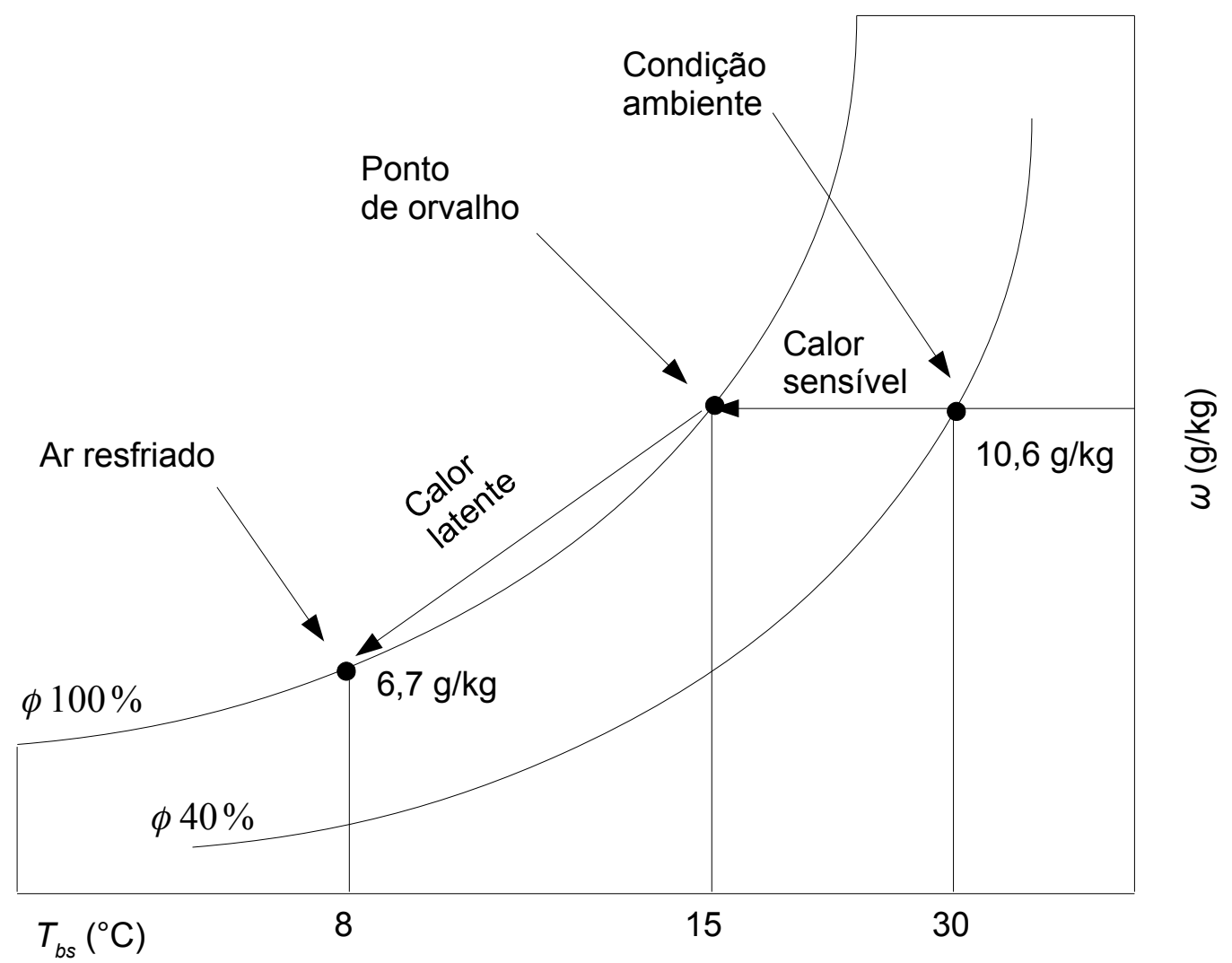

Figura 44: Resfriamento do ar a $30^{\circ} \mathrm{C}$ e $\phi 40 \%$ até a temperatura de $8^{\circ} \mathrm{C}$ representada no diagrama psicrometrico: A - condição ambiente; $\mathrm{O}$ - ponto de orvalho; C - condição desejada.

A simulação compara a temperatura desejada, $T_{C}$, com a temperatura de orvalho do ar ambiente, $T_{O}$. Se $T_{C} \leqslant T_{O}$ o ar é considerado saturado na condição desejada. Se $T_{C}>T_{O}$ a umidade do ar é considerada igual à umidade ambiente na condição desejada, $\omega_{C}=\omega_{A}=\omega_{a t}$. A temperatura de entrada do ar na turbina é considerada igual à temperatura desejada, $T_{C}$. O modelo também avalia qual a capacidade necessária ao chiller para manter a temperatura desejada do ar de entrada, que é o valor máximo de $\dot{Q}_{\text {resf }}$.

No caso em que o CTC tem uma capacidade limitada que não permite manter a temperatura do ar resfriado no valor desejado todo o tempo o modelo calcula a 
condição de saída do ar em função da condição de entrada do ar e da capacidade do sistema de resfriamento.

Em cada instante de simulação o modelo verifica se a capacidade projetada do sistema de resfriamento, $\dot{Q}_{\text {resfp }}$, é suficiente para levar o ar até a temperatura desejada. Se isto se verificar, a carga de resfriamento necessária, $\dot{Q}_{\text {resf }}$, para resfriar o ar até $T_{C}$ é calculada seguindo o procedimento do caso anterior.

Se a capacidade do sistema é insuficiente o modelo verifica tentativamente a condição de saída do ar resolvendo o sistema de equações:

$$
h_{t C}=h_{t A}-\frac{\dot{Q}_{r e s f}}{\dot{m}_{a s}}
$$

e

$$
\omega_{C}=\omega_{A}=\omega_{a t}
$$

Se a resolução deste sistema resultar numa condição em que $T_{C} \geqslant T_{O}$, a condição é aceita como sendo a de saída do sistema. Caso contrário o seguinte sistema é resolvido:

$$
h_{t C}=h_{t A}-\frac{\dot{Q}_{c}}{\dot{m}_{a s}}
$$

$\mathrm{e}$

$$
\phi=100 \%
$$

A temperatura correspondente à condição que satisfaz as equações 4.7 e 4.8 , é a temperatura de saída do sistema. 
O aumento de potência gerada na turbina é a diferença entre as potências geradas com resfriamento, $\dot{W}_{t g C T C}$, e sem resfriamento, $\dot{W}_{t g}$, reduzida da potência gasta pelo sistema de resfriamento, $\dot{W}_{\text {resf }}$ :

$$
\dot{W} G=\dot{W}_{t g C T C}-\dot{W}_{t g}-\dot{W}_{\text {resf }}
$$

A potência consumida pelo sistema de resfriamento é calculada a partir da carga instantânea de resfriamento, $\dot{Q}_{\text {resf }}$, usando um coeficiente de performance, $\beta$, com valor 4,0 (CHACARTEGUI et al., 2008).

$$
\dot{W}_{\text {resf }}=\dot{Q}_{\text {resf }} / \beta
$$

Os valores de $\dot{W} G$ são calculados a cada hora do ano típico, TMY ou TRY, então o ganho de energia, $E G_{a n}$ pode ser definido por:

$$
E G_{a n}=\sum_{t=1}^{8} 760 \dot{W G}(t)
$$

O ganho relativo de energia em um ano, $E G_{a n r}$, é:

$$
E G_{a n r}=\frac{E G_{a n}}{\sum_{t=1}^{8} 760 \dot{W}_{t g}(t)}
$$

O CTC consome água na torre de resfriamento do sistema. Considerando $\beta=4,0$, a vazão evaporada na torre é (DOSSAT, 1980):

$$
\dot{m}_{a v}=0,553 \dot{Q}_{r e s f}
$$

Onde $\dot{m}_{e v}$ é dado em $\mathrm{kg} / \mathrm{s}$ e a carga de resfriamento no CTC, $\dot{Q}_{r e s f}$, em MW. Assumindo o diferencial de temperatura entre a água que entra e a que sai 
da torre como sendo $5^{\circ} \mathrm{C}$ a vazão de água circulando entre a torre e o chiller é (DOSSAT, 1980):

$$
\dot{m}_{\text {circ }}=59,7 \dot{Q}_{\text {resf }}
$$

Sendo $\dot{m}_{\text {circ }}$ dado em kg/s e $\dot{Q}_{\text {resf }}$, em MW.

A perda de água por névoa na torre $\dot{m}_{n}$ é $0,25 \%$ de $\dot{m}_{\text {circ }}$ (ASHNER, 1977) e a perda de água por drenagem, $\dot{m}_{d}$ para o diferencial de $5^{\circ} \mathrm{C}$ entre a entrada e saída de água $0,33 \%$ de $\dot{m}_{\text {circ }}$ (DOSSAT, 1980).

Água é recuperada por condensação do vapor no ar de entrada da turbina. A vazão de água condensada é dada por:

$$
\dot{m}_{\text {cond }}=\dot{m}_{a s}\left(\omega_{C}-\omega_{A}\right)
$$

O balanço de água no CTC fornece a quantidade de água de alimentação consumida no sistema, $\dot{m}_{\text {alim }}$ :

$$
\dot{m}_{a l i m}=\dot{m}_{a v}+\dot{m}_{n}+\dot{m}_{d}-\dot{m}_{\text {cond }}
$$

Como os valores de $\dot{m}_{\text {alim }}$ são calculados para cada hora do ano climático típico, TMY ou TRY, o volume de água consumido em um ano, $V A C_{a n}$, é dado por:

$$
V A C_{a n}=8760 \dot{m}_{a l i m}
$$




\subsection{Simulação do resfriamento por do ciclo de compressão}

A tabela 4.3 mostra os resultados da simulação do resfriamento CTC com $T_{C}=10{ }^{\circ} \mathrm{C}$ e $\dot{Q}_{\text {resfp }}=100 \mathrm{MW}$ para 27 localidades brasileiras. A temperatura de $10^{\circ} \mathrm{C}$ foi escolhida por estar abaixo das temperaturas médias de bulbo seco no Brasil e acima, com margem de segurança, do limite mínimo de temperatura onde há risco de formação de gêlo no compressor, $7^{\circ} \mathrm{C}$. A tabela inclui dados climáticos e geográficos das localidades: faixa de altitude, $F A$; temperatura média anual de bulbo seco, $T_{b s m}$; temperatura média anual de bulbo úmido, $T_{b u m}$. $\mathrm{O}$ resultados da simulação apresentados são: ganho de energia anual, $E G_{a n}$; ganho de energia anual relativo, $E G_{a n r}$; capacidade requerida pelo chiller para resfriar o ar até a temperatura desejada, $10^{\circ} \mathrm{C}$, quaisquer que sejam as condições ambientes, $\dot{Q}_{\text {resfR }}$; volume de água consumido anualmente na torre de resfriamento, $V A C_{a n}$.

Os ganhos de energia com o resfriamento CTC vão de 3,62 a 11,20 \% em termos de $E G_{a n r}$ e de 48 a 133 GWh em termos de $E G_{a n}$. A figura 45 mosta $E G_{a n}$ em função de $T_{b s m}$ para $T_{C}=10^{\circ} \mathrm{C}$ a partir de dados da tabela 4.3. É observada a dependência quase linear do ganho de energia anual em função da temperatura média de bulbo seco do local. Há uma pequena redução no ganho de energia para altutides na faixa de $1000 \mathrm{~m}$. O ganhos anuais de energia com o resfriamento CTC para $T_{C}$, tabela 4.3, são maiores que os obtidos com o EMR, tabela 6. Isto se deve ao fato de que o resfriamento CTC não está limitado pela temperatura de bulbo úmido do ar ambiente.

A capacidade do chiller para resfriar o ar até $10^{\circ} \mathrm{C}, \dot{Q}_{r e s f R}$, é calculada nesta simulação para cada localidade variando de 17,6 a 39,2 MW de refrigeração.

A tabela 4.3 apresenta o consumo anual de água na torre para resfriar o ar até $10^{\circ} \mathrm{C}$. O volume da água consumida é muito maior que consumido no resfriamento evaporativo, acompanhando o aumento de carga de resfriamento. 


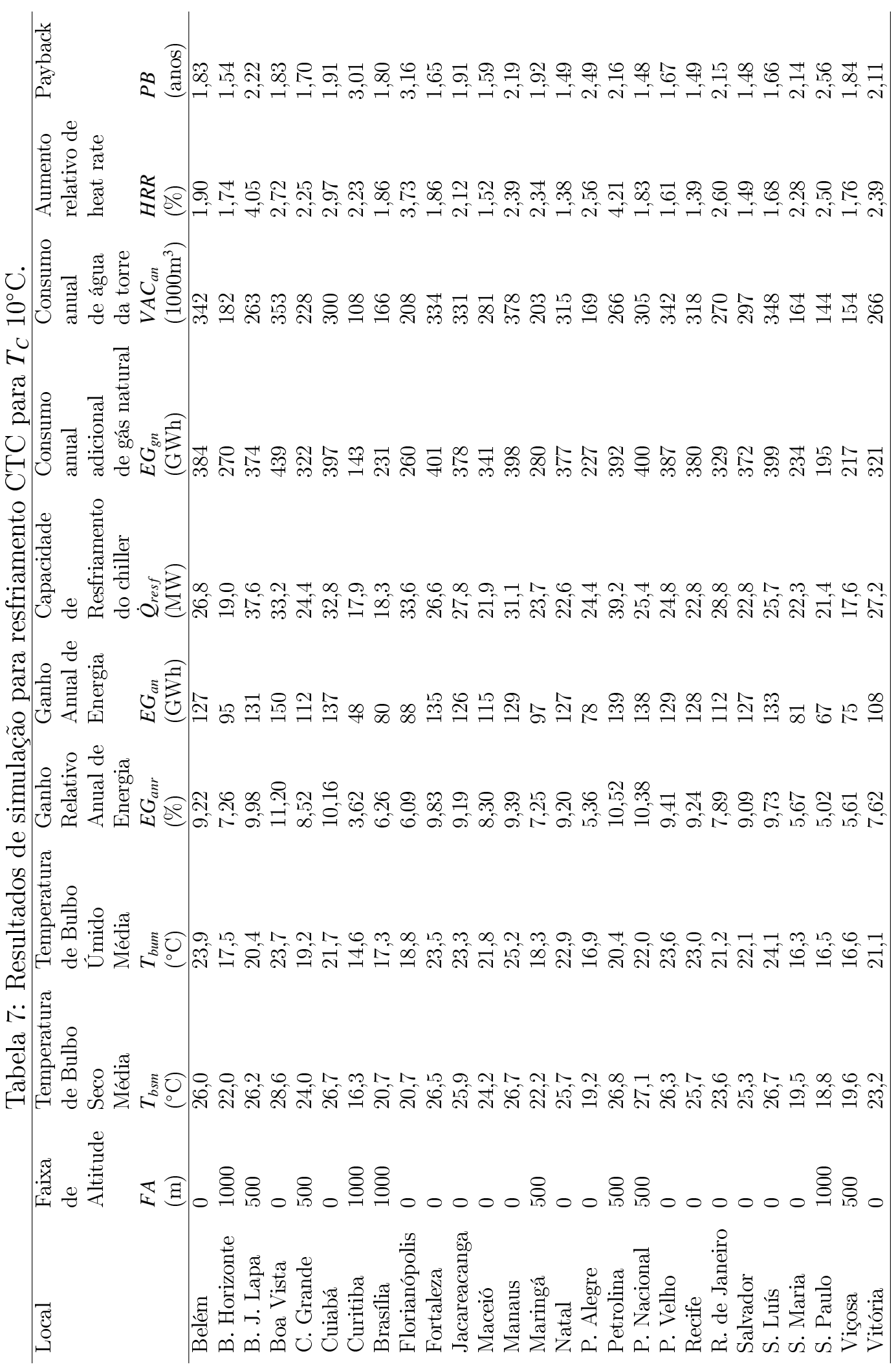




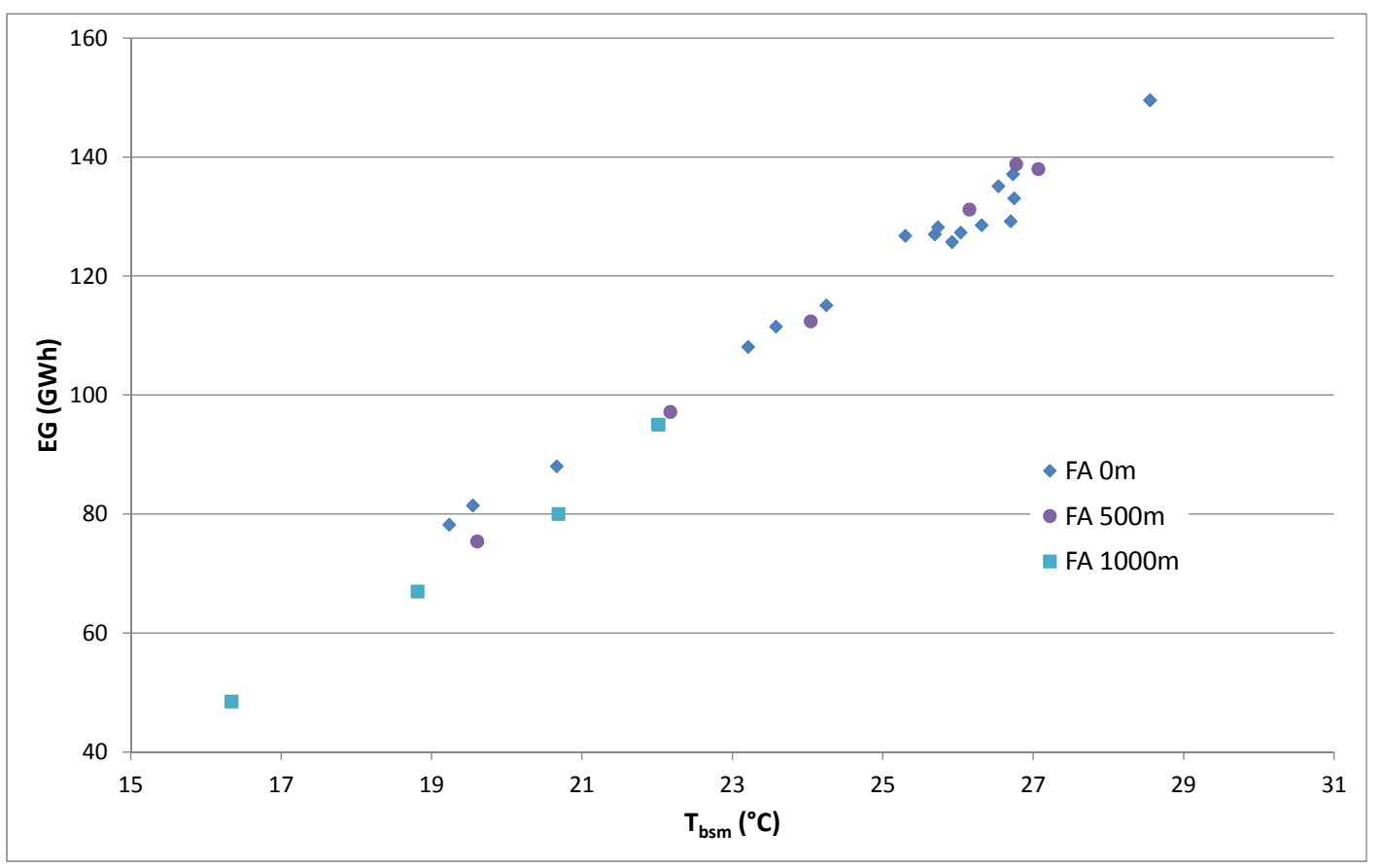

Figura 45: Ganho anual de energia em GWh, $E G_{a n}$, para uma turbina GE 7FA em função da temperatura de bulbo seco média anual, $T_{b s m}$, e da faixa de altitute, $F A$, para 27 locais no Brasil.

O efeito da temperatura desejada de resfriamento, $T_{C}$, no ganho de energia relativo, $E G_{a n r}$, em função de $T_{b s m}$ é mostrada na figura 46 . Conforme esperado o ganho de energia diminui com o aumento de $T_{C}$. Para $T_{C}=25^{\circ} \mathrm{C}$ há redução da energia gerada nas localidades com $T_{b s m}$ menor. Nestes casos o sistema de resfriamento permanece inativo por grande período, mas a perda de carga adicionada pela serpentina de resfriamento na entrada da turbina reduz permanentemente a potência gerada.

Os valores de capacidade de refrigeração requerida, $\dot{Q}_{\text {resfR }}$, mostrados na tabela 4.3 são os necessários para resfriar o ar até $10^{\circ} \mathrm{C}$ inclusive nos picos de temperatura ambiente. Estas capacidades são superdimensionadas pois estes picos são atingidos com pouca frequência . Para determinar a capacidade de resfriamento requerida adequada para cada localidade simulamos o CTC com diferentes capacidades de resfriamento de projeto, $\dot{Q}_{\text {resfp }}$, e temperatura desejada, $T_{C}$, de $10^{\circ} \mathrm{C}$ na saída do sistema. Os resultados desta simulação são apresentados na 


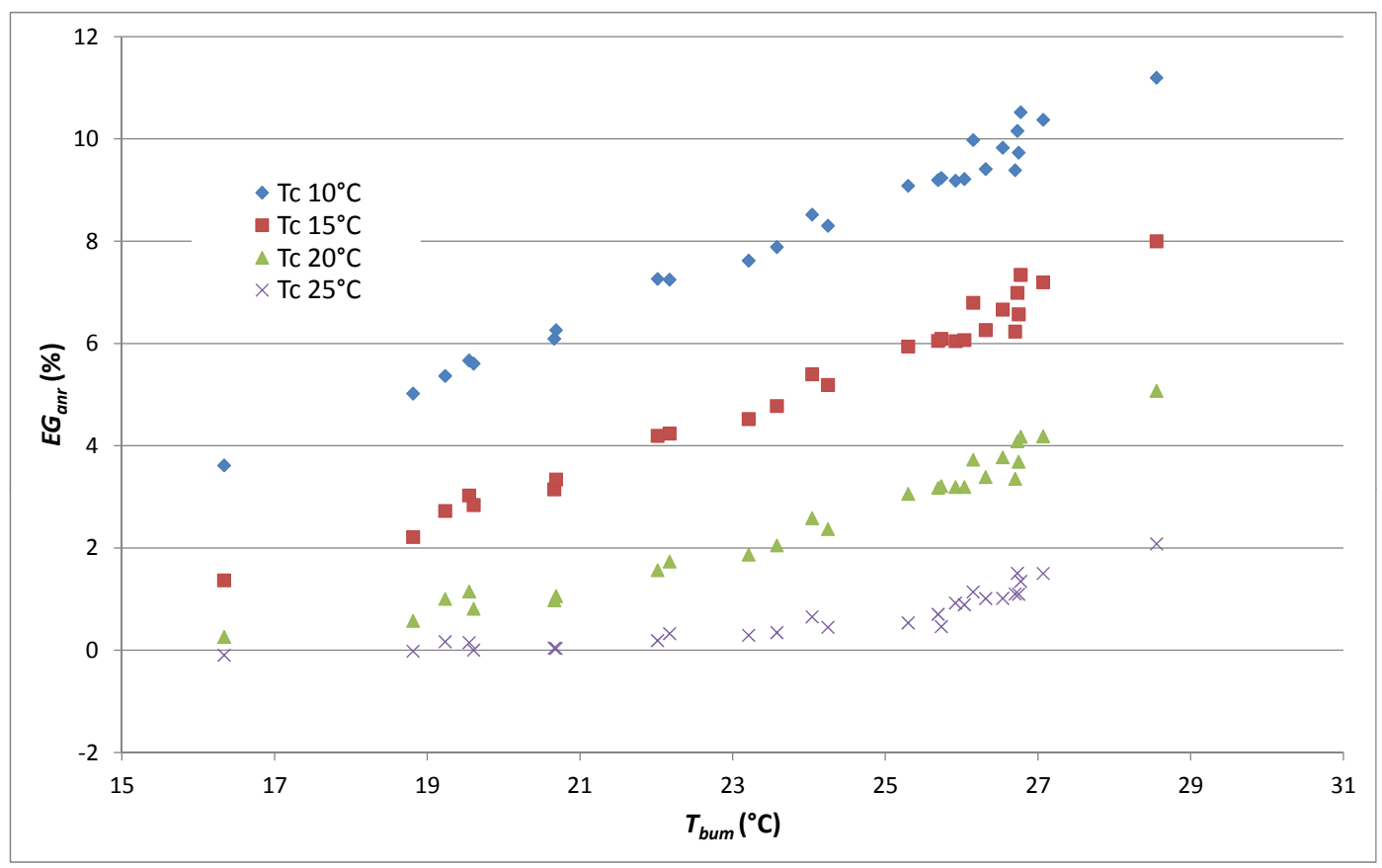

Figura 46: Ganho anual de energia , $E G_{a n r}$, em função de $T_{b s m}$ para diferentes valores de $T_{C}$.

tabela 8. O parâmetro de avaliação dos resultados é a fração de ganho de energia expressa em percentagem, $F E G$, definida como sendo o ganho de anual de energia, $E G_{a n}$, obtido com a capacidade resfriamento, $\dot{Q}_{r e s f p}$, dada no topo da tabela 8 dividido pelo ganho de energia quando o sistema de resfriamento é capaz de manter a temperatura desejada, $T_{C}$, na entrada da turbina qualquer a condição do ar ambiente, mostrado na tabela 4.3.

O gráfico de $F E G$ em função de $\dot{Q}_{r e s f p}$ para quatro locais diferentes é apresentado na figura 47. FEG atinge $100 \%$, isto é o ganho de energia atinge seu valor máximo para capacidades de resfriamento da ordem de 20 MW. Esta capacidade chega a estar mais de $50 \%$ abaixo da capacidade de resfriamento calculada na tabela 4.3 no caso de Petrolina.

A figura 48 mostra $E G_{a n}$ como função de $\dot{Q}_{\text {resfp }}$ para três locais indicados juntamente com as suas temperaturas médias de bulbo úmido, $T_{b u m}$. Nesta figura pode ser observada a tendência de aumento do valor de $\dot{Q}_{\text {resfp }}$ que faz com que 


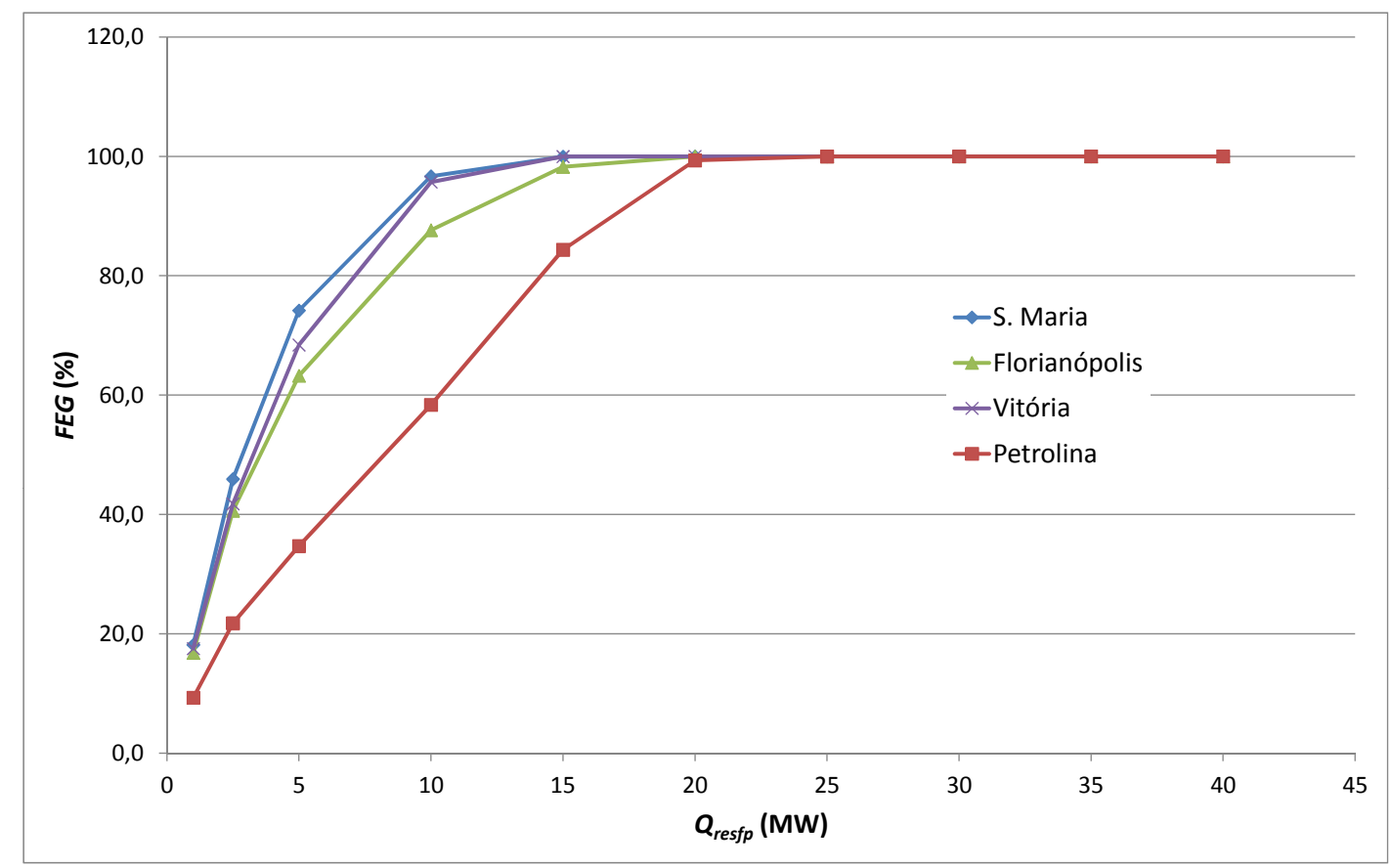

Figura 47: Fração de ganho de energia, FEG, em função da capacidade de resfriamento de projeto, $\dot{Q}_{\text {resfp }}$, em quatro locais diferentes do Brasil.

$E G_{a n}$ atinja o seu valor máximo com o aumento de $T_{b u m}$. A explicação desta dependência é o fato da carga de resfriamento aumentar conforme aumenta a quantidade de vapor do ar que deve ser condensado para atingir a temperatura desejada, $T_{C}$.

A figura 49 mostra a fração de ganho de energia, $F E G$, com $T_{C}=10^{\circ} \mathrm{C}$ para diferentes capacidades de resfriamento, $Q_{\text {resfp }}$, em função da temperatura de bulbo úmido média, $T_{\text {bum }}$. A redução de $F E G$ com o aumento de $T_{b u m}$ vem do fato de que carga de resfriamento está concentrada no resfriamento que ocorre quando a temperatura é reduzida do ponto de orvalho "O" até o ponto "C" na figura 44. Quanto mais próxima a temperatura de orvalho $T_{O}$ da temperatura desejada $T_{C}$, menor a carga de resfriamento. A temperatura de bulbo úmido no caso serve de estimativa da temperatura de orvalho. A figura 50 mostra a redução de temperatura em função da capacidade de resfriamento, $Q_{\text {resf } p}$, para o ar com temperaturas de bulbo úmido 23,81 e $27,08^{\circ} \mathrm{C}$ com uma temperatura de bulbo 
seco fixa de $30^{\circ} \mathrm{C}$ e $T_{C}=10^{\circ} \mathrm{C}$. O aumento de redução de temperatura com a capacidade de resfriamento apresenta uma taxa maior até atingir o ponto de orvalho, porção mais inclinada das curvas. A partir deste ponto a redução de temperatura demanda um aumento maior de capacidade de resfriamento.

É possível dimensionar a capacidade do chiller do CTC em função fração de de ganho de energia, FEG, desejada para um determinado local e temperatura de resfriamento desejados, $T_{C}$.

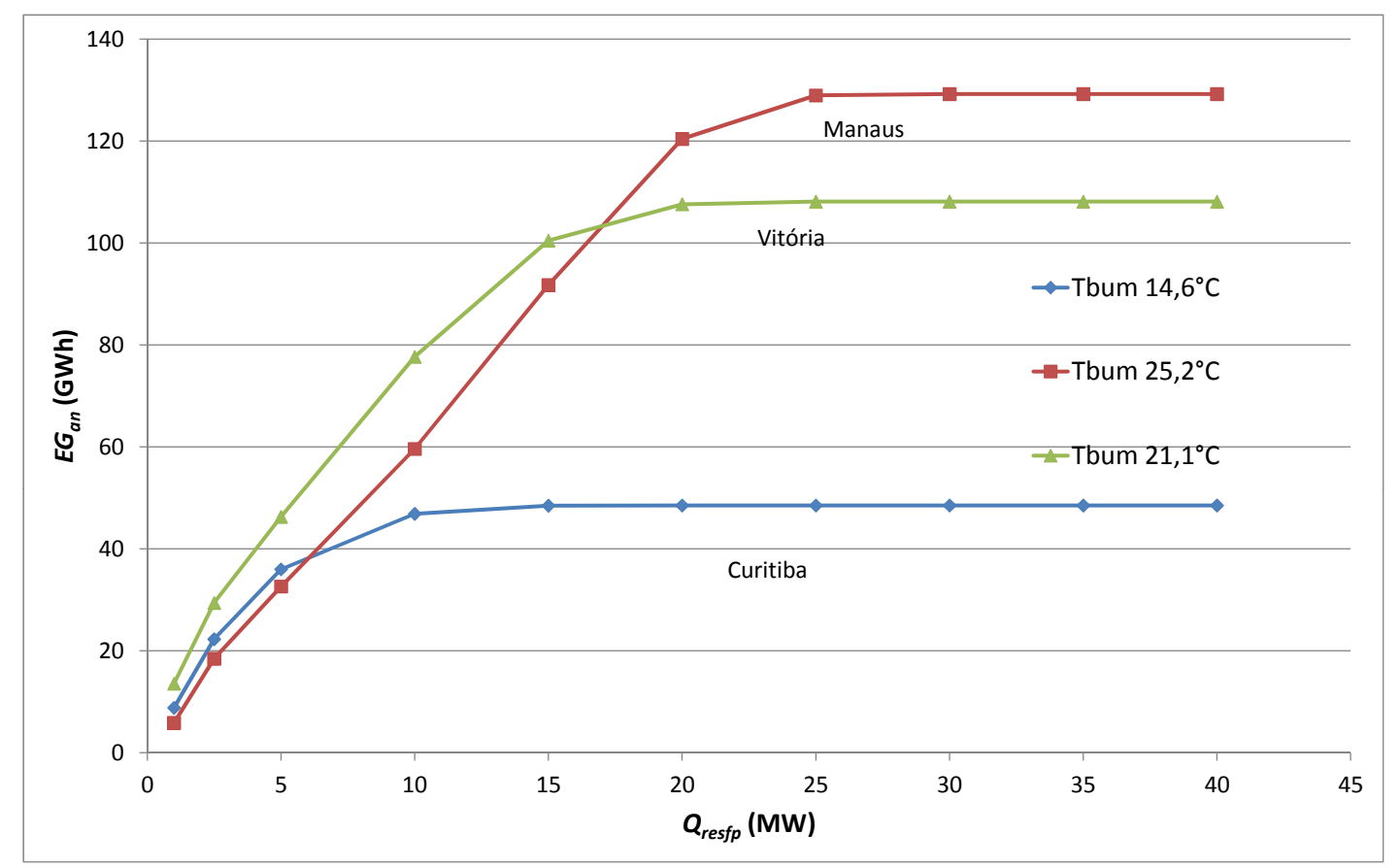

Figura 48: Ganho anual de energia, $E G_{a n}$, em função da capacidade de resfriamento de projeto, $\dot{Q}_{\text {resfp }}$, em três locais diferentes do Brasil com $T_{b u m}$ indicado.

A tabela 4.3 apresenta também as variações relativas do heat rate da turbina, $H R R$, com a aplicação do CTC. Em todos os locais de aplicação há uma perda de eficiência da turbina, com heat rates aumentando até 4,2\%. Não conseguimos relacionar este aumento do heat rate com o clima do local de instalação do CTC, embora os lugares com maiores temperaturas de bulbo seco médias, $T_{b s m}$, apresentem as maiores perdas de eficiência. 


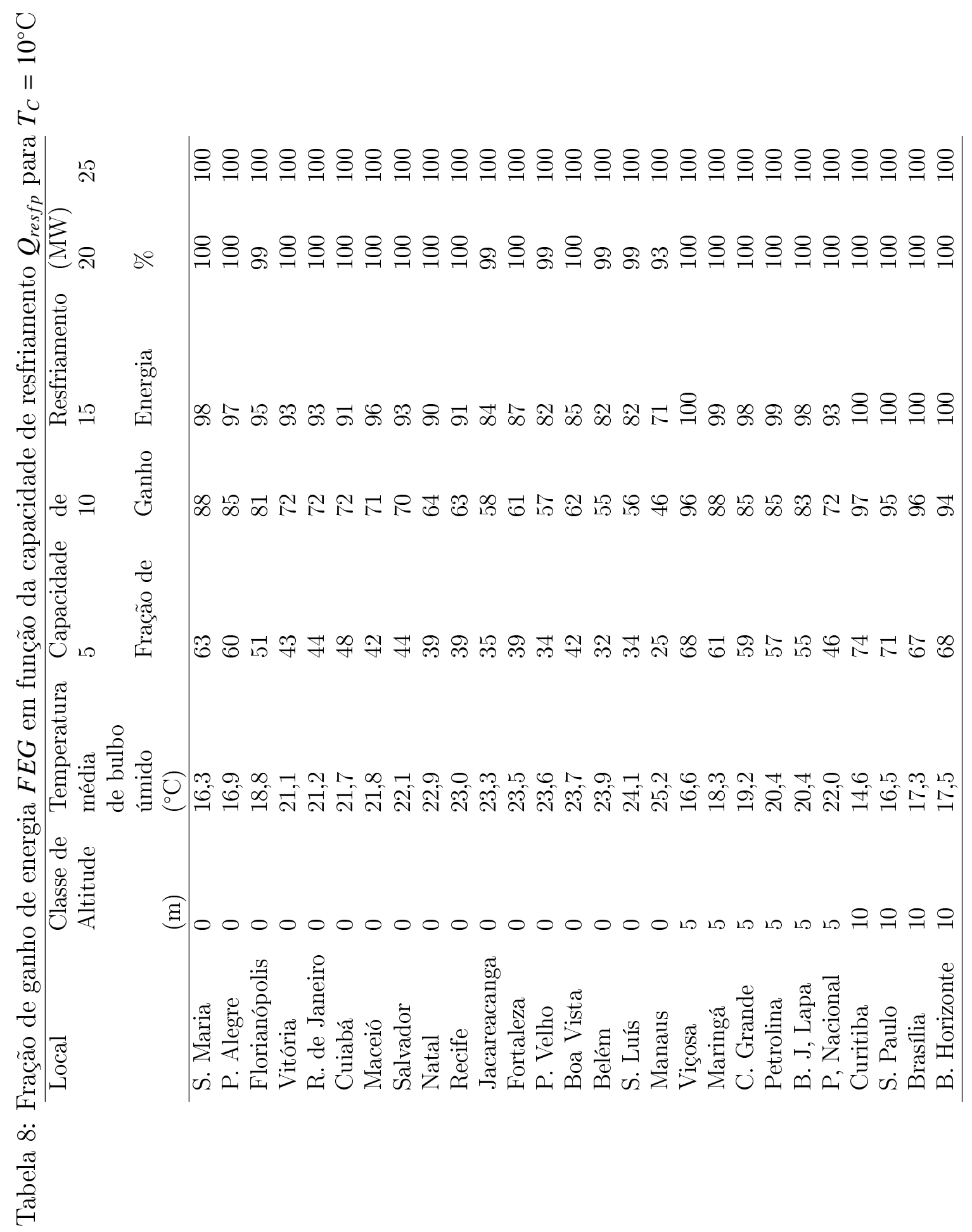




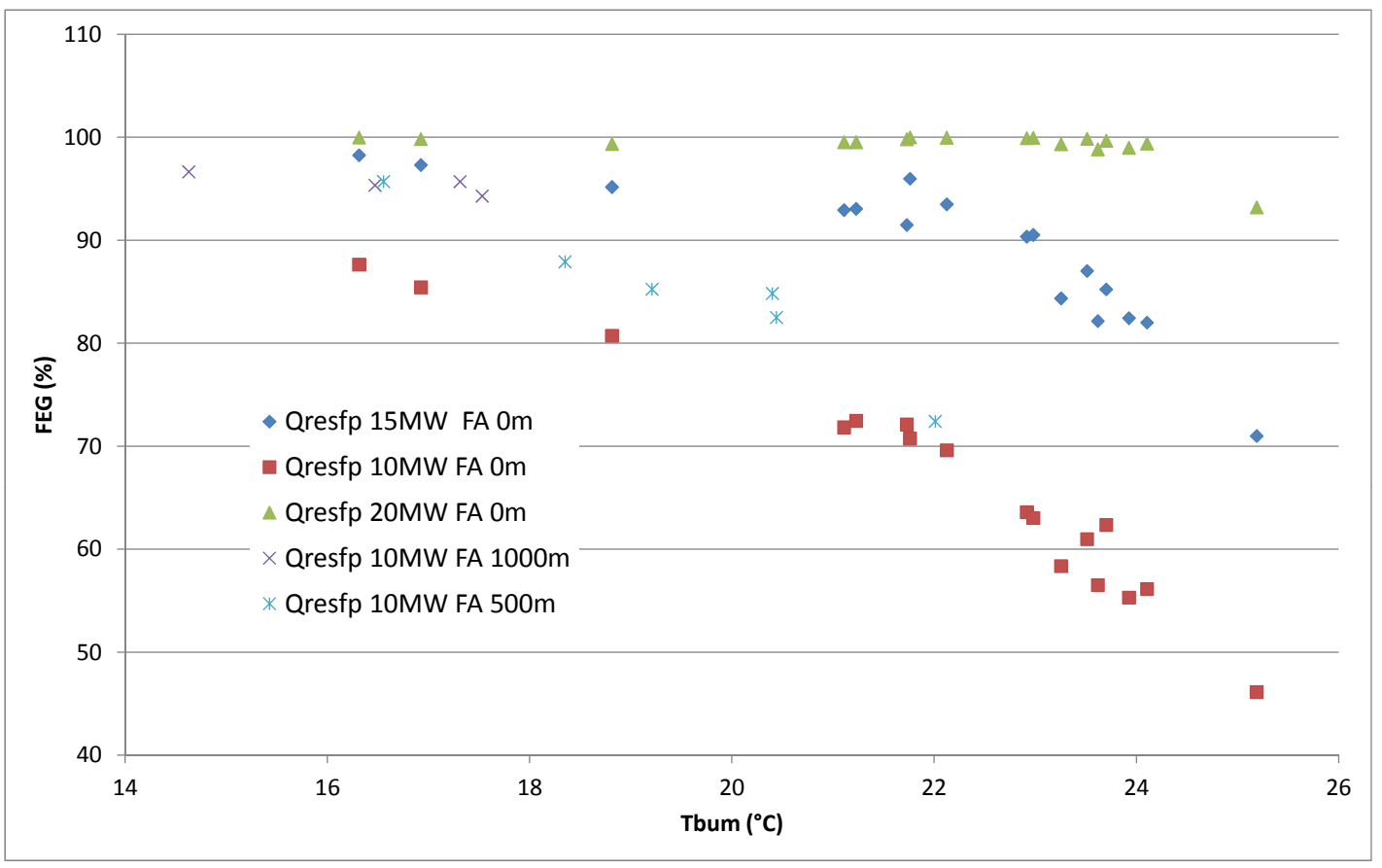

Figura 49: Fração de ganho de energia, $F E G$, em função da temperatura de bulbo úmido média, $T_{\text {bum }}$, para diferentes capacidades de resfriamento, $\dot{Q}_{\text {resfp }}$, e diferentes faixas de altitude, $F A$.

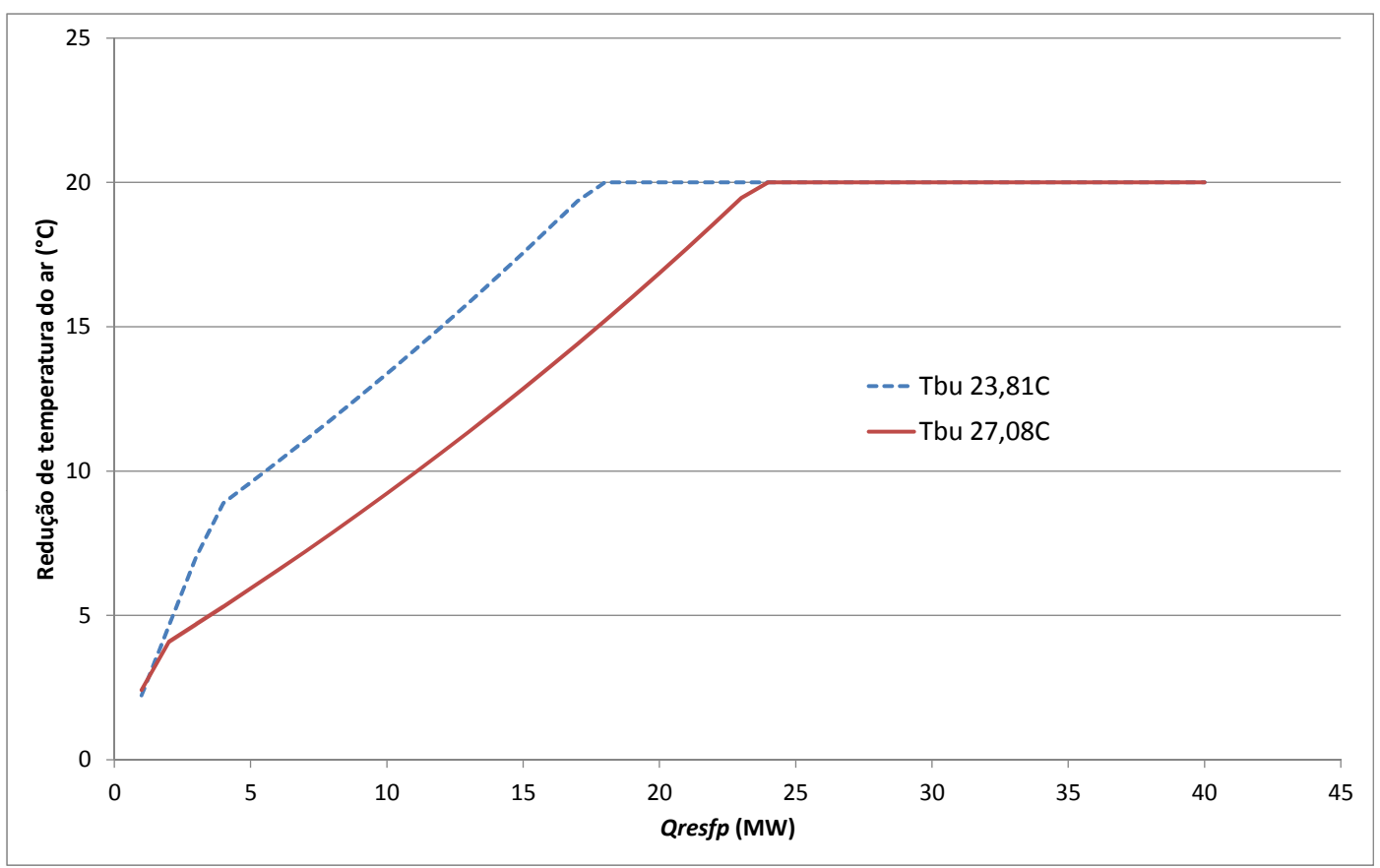

Figura 50: Redução de temperatura do ar em função da capacidade de resfriamento $\dot{Q}_{\text {resfp }}$ a partir de temperatura de bulbo seco $30^{\circ} \mathrm{C}$ e temperaturas de bulbo úmido $23,8^{\circ} \mathrm{C}$ e $27,08^{\circ} \mathrm{C}$ a $101,3 \mathrm{kPa}$. 


\subsection{Análise Econômica do Resfriamento CTC}

A análise economica do resfriamento CTC é feita pelo método do payback simples, seguindo o mesmo procedimento da seção 3.5. A receita líquida, $R L$, é calculada pela equação 3.39 .

O custo de investimento do CTC é dado pelo custo do chiller, $\mathrm{CCH}$. Este custo é calculado a partir do custo específico do chiller, $C E C H$, que é apresentado na referência (CHACARTEGUI et al., 2008). O custo apresentado é $870 €$ /tonelada de refrigeração.em valor de fevereiro de 2008. Este valor foi convertido em dólares americanos usando (Banco Central do Brasil, 2012), atualizado pelo (United States Department of Labor, 2012) para o valor em 2012 e foi adicionada a carga tributária brasileira de 13,68\%, resultando em $C E C H=440.985,00 \mathrm{U} \$ / \mathrm{MW}$ de refrigeração. A equação que determina $C C H$ é:

$$
C C H=C E C H \dot{Q}_{r e s f p}
$$

A figura 51 mostra que tanto a receita de energia como os custos de gás e água e, consequentemente, a receita líquida, têm uma relação linear com a temperatura média de bulbo seco do local, $T_{b s m}$. O custo do chiller, $C C H$, não apresenta a mesma correlação, embora tenda a aumentar com $T_{b s m}$.

Os tempos do payback do resfriamento CTC, calculados de acordo com a equação 3.40, são apresentados na tabela, para resfriamento do ar até $T_{C}=$ $10^{\circ} \mathrm{C}$. Os tempos vão até em torno de 3 anos, indicando viabilidade econômica da instalação do CTC, uma vez que a vida útil do sistema pode chegar a mais e 20 anos. 


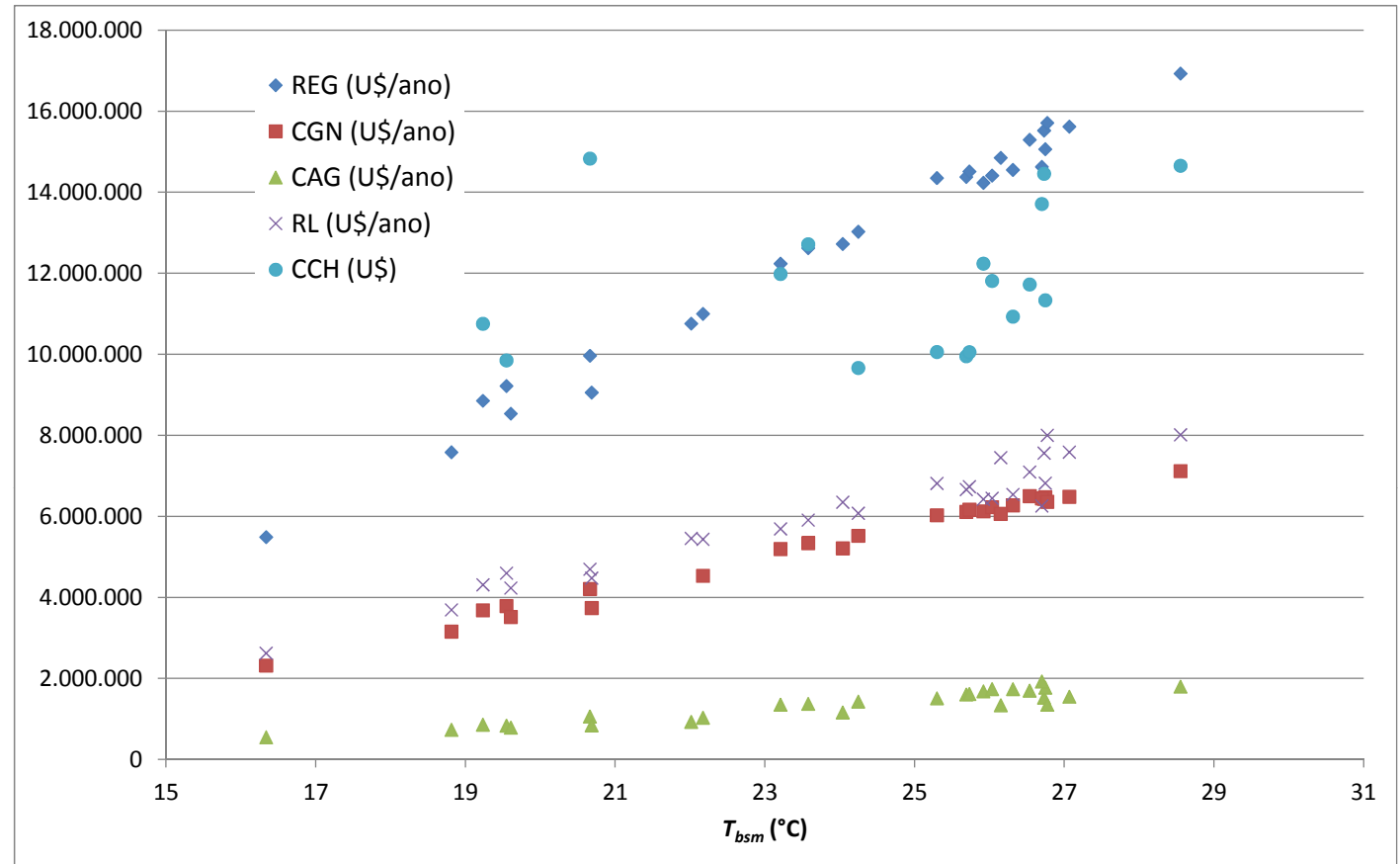

Figura 51: RL, CCH,CAG, REG e $C G N$ em função de $T_{b s m}$ 


\section{CONCLUSÕES}

Um modelo para simular a resposta de uma turbina a gás a variações nas condições do ar atmosférico foi desenvolvido. Este modelo necessita somente dos parâmetros de catálogo das turbinas e apresenta boa aderência às curvas de condição do ar de entrada publicadas. O modelo pode servir para estudos preliminares na implantação de turbinas a gás e sistemas de resfriamento de ar de entrada em território brasileiro.

Modelos dos sistemas de resfriamento EMR e por ciclo térmico CTC foram também desenvolvidos e podem ser empregados nestes estudos preliminares de viabilidade.

Um estudo do ganho de energia gerado por ano dos sistemas evaporativos mostrou que é possível aumentar a geração de turbinas a gás de 1 a $4 \%$ aplicando este tipo de resfriamento. As localidades de clima mais seco, conforme esperado, apresentam maior ganho de energia gerada. O consumo de água pelo sistema de resfriamento chega até $65.000 \mathrm{~m}^{3}$ por ano, para o local onde há também o maior ganho de energia. Foi verificada uma dependência direta entre a depressão de bulbo úmido média anual e o ganho de energia do resfriamento EMR. A eficiência das turbinas varia muito pouco com a aplicação do EMR.

O estudo do ganho de energia do resfriamento por ciclo térmico de compressão, CTC, foi conduzido também. Quando a temperatura de resfriamento escolhida é $10^{\circ} \mathrm{C}$ os ganhos de energia vão de $3,6 \%$ a $11,2 \%$. Correspondentemente a 
um aumento de consumo de água devido ao aumento na carga de resfriamento em relação ao sistema evaporativo, chegando até $353.000 \mathrm{~m}^{3}$ por ano. Foi verificada a dependência linear do ganho de energia com a temperatura média de bulbo seco do local de instalação, explicada pela relação linear do aumento de potência na turbina com a redução de temperatura do ar de entrada. Já a carga de resfriamento do CTC para atingir uma determinada temperatura de ar de entrada é função da temperatura de bulbo úmido média do local. A carga de resfriamento também é levemente reduzida para altitudes maiores o mesmo ocorrendo para o ganho de energia. Há perda de eficiência da turbina pela aplicação do CTC em todos os locais. Nos locais com maiores temperaturas o "heat rate" chega a aumentar até $4,2 \%$.

Uma análise econômica indicou que tanto o resfriamento evaporativo como o por ciclo térmico de compressão são viáveis no Brasil. O resfriamento EMR tem um tempo menor de payback, 0,34 a 1,8 anos, enquanto que o resfriamento CTC, 1,48 a 3,16 anos. A escolha entre os dois sistemas repousa no ganho de energia que se deseja obter da turbina.

\subsection{Trabalhos futuros}

Devido ao papel complementar das termelétricas no parque gerador brasileiro, as turbinas a gás das plantas podem passar longos períodos desligadas. Uma complementação ao estudo do potencial dos sistemas de resfriamento de ar incluiria uma verificação dos ganhos de energia com o funcionamento esporádico das turbinas, usando históricos de despacho das termelétricas.

Os sistemas de resfriamento estudados podem ser implementados em menos de um ano e com custos por $\mathrm{kW}$ instalado menores que o custo do $\mathrm{kW}$ instalado de uma nova turbina a gás. O ganho de energia derivado destes sistemas pode ser 
incorporado à capacidade de geração do sistema elétrico também neste período. As questões sugeridas com base nestas considerações são:

- Qual seria o impacto de incluir o ganho de energia dos sistemas de resfriamento nos leilões de ajuste para o fornecimento de energia elétrica?

- Como regulamentar a oferta deste tipo de energia, visto que ao contrário da energia normalmente fornecida pelas termelétricas que independe de condições climáticas, este ganho de energia depende fortemente do clima? 


\section{REFERENCIAS}

Empresa de Pesquisa Energética. Informe Técnico - EPE-DEE-IT-027/2012

- Leilão A-5 de 2012 de Compra de Energia Elétrica Proveniente de Novos Empreendimentos de Geração - Preços dos Combustíveis para Cálculo do CVU de Usinas Termelétricas a Gás Natural. 2012. Disponível em: http://www.epe.gov.br. Acesso em: 10 de junho de 2012.

Agência Nacional de Energia Elétrica. Atlas de energia elétrica do Brasil / Agência Nacional de Energia Elétrica. 3. ed. - Brasília : Aneel, 2008. 2008. Disponível em: http://www . aneel.gov.br/visualizar_texto.cfm?idtxt=1689 . Acesso em: 5 de outubro de 2011.

AL-IBRAHIM, A. M.; VARNHAM, A. A review of inlet air-cooling technologies for enhancing the performance of combustion turbines in saudi arabia. Applied Thermal Engineering, v. 30, p. 1879-1888, 2010.

ASHNER, F. S. Planning Fundamentals of Thermal Power Plants. New York USA: John Wiley \& Sons, Inc., 1977.

BADEER, G. H. GE aeroderivative gas turbines - design and operating features. 2000. GE eprint Archive, Report GER-3695E. Disponível em: http: //site.ge-energy.com/prod_serv/products/tech_docs/en/all_gers.htm . Acesso em: 20 de dezembro de 2011.

Banco Central do Brasil. Taxas de Câmbio - Conversão de Moedas. 2012. Disponível em: http://www.bcb.gov.br/ . Acesso em: 10 de junho de 2012.

BOONNASA, S.; NAMPRAKAI, P. Sensitivity analysis for the capacity improvement of a combined cycle power plant (100-600 mw). Applied Thermal Engineering, v. 28, p. 1865-1874, 2008.

BROOKS, F. G. GE gas Turbine Performance Characteristics. 2000. GE eprint Archive, Report GER-3567H. Disponível em: http://site.ge-energy.com/ prod_serv/products/tech_docs/en/all_gers.htm . Acesso em: 11 de novembro de 2011.

BUCK, A. L. New equations for computing vapor pressure and enhancement factor. Journal of Applied Metereology, v. 20, p. 1527-1532, 1981.

CARVAlHO, H. M. de. Desenvolvimento de um modelo matemático para avaliação de desmpenho de turbinas a gás de um eixo. Tese (Mestrado) Universidade Federal de Itajubá - Instituto de Engenharia Mecânica, 2006. 
CASTRO, W. P. de; PIMENTA, J. M. D. Modelagem e simulação de painéis evaporativos diretos. In: Proceedings of 10th Brazilian Congress of Thermal Sciences and Engineering - ENCIT 2004. Rio de Janeiro, BR: [s.n.], 29 Novembro 3 Dezembro 2004.

CHACARTEGUI, R. et al. Analysis of combustion turbine inlet air cooling systems applied to an operating cogeneration power plant. Energy Conversion and Management, v. 49, p. 2130-2141, 2008.

CHAKER, M.; MEHER-HOMJI, C. B. Inlet fogging of gas turbine engines: Climatic analysis of gas turbine evaporative cooling potential of international locations. Transactions of the ASME: Journal of Engineering of Gas Turbines and Power, v. 128, p. 815-825, 2006.

CHAKER, M. et al. Inlet fogging of gas turbine engines - detailed climatic analysis of gas turbine evaporation cooling potential in the USA. Transactions of the ASME: Journal of Engineering of Gas Turbines and Power, v. 125, p. 300-309, 2003.

Câmara de Comercialização da Energia Elétrica . Visão geral das operações na CCEE. 2011. Disponível em: http://www.ccee.org.br/StaticFile/ Arquivo/biblioteca_virtual/Treinamento/Visao_Geral_Operacoes_ CCEE_final.pdf . Acesso em: 15 de outubro de 2011.

CSANADY, G. T. Theory of Turbomachines. New York USA: McGraw-Hill, 1964 .

Donaldson Europe. Evaporative cooler for gas turbine combustion air cooling. 2011. Disponível em: http://www .emea.donaldson.com/en/gasturbine/ support/datalibrary/033682 .pdf . Acesso em: 14 de dezembro de 2011.

DOSSAT, R. J. Principles of Refrigeration - Second Edition - SI Version. New York USA: John Wiley \& Sons, Inc., 1980.

DRBAL, L. F.; WESTRA, K. Power Plant Engineering by Black \& Veatch. New York, USA: Springer Science+Business Media Inc., 1996.

FARZANEH-GORD, M.; DEYMI-DASHTEBAYAZ, M. Effect of various inlet air cooling methods on gas turbine performance. Energy, v. 36, p. 1196-1205, 2011.

FERRAZ, A. C. P. C.; GOMES, E.; PEREZ, J. M. G. T.; XAVIER, M. B.; BARCELLOS, W. J. Otimização do sistema de compressão de gás natural da UTE Nova Piratininga - Relatório apresentado à comissão de transferência e aceitação dos sistemas operacionais da UTE Nova Piratininga, em 09/02/2006. 2006. Relatório Interno Petrobras.

FLACK, R. Component matching analysis for a power generation gas turbine - classroom applications. In: Proceedings of ASME TURBO EXPO 2002.

Amsterdam, NL: ASME, 3-6 Junho 2002. 
GARETA, R.; ROMEO, L. M.; GIL, A. Methodology for the economic evaluation fo gas turbine air cooling systems in combined cycle applications. Energy, v. 29, p. 1805-1818, 2004.

GE Energy. Evaporative cooler. 2008. GE eprint Archive. Disponível em: http://site.ge-energy .com/businesses/ge_oilandgas/en/literature/ en/downloads/evaporativecooler .pdf . Acesso em: 15 de dezembro de 2011.

. Inlet air cooling. 2008. GE eprint Archive. Disponível em: http: //site.ge-energy.com/businesses/ge_oilandgas/en/literature/en/ downloads/inletair_cooling.pdf . Acesso em: 13 de dezembro de 2011.

GUIRARDI, W. Análise da influência das condições do ar atmosférico no desempenho de turbinas a gás com sistemas de resfriamento do ar de entrada. Tese (Mestrado) - Escola de Engenharia Mauá do Instituto de Mauá de Tecnologia, 2008.

ISO. Gas turbines - Procurement - Part 2: Standard reference conditions and ratings ISO 3977-2. [S.1.], 1997.

JABER, Q. M.; JABER, J. O.; KHAWALDAH, M. A. Assessment of power augmentation from gas turbine power plants using different inlet air cooling systems. Jordan Journal of Mechanical and Industrial Engineering, v. 1, n. 1, p. 42186, 2007.

JOHNSON, R. S. The theory and operation of evaporative coolers for industrial gas turbine installations. Journal of engineering for gas turbines and power, v. 111, p. 327-334, 1989.

JOLLY, S. et al. Inlet air cooling for a Frame 7EA based combined cycle power plant. In: Power-Gen International. Dallas, USA: [s.n.], 9-11 Dezembro 1997.

JONES, C.; Jacobs III, J. A. Economic and technical considerations for combinedcycle performance-enhancement options. 2000. GE eprint Archive, Report GER-4200. Disponível em: http://site.ge-energy.com/home/index.htm . Acesso em: 5 de janeiro de 2012 .

KITCHEN, B. J.; EBELING, J. A. Qualifying combustion turbines for inlet air cooling capacity enhancement. In: ASME. International Gas Turbine and Aeroengine Congress and Exposition. Houston, USA: ASME, 5-8 Junho 1995.

KOSTYUK, A.; FROLOV, V. Steam and Gas Turbines. Moscow RU: Mir Publishers, 1988.

KSB. Performance Curves Booklet No A2740/42/44.1P/E/S/6. 2009. Disponível em: www.ksb.com.br . Acesso em: 1 de novembro de 2011.

LABEEE - Laboratório de Eficiência Energética em Edificações. Arquivos climáticos para simulação energética de edificações para 17 cidades brasileiras (.BIN) e algumas cidades americanas (formato TMY2). 2011. Disponível em: http://www. labeee.ufsc.br/. Acesso em: 25 de setembro de 2011. 
LAPINA, R. P. How to use the performance curves to evaluate behavior of centrifugal compressors. Chemical Engineering, v. 89, n. 2, p. 86-93, 1982.

LEE, J. J.; KANG, D. W.; KIM, T. S. Development of a gas turbine performance analysis program and its application. Energy, v. 36, p. 5274-5285, 2011.

LINDEN, S. V. D.; SEARLES, D. E. Inlet conditioning enhances performance of modern combined cycle plants for cost-effective power generation. In: ASME. International Gas Turbine and Aeroengine Congress and Exhibition. Birmingham, UK: ASME, 10-13 Junho 1996.

LUCIA, M. D.; BRONCONI, R.; CARNEVAlE, E. Performance and economic enhancement of cogeneration gas turbines through compressor inlet air cooling. J. Eng. Gas Turbines Power, v. 116, n. 2, p. 360-365, 1994.

MCNEILLY, J. D. Application of evaporative coolers for gas turbine power plants. In: ASME. ASME Turboexpo 2000. Munique, DE, 8-11 Maio 2000.

Mee Industries. Gas turbine inlet air fogging. 2008. Disponível em: www.meefog.com . Acesso em: 17 de dezembro de 2011.

MEHER-HOMJI, C. B.; MEE III, T. R. Inlet fogging of gas turbine engines part a: theory, psychrometrics and fog generation. In: ASME. ASME Turboexpo 2000. Munique, DE, 8-11 Maio 2000.

Ministério de Minas e Energia . Portaria No 42, de $1^{\circ}$ de março de 2007. 2007. Disponível em: http://www .mme.gov.br/mme/menu/legislacao.html . Acesso em: 5 de julho de 2011.

Ministério de Minas e Energia (Brasil). Superintendência de Regulação dos Serviços de Geração - Despacho do Superintendente em 15 de abril de 2010 - No 1.031. 2010. Diário Oficial da União, 16 abr. 2010. Seção 1, p. 78.

MUNTERS. Evaporative Cooling for Gas Turbine. 2011. Disponível em: www.munters.us/precoolers . Acesso em: 20 de dezembro de 2011.

Munters. Gas Turbine Inlet Air Cooling. 2012. E-newsletter. Disponível em: http://www . munters.us/en/us/News--Media/E-newsletter-articles/ Munters-Now-Offers-Free-Media-Inspections/. Acesso em: 5 de janeiro de 2012.

NAJJAR, Y. S. H. Enhancement of performance of gas turbine engines by inlet air cooling and cogeneration system. Applied Thermal Engineering, v. 16, n. 2, p. $163-173,1996$.

NOBLE, R. G.; SOUZA, M. A.; de Almeida, L. B. Investimentos de capital, custo tributário e competitividade: um caso do setor siderúrgico brasileiro. Revista Universo Contábil, v. 2, n. 2, p. 24-36, 2006.

OLIVEIRA, R. G.; MARRECO, J. M. Natural gas power generation in brazil: New window of opportunity. Energy Policy, n. 34, p. 2361-2372, 2006. 
OMIDVAR, B. Gas Turbine Inlet Air Cooling System. 2001. Disponível em: www. albadronline.com . Acesso em: 10 de junho de 2012.

ONDRYAS, I. S. et al. Options in gas turbine power augmentation using inlet air chilling. Journal of Engineering for Gas Turbines and Power, v. 113, p. 203-211, 1991.

ONS - Operador Nacional do Sistema Elétrico . Programa Mensal de Operação Eletroenergética para o mês de dezembro - Sumário Executivo - Metas e diretrizes para a semana operativa de 26/11/2011 a 02/12/2011 - ONS NT-3-173-2011. 2011. Disponível em: http://www.ons.org.br/download/ agentes/pmo/NT_3-173-20111.pdf . Acesso em: 3 de janeiro de 2012.

Paul Mueller Company. Mueller avalanche ice harvester system for gas turbine inlet air cooling. 2000. Disponível em: http://www.muel.com/pdfs/ literature/TE-2034Avalanche-GTIC.pdf . Acesso em: 7 de janeiro de 2012.

PEEL, M. C.; FINLAYSON, B. L.; MCMAHON, T. A. Updated world map of the Köppen-Geiger climate classification. Hydrology and Earth System Sciences, v. 11, p. 1633-1644, 2007.

Pneumafil Corporation. System Components: Gas Turbine Inlet Evaporative Cooling. 2011. Disponível em: www . pneumafil . com/gasturbine/sc/evap.html . Acesso em: 25 de outubro de 2011.

PUNWANI, D. V. et al. Absorption chiller application for power generation: a case study for a 316mw gas turbine cogeneration plant in Pasadena, Texas, USA. In: Proceedings of the 2001 International Gas Research Conference. Amsterdam, NL: [s.n.], 5-8 Novembro 2001.

ROWEN, W. I. Simplified mathematical representations of heavy-duty gas turbines. Journal of Engineeing for Power, v. 105, p. 865-869, 1983.

. Operating characteristics of heavy-duty gas turbines in utility service. In: ASME. Gas Turbine and Aeroengine Congress. Amsterdan, NL: ASME, 1988. 88-GT-150.

ROWEN, W. I.; HOUSEN, R. L. V. Gas turbine airflow control for optimum heat recovery. J. Eng. Power, v. 105, n. 1, p. 72-79, 1983.

SABESP. Tarifas e serviços. 2011. Disponível em: http://site. sabesp.com. $\mathrm{br} /$ site/interna/Default. aspx?secaoId=183. Acesso em: 10 de dezembro de 2011 .

SANAYE, S.; FARDAD, A.; MOSTAKHDEMI, M. Thermoeconomic optimization of an ice thermal storage system for gas turbine inlet cooling. Energy, v. 36, p. 1057-1067, 2011.

SIEMENS. Siemens gas turbine SGT6-5000F - Application overview. 2008. Disponível em: http://www. energy.siemens. com . Acesso em: 21 de dezembro de 2011. 
SOARES, F. H. N.; RAMOS, D. S. Impactos da operação de usinas termelétricas contratadas por disponibilidade no custo da energia adquirida em leilões de energia nova. In: XIII ERIAC DéCIMO TERCER ENCUENTRO REGIONAL IBEROAMERICANO DE CIGRé,. Proceedings. Puerto Iguazu, AR, 24-28 Maio 2009.

Solar and Wind Energy Resource Assessment (SWERA). TMY Resource Information. 2011. Disponível em: http://swera. unep.net . Acesso em: 3 de setembro de 2011.

T. Ambrizzi. Climatologia 1 - ACA0223. 2010. Notas de Aula do Departamento de Ciências Atmosféricas - IAG-USP. Disponível em: : http://www.dca.iag . usp.br. Acesso em: 22 de junho de 2011.

TAVAKOLI, M. R. B.; VAHIDI, B. An educational guide to extract the parameters of heavy duty gas turbines model in dynamic studies based on operational data. IEEE Transactions on Power Systems, v. 24, n. 3, p. 1366-1374, 2009.

Turbine Inlet Cooling Association (TICA). Partial Database of Turbine Inlet Cooling (TIC) Instalations. 2012. Disponível em: http://www. turbineinletcooling.org . Acesso em: 20 de junho de 2012.

United States Department of Labor. Bureau of Labor Statistics - CPI Calculator. 2012. Disponível em: http://www.bls.gov . Acesso em: 10 de junho de 2012.

U.S. Department of Energy. EnergyPlus Energy Simulation Software - Weather Data. 2011. Disponível em: http://apps1.eere .energy.gov/buildings/ energyplus/cfm/weather_data.cfm . Acesso em: 28 de junho de 2011.

WYLEN, G. V.; SONNTAG, R.; BORGNAKKE, C. Fundamentos da Termodinâmica Clássica - Tradução da $4^{\mathrm{a}}$ Edição Americana. São Paulo, BR: Editora Edgard Blücher LTDA, 1995.

XIAO, J. et al. Performance analysis of a centrifugal compressor with variable inlet guide vanes. Front. Energy Power Eng. China, v. 1, n. 4, p. 473-476, 2007.

YEE, S. K.; HUGHES, F. M.; MILANOVIC, J. V. Comparative analysis and reconciliation of gas turbine models for stability studies. In: POWER ENGINEERING SOCIETY GENERAL MEETING. Proceedings. Tampa, USA: IEEE, 24-28 Junho 2007. 